$$
\text { DOE/ER/12821-TI }
$$

NUCLEAR-DRIVEN FLASHLAMP PUMPING OF THE ATOMIC IODINE LASER

DOE Contract DEFG07-88ER12821

Final Report
$\mathrm{DOE} / \mathrm{ER} / 12821--\mathrm{T} 1$

DE92 010609

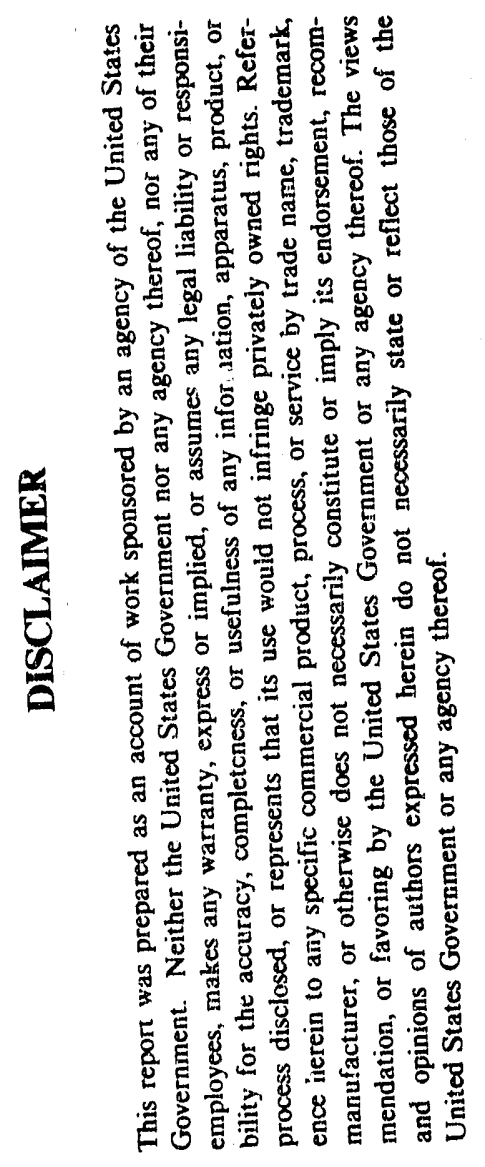

March 1992 


\begin{abstract}
*
This report is a study of the atomic iodine laser pumped with nuclearexcited $\mathrm{XeBr}$ fluorescence. These results represent the first demonstration of a nuclear flashlamp pumped laser.
\end{abstract}

Preliminary experiments, conducted in the TRIGA reactor on the campus of the University of Illinois at Urbana-Champaign, investigated the fluorescence of the excimer XeBr under nuclear pumping with ${ }^{10} \mathrm{~B}$ and ${ }^{3} \mathrm{He}$, for use as a flashlamp gas to stimulate the laser. These measurements included a determination of the fluorescence efficiency (light emitted in the wavelength region of interest, divided by energy deposited in the gas) of $\mathrm{XeBr}$ under nuclear pumping, with varying excimer mixtures. They represent the first thorough experimental investigation of this efficiency for XeBr. Maximum fluorescence efficiencies were approximately $1 \%$.

In order to better understand $\mathrm{XeBr}$ under nuclear excitation, a kinetics model of the system was prepared. The model generated the time-dependant concentrations of 20 reaction species for three pulse sizes, a TRIGA pulse, a fast burst reactor pulse, and an e-beam pulse. This is the first reported time-dependant modeling of the $\mathrm{XeBr}$ system, and the first modeling of an excimer at the low pumping powers (ca. $50 \mathrm{~W} / \mathrm{cm}^{3}$ ) provided by the TRIGA. The modeling results predicted fluorescence efficiencies significantly higher (peak efficiencies of approximately 10\%) than recorded in the fluorescence experiments. The cause of this discrepancy was not fully determined; several possibilities were considered.

A ray tracing computer model was also prepared to evaluate the efficiency with which nuclear-induced fluorescence generated in one cavity of a laser could be coupled into another cavity containing an iodine lasant. Several simple geometries were considered, aiding in design and evaluation of a test laser.

Finally, an experimental laser cell was constructed to verify that nuclear-induced $\mathrm{XeBr}$ fluorescence could be used to stimulate a laser. Lasing was achieved at 1.31 micron in the TRIGA using $\mathrm{C}_{3} \mathrm{~F}_{7} \mathrm{I}$, a common iodine lasant. Peak laser powers 
were approximately $20 \mathrm{~mW}$. Measured flashlamp pump powers at threshold agreed well with literature values, as did lasant pressure dependency on laser operation, indicating that the laser was operating as anticipated. Outside of the use of radiation-resistant glass in the laser, no special considerations were found necessary in applying the iodine laser to the intense radiation environment of nuclear pumping. It is hoped that these results will encourage further studies into this, as well as other nuclear flashlamp pumped laser systems.

* Much of the material in this report was taken from the Ph.D. thesis by Wade Henry Wi1liams which was submitted to the University of Illinois in 1992. Dr. William's research was supported under this contract. 


\section{TABLE OF CONTENTS}

Chapter

Page

1. INTRODUCTION ................................................................................................................. 1

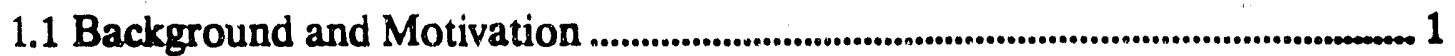

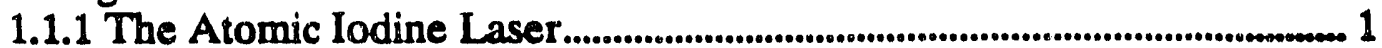

1.1.2 Excimer Flashlamps.......................................................................................... 2

1.1.3 Nuclear Pumped Lasers ............................................................................................. 4

1.1.4 Nuclear Flashlamp Pumped Lasers ..............................................................m. 5

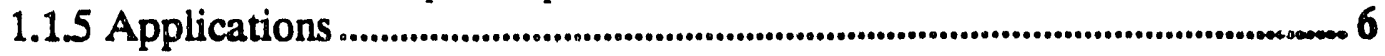

1.2 Motivation.............................................................................................................................encos. 7

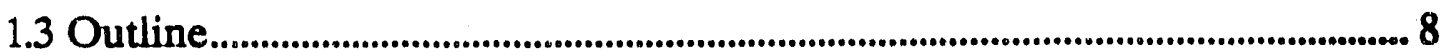

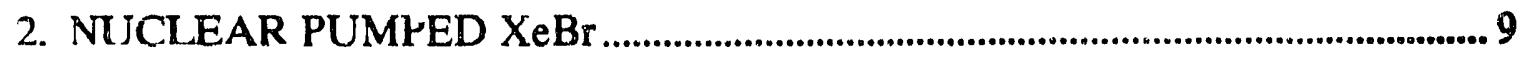

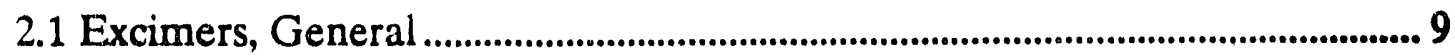

2.1.1 Excimers as Lasers............................................................................................. 9

2.1.2 Rare Gas Halide Excimers...................................................................... 10

2.1.3 Formation Mechanisms................................................................................. 12

2.1.4 Fluorescence Efficiencies ............................................................................ 13

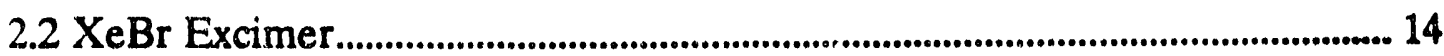

2.3 Nuclear Pumping Mechanisms .................................................................................... 14

2.3.1 ${ }^{235}$ U Pumping .................................................................................................. 15

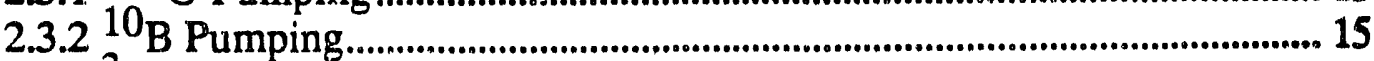

2.3.3 ${ }^{3} \mathrm{He}$ Pumping .............................................................................................. 16

3. FLUORESCENCE EXPERIMENTS ….............................................................. 17

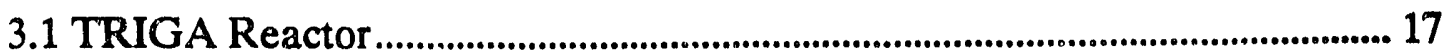

3.2 Experimental Set-Up .......................................................................................... 18

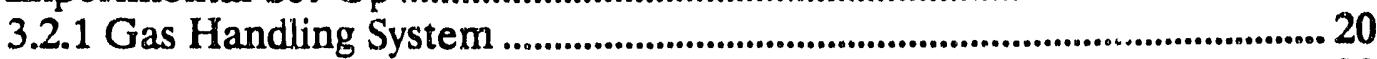

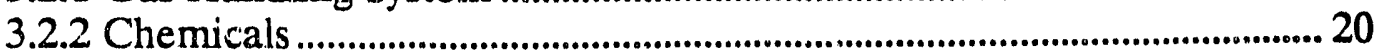

3.2.3 Diagnostic Equipment...................................................................................... 21

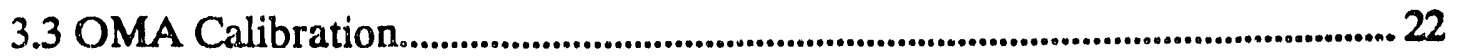




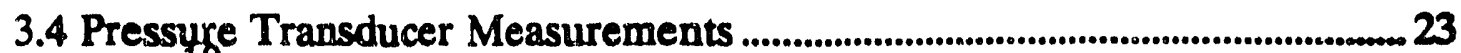

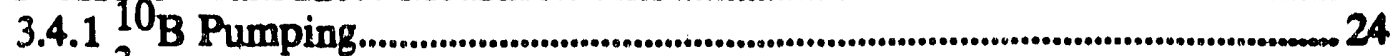

3.4.2 ${ }^{3} \mathrm{He}$ Pumping .......................................................................................... 27

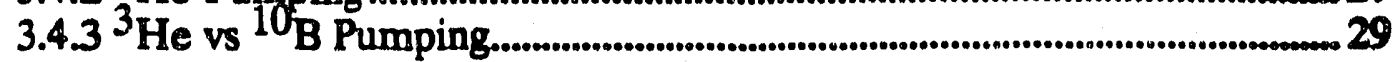

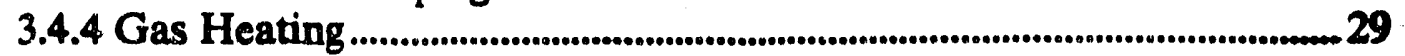

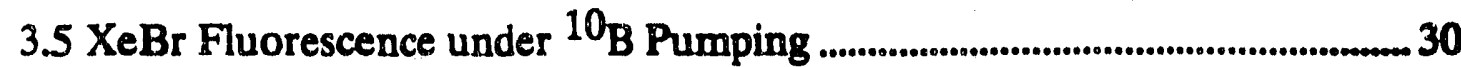

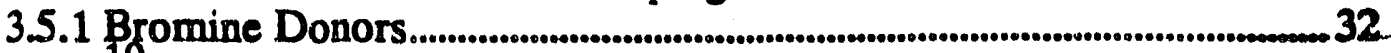

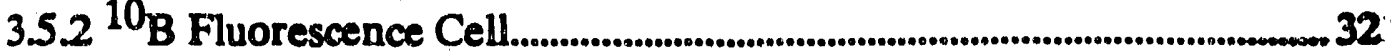

3.5.3 Br2 Fluorescence Results ......................................................................................on 33

3.5.4 $\mathrm{CHBr}_{3}$ Fluorescence Results............................................................................. 37

3.6 XeBr Fluorescence under ${ }^{3} \mathrm{He}$ Pumping..........................................................40

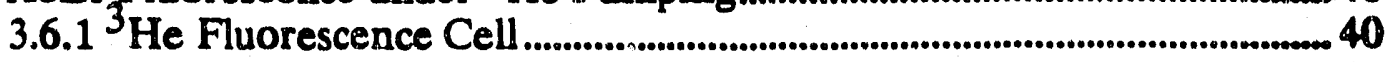

3.6.2 Fluorescence Results.......................................................................................m. 41

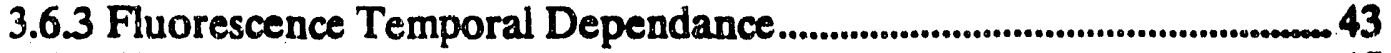

3.6.4 Fluorescence Linearity with Power................................................................. 45

3.7 Fluorescence Efficiencies.................................................................................................. 47

3.7.1 Fluorescence Efficiency Determination.......................................................... 47

3.7.2 Corrected Spectra ......................................................................................... 48

3.7.3 ${ }^{10} \mathrm{~B}$ and ${ }^{3} \mathrm{He}$ Pumping Results ................................................................... 49

3.7.4 ${ }^{3} \mathrm{He}$ Pressure Dependance .................................................................................... 50

3.8 Application of $\mathrm{XeBr}$ Fluorescence to a Laser ....................................................... 51

3.9 Fluorescence Studies with KrF............................................................................. 53

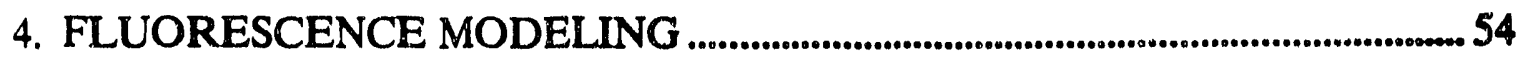

4.1 Kinetics Code .................................................................................................................... 54

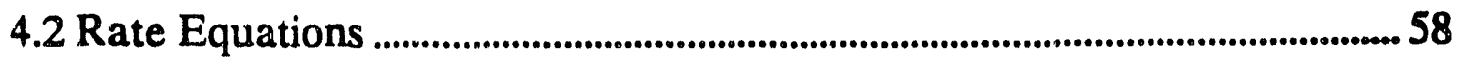

4.3 Modeling Results ............................................................................................................ 60

4.4 Comparison of Published Results to Modeling Results....................................... 70

4.5 Comparison of TRIGA Results to Modeling Results ........................................ 71

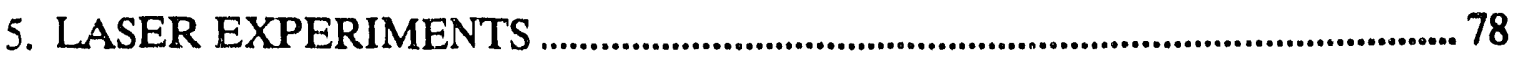

5.1 Coupling Efficiency Calculations ................................................................................ 78 
5.2 Nuclear Radiation Effects on Lasant ..................................................................... 82

5.3 Laser Cell Design and Experimental Set-Up............................................................ 83

5.3.1 Laser Cell ...................................................................................................................... 83

5.3.2 Experimental Set-Up....................................................................................................... 85

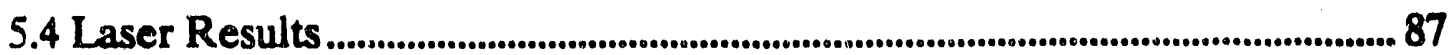

5.4.1 Laser Signal................................................................................................................. 87

5.4.2 Lasing Threshold............................................................................................................... 89

5.4.3 Lasant Pressure Dependance.................................................................................. 89

5.4.4 Multiple Pulses ................................................................................................................. 90

5.5 Direct Lasant Pumping.............................................................................................................. 91

5.6 Laser Scale-Up................................................................................................................... 91

6. CONCLUSIONS AND RECOMMENDATIONS .................................................... 94

6.1 Summary and Conclusions .................................................................................... 94

6.1.1 XeBr Fluorescence ........................................................................................... 94

6.1.2 Laser Experiments ...................................................................................................... 97

6.2 Suggestions for Future Work ................................................................................... 98

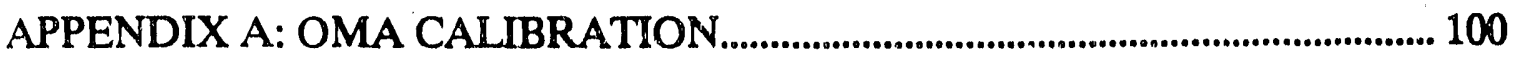

APPENDIX B: KINETICS CODE ............................................................................ 102

APPENDIX C: I2 BUILDUP ........................................................................................ 110

APPENDIX D: RAY TRACING CODE ............................................................... 112

APPENDIX E: ERROR ANALYSIS .................................................................. 126

APPENDIX F: PRESSURE RISE MEASUREMENT CORRECTION.............. 128

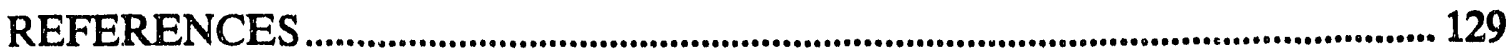




\section{Chapter 1}

\section{INTRODUCTION}

\subsection{Background and Motivation}

The work discussed in this report was a study, experimental and theoretical, of a new approach to exciting the atomic iodine laser, that being the use of a nuclear pumped flashlamp. Experimental and modeling efforts were conducted on a flashlamp gas under nuclear excitation, followed by construction and testing of a laser. This section of the report will discuss several areas of background for the work, as well as motivations for studying such a system.

1.1.1 The Atomic Iodine Laser. The atomic iodine laser was first discovered in 1964 by Kasper and Pimentel [1,2]. In its most common pumping scheme, it is one of a large class of lasers, called photodissociation lasers, which use incoherent flashlamp light in one wavelength region to excite a laser gas, which then lases at a longer wavelength. The atomic iodine laser uses light in the ultraviolet region of the spectrum to cause photodissociation of a gaseous molecule containing iodine, typically $\mathrm{C}_{3} \mathrm{~F}_{7} \mathrm{I}$, or $\mathrm{CF}_{3} \mathrm{I}$. The free iodine atom formed from photodissociation is left in an excited electronic state in nearly $100 \%$ of dissociations. Lasing is achieved between this excited $\left({ }^{2} \mathrm{P}_{1 / 2}\right)$ state and the lower $\left({ }^{2} \mathrm{P}_{3 / 2}\right)$ ground state at a wavelength of 1.3152 micron. (Another important pumping scheme, not pertinent to this work, is through chemical generation of $\mathrm{O}_{2}\left({ }^{1} \Delta\right)$, which reacts with $\mathrm{I}_{2}$ to form excited atomic iodine.)

This laser has been well-studied since its discovery, principaily for its application in Inertial Confinement Fusion (ICF) research. The largest iodine laser built to date is in the USSR, with an output of $100 \mathrm{TW}$ and $30 \mathrm{~kJ}$ [3]. Considerable work on this laser has also been done in Garching [4].

Accomplishments discussed in this report center on the development of a new type of flashlamp to stimulate the atomic iodine laser, and then showing its viability 
through demonstrated lasing. For this reason, theoretical aspects detailed in this thesis will focus on the flashlamp, rather than the laser kinetics. The interested reader is referred to excellent references on the atomic iodine laser under war pumping conditions $[4,5]$.

1.12 Excimer Flashlamps. The UV light source typically used to the pump the atomic iodine laser is a xenon flashlamp. This lamp emits light as an electatah current is passed through a glass cell containing high pressure xenon, ioniving the gas. It was suggested by several workers [6-8] that this electrical flashlamp could be replaced by a nuclear flashlamp; that is, a fluorescing gas ionized by molan reaction products (i.e. filssion fragments), rather than an electrical current. Whinon and Shapiro [6,7] performed kinetic modeling to predict flashlamp power output for a neutron flux as would be produced by a fast burst reactor, and applied this output to determine a predicted laser performance. To a large extent, this work was initiated as an experimental examination of their predictions, but utilizaing the TRIGA reactor. Separate kinetic modeling work was also conducted to gain a more detailed understanding of the system.

Three different gas mixtures, all excimers, were suggested as flashlamp gases by Wilson and Shapiro [6,7] due to the good overlap of the emissions of these gases with the photoabsorption bands of the common iodine lasants. A discussion of excimers will be given later. However, two important characteristics of excimers are 1) emission in a few, relatively narrow wavelength bands, often in the UV; and 2) an extraordinary efficiency (termed "fluorescence efficiency") at converting energy deposited in the gas into light emitted into the strongest of these bands. This efficiency is $>50 \%$ for some gases.

The econornic benefit in reduced size of having an efficient fluorescer in a large laser system is evident. The added advantage for the iodine laser of having a significantly monochromatic source is seen by inspecting the photodissociation cross-section of the three common atomic iodine lasants (see Figure 1). This photodissociation band for formation of the atomic iodine species is fairly narrow, located between approximately 230 and $330 \mathrm{~nm}$. This means that a flashlamp source which has a broad spectral output and good fluorescence efficiency may still 


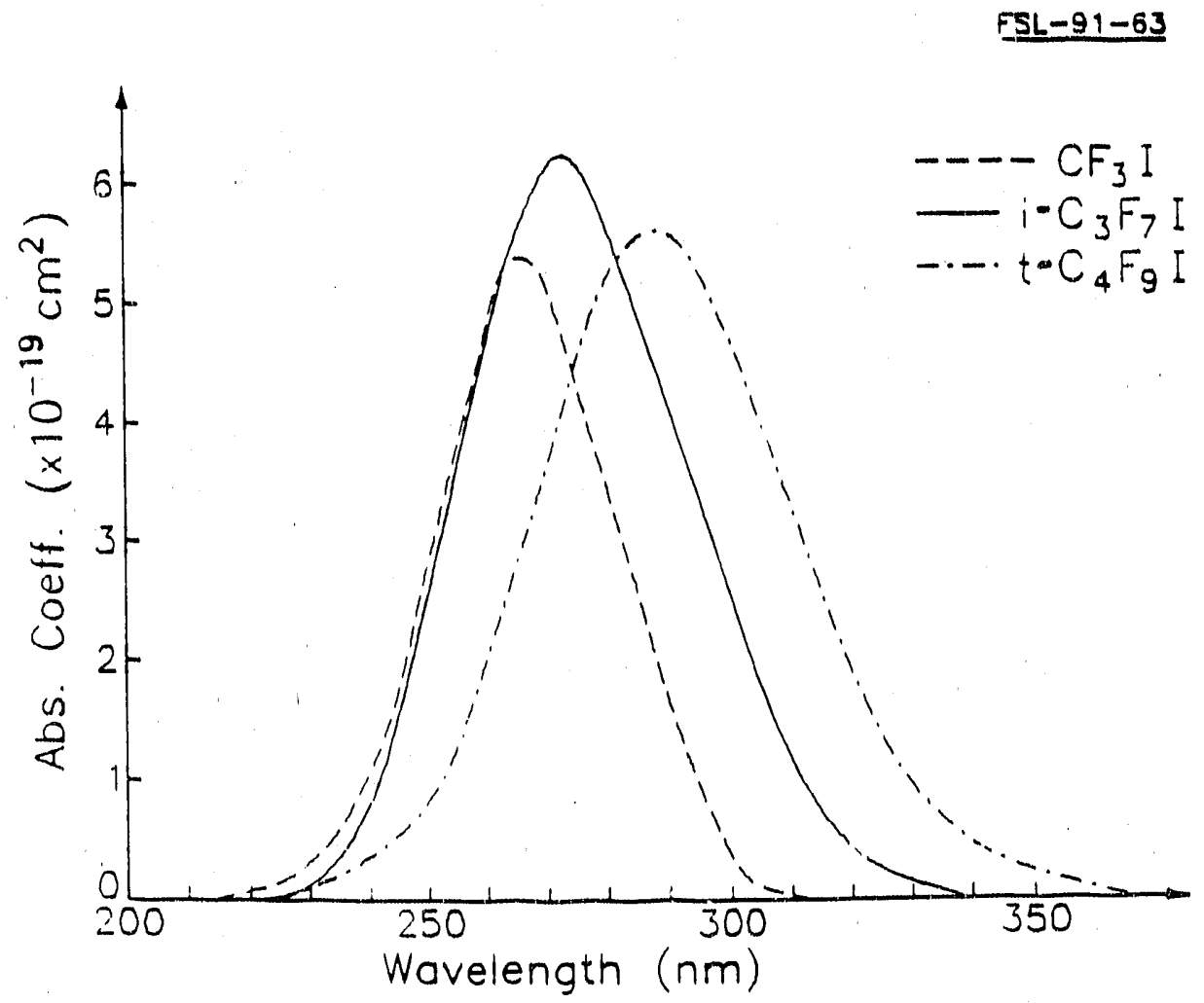

Figure 1. Photodissociation cross-sections for three common atomic iodine lasants.

be inefficient in pumping this laser because a significant portion of the fluorescence will not be absorbed by the lasant. This is the case with the electrical xenon flashlamps usually used to pump large iodine lasers, such that only approximately $10 \%$ of the flashlamp output is in the spectral absorption range of the lasant. (The efficiency based on electrical energy required is $8 \%$ [4].)

Considering, then, the good fluorescence efficiencies and fairly monochromatic nature of excimers, an excimer with output within the lasant absorption band of 230 to $330 \mathrm{~nm}$ could have a reasonably high overall efficiency (compared to the $8 \%$ given above). Of the large number of excimers discovered, a few have been identified [6] as exhibiting strong emission in this wavelength range. These include $\mathrm{KrF}^{*}$ at $249 \mathrm{~nm}, \mathrm{XeI}^{*}$ at $252 \mathrm{~nm}, \mathrm{XeBr}^{*}$ at $282 \mathrm{~nm}, \mathrm{Ar}_{2} \mathrm{~F}^{*}$ at $284 \mathrm{~nm}$, and $\mathrm{XeCl}^{*}$ at $308 \mathrm{~nm}$. For these experiments, $\mathrm{XeBr}$ was chosen because of its better spectral 
ouerlap with the iodine lasants than $\mathrm{KrF}, \mathrm{XeI}$ or $\mathrm{XeCl}$, and because it was expected to have better fluorescence efficiency than $\mathrm{Ar}_{2} \mathrm{~F}$. (If $\mathrm{XeBr}$ had been unsuccessful then other excimers would have been investigated. Some fluorescence measurements were attempted with $\mathrm{KrF}$.)

Non-nuclear pumped excimers have previously been used to excite the iodine laser, including electrically-pumped $\mathrm{KrF}$ and $\mathrm{XeCl}$. In those cases, the excimer was stimulated to lase, then this laser light was used to stimulate the iodine [4]. More closely related to this work was the use of e-beam-induced spontaneisus emirsion from $\mathrm{XeBr}$ to achieve lasing in iodine [9]. Those results are especially pertinent because there are important similarities between e-beam and nuclear pumping mechanisms (especially a low electron temperature compared to electrical discharges). The fluorescence efficiency measurements reported as part of the ebeam pumping will be compared later to measurements made in this work.

Given these advantages of excimers as flashlamps, and successful demonstrations of lasing with such an approach, it is not fully clear to the author why excimers are not used in current large iodine laser systems. For e-beam pumped excimers, it may relate to the complexity of an e-beam machine, plus the added difficulty of coupling fluorescence from a large flashlamp volume (inherent in e-beam pumping) into a small lasant cavity. For electrical discharge pumped excimers, it may relate to service life problems in the lamp, given the caustic nature of rare gas/halogen mixtures.

1.1.3 Nuclear Pumped Lasers. This approach of pumping with a nuclear flashlamp makes this laser one of a larger class of lasers termed "Nuclear Pumped Lasers". This work, however, differs from past research in nuclear pumped lasers in that all previous efforts have utilized nuclear reaction energy to directly excite the laser (no flashlamp) by, for example, having fission fragments slow down in the aser gas $[10,11]$. That approach is termed "direct pumping" of the laser, as opposed to the flashlamp pumping developed here. A review of past work in nuclear pumped lasers is given in references 10 and 11. 
An interest in using nuclear reaction energy to pump any laser, including this flashlamp system, is motivated by two important characteristics. The first is that nuclear pumping uses neutrons reacting with an appropriate material, such as ${ }^{235} \mathrm{U}$, to provide energy for the laser. Because neutrons have an ability to penetrate largedistances through many materials before being absorbed, there is a potential to pump large gas volumes, ne iessary for developing high energy/high power syatems. The second characteristic is the large amount of energy "stored" inc. relatively small amounts of nuclear fuel. This is an advantage in comparison with, for example, electrically pumped lasers, which utilize large (and expensive) capacitive storage systems to reach high powers.

While these are significant potential advantages, it should be mentioned that there are, of course, trade-offs. A significant challenge in developing a high-power nuclear pumped laser is the relatively low pump powers available in nuclear pumping ( $\mathrm{kW} / \mathrm{cm}^{3} \mathrm{vs} \mathrm{MW} / \mathrm{cm}^{3}$ for e-beams), and slow rise times (1.0's of microsecs to msecs vs nsecs for e-beams). This restriction comes from the maximum neutron fluxes (approximately $10^{17} \mathrm{n} / \mathrm{cm}^{2} \mathrm{~s}^{\prime} \mathrm{sc}$ from a fast burst reactor) which can be readily generated over a large enough area for laser pumping. This limitation, for example, makes it difficult to nuclear pump excimer lasers, which require high pump powers. It is less restrictive with other systems.

1.1.4 Nuclear Flashlamp Pumped Lasers. As mentioned above, this concept of flashlamp pumping differs from the direct pumping used in past nuclear pumped laser research. Although flashlamp laser pumping has not previously been successful, there has been significant study of the field in the past. Reference 8 gives a review of previous work.

There are several advantages to this approach of laser pumping with a nuclear flashlamp. The first is the possibility of exciting large fluorescer volumes at the modest pumping powers attainable in nuclear pumping (compared to e-beam pumping), and then coupling this fluorescence into a small laser volume to generate sizable laser pump powers, greater than would be attainable in direct pumping. This advantage utilizes well one major characteristic of nuclear pumping, the ability 
of neutrons to peretrate large distances in materials, and, hence, exciter large. volumes.

A second advantage is one common to all flashlamp pumped lasers (nuclearomot) over direct pumped systems, and has to do with the spatial uniformity of excitation. With direct pumping, most of the deposited energy goes into heating ther gas. Unless this energy can be distributed with good uniformity over the gas optical inhomogeneities develop in the non-uniformly heated gas, spoiling the ability of a laser beam to propagate well in the volume. In nuclear pumped systemathis is less of a problem when direct pumping with ${ }^{3} \mathrm{He}$, where the energy depoditimen. be fairly uniform. In fission foil pumped systems, however, strong pumpumer gradients exist (if the foils are spaced more than a few $\mathrm{cm}$ apart), causing difitulties in laser cavity stability.

For flashlamp pumped lasers, however, the energy going into the lasant is provided as light from the flashlamp. It is much easier to distribute this energy with good uniformity over the laser gas volume using mirrored wails, etc. In addition, if the flashlamp is fairly monochromatic, as with an excimer, most of this light energy is usable in pumping the lasant, so less goes into gas heating. Hence, large vollunes can be pumped to high powers, as is done in present large atomic iodine lasers [4]. Optical inhomogeneities in the flashlamp are less important because it is only an incoherent radiation source. Hence, fairly steep energy deposition gradients in nuclear pumped flashlamps can be tolerated, allowing potentia' scaling to higher powers than may be possible in direct nuclear pumped systems.

A final advantage of nuclear flashlamp pumped systems is the potential good efficiency of such lasers. Outside of exceptional results with the $\mathrm{Ar} / \mathrm{Xe}$ laser [12,13] (1-3\%), most systems have shown relatively low efficiency $(<<1 \%)$ on direct nuclear pumping $[10,11]$. If nuclear pumped flashlamps, especially excimers, can be shown to be efficient, this, coupled with the efficiency of converting fluorescence light to laser light, could mean un overall good systern efficiency (1-5\%).

1.1.5 Applications. Such advantages of nuclear pumped lasers would be especially important in large pulsed or steady state laser systems (megajoule). Applications 
for such lasers are limited, but may include Inertial Confinement Fusion, military defensive/offensive systems, and power transmission on earth or in space. Nuclear pumped lasers have been looked at for all these concerns. To date, however; with the possible exception of the Ar/Xe laser [12,13], all lasers investigated have been: ton inefficient for current use. (To the knowledge of the author, no nuclear pumped: laser has been implemented in an end-use ppplication.) Other difficulties associated with nuclear pumping are the safety concerns of working around an intense radiation source, and activation of component materials. Also, an added complexity in scaling up to a large laser will be the need to integrate a reactor and laser together. It is hoped that coninued research in this field, such as that detailedin this work, will help overcome these obstacles, making nuclear pumped systems more attractive as high-power lasers.

It is also worth noting that nuclear pumped flashlamps could have other applications outside gas laser pumping. Especially in chemical processing, intense UV light sources are an important tool. Prelas, et al. $[14,15]$ have investigated options for use of nuclear driven fluorescence in a number of capacities, included driving a solid state laser.

\subsection{Motivation}

Some suggestions of motivation for this work are included in the background discussions given above. By way of summary, however, the primary motivation was to show operation of a laser that has potential scale-up to a high-energy/high-power system for space-based or terrestrial applications. Nuclear tlashlamp pumping of the atomic iodine laser had previously been suggested, but not studied experimentally.

The work was also an opportunity to demonstrate the idea of nuclear flashlamp pumped lasers as a new laser class, with hope that investigations into other potential lasers in this class would be motivated.

Finally, these studies were a vehicle to study nuclear pumped excimers in more depth. High-energy excimer fluorescence also has potential application outside of the laser field (e.g. chemicals processing). 


\subsection{Outline}

This project was largely experimental in nature, with some theoretical modeling done to aid in understanding the system. Measurements were first taken to study the fluorescence of $\mathrm{XeBr}$ under nuclear pumping. These measurements included parametric evaluations of gas mixtures under ${ }^{10} \mathrm{~B}$ excitation in a boron-coated test cell, and then studies of fluorescence efficiencies in another test cell with ${ }^{3} \mathrm{He}$ excitation. (As will be discussed below, it was necessary to use ${ }^{3} \mathrm{He}$ in laser experiments because of its higher pumping power and larger available pumping volume as compared to ${ }^{10} \mathrm{~B}$ pumping. $10_{\mathrm{B}}$ was used for parametric evaluations because of the high cost of ${ }^{3} \mathrm{He}$ ) The results of these fluorescence measurements were used in the design of a laser cell. Experiments were then done with this laser to verify lasing of atomic iodine under nuclear flashlamp pumping.

This report will be structured as follows: background theoretical considerations of nuclear pumped $\mathrm{XeBr}$ will first be given, followed by results of experiments done at the University of Illinois to measure nuclear pumped $\mathrm{XeBr}$ fluorescence. These will be compared to a computer model of the $\mathrm{XeBr}$ system under such excitation. A discussion of laser experiments and results will follow, with a final section of conclusions and recommendations for future experiments. 


\section{Chapter 2}

\section{NUCLEAR PUMPED XeBr}

This chapter will discuss in detail the nuclear pumped XeBr flashlamp studied in these experiments. A review of excimers in general and their characteristics will first be given, followed by details specific to the $\mathrm{XeBr}$ system. A final section will discuss nuclear pumping considerations for the flashlamp. A description of a modeling effort conducted to look at the nuclear pumped $\mathrm{XeBr}$ system will be given in chapter 4 , following presentation of experimental results in chapter 3.

\subsection{Excimers, General}

Excimers are a class of molecular compounds which have the common characteristic of only forming with the molecules being in an excited electronic state. In the ground state the molecules dissociate into their constituent atoms. The range of molecules covered by the term is broad, from simple diatomic excimers (e.g. Xe2") to complex aromatic molecular systems. (The term "excimer" is short for "exited dimer". It strictly refers to homonuclear molecules, such as $\mathrm{Xe}_{2}{ }^{*}$; heteronuclear sustems, such as $\mathrm{XeBr}^{*}$, are more accurately referred to as exciplexes, but "excimer" has come to be commonly used to refer to both classes.) The following discussion will center on one class of excimers, the rare gas halides, of which $\mathrm{XeBr}$ is an example. Refereuces 16 and 17 are excellent reviews on the subject of excimers and excimer lasers.

2.1.1 Excimers as Lasers. The interest in excimer systems has increased greatly since the demonstration of their use in lasers [18]. Lasers rely on establishing a population inversion between electronic (or vibrational) states in a medium; that is, there must be more atoms (or molecules) in a higher lying energy state than in a lower state. Excimers meet this criterion by definition, in that the molecules only exist in the excited state, and dissociate in the ground state; hence, there are, more or less, no molecules in the ground state. Lasing has been demonstrated in numerous excimer systems, some to very high powers for ICF applications [19]. It 
should also be mentioned that much of their continued commercial development has been driven by the fact that many excimers emit in the UV, a region of the spectrum of interest for many applications (e.g., medical, materials proceing; semiconductor processing) in which there were previously relatively few lasers:

One significant drawback to the more common excimer lasers (e.g. $\mathrm{KrF}$ ) is that they require a relatively high power to attain lasing. This is because the excimentates. bave a relatively short lifetime (ca. $10 \mathrm{nsec}$ ), so a large pumping power is required to maintain sufficient molecules in this state to attain a population inversion, i.e. laxing. [20, pg. 347]. Purnp power requirements may be on the order of $100 \mathrm{~kW} / \mathrm{cm}^{3}$ This is mentioned here because such pump powers are very difficult to attain though nuclear pumping; transient electrical discharges or e-beams are typically ured. (Pump powers in experiments done for this work were on the order of $40 \mathrm{~W} / \mathrm{cm}^{3}$.) For this reason, lasing of the excimer was not attempted in this work; rather, the excimer is used as an intense incoherent flashlamp.

2.1.2 Rare Gas Halide Excimers. A common type of excimer is a molecule containing a rare gas atom and a halogen atom (e.g. KrF). Much work has been done with this class of lasers, probably more than any other.

The rare gas halide excimers can be pictured as a positive rare gas ion attached to a negative halogen ion. As such, the molecule is electronically similar to an alkalihalogen molecule (e.g. $\mathrm{NaCl}$ ). A generalized potential energy level diagram is shown in Figure 2. As indicated, there are potential minima for the states labeled B, C, and D where molecules can be "trapped". (Labels are historical, and have no spectroscopic significance.) These are the excited excimer states. The lower states, $\mathrm{A}$ and $\mathrm{X}$, are the ground states, and are repulsive, so molecules in these states immediately dissociate into their constituent atoms. (There is a slight minimum in these lower states for some of the excimers, most notably XeF [17], but thermal agitation does not allow buildup of large populations.)

Transitions seen in excimer plasmas are from the upper to the lower states. The strongest transition is always from the $B$ to $X$ states, and is usually the transition made to lase. Other common transitions include $C$ to $A$ and $D$ to $X$. 
$\underline{S L-91-62}$

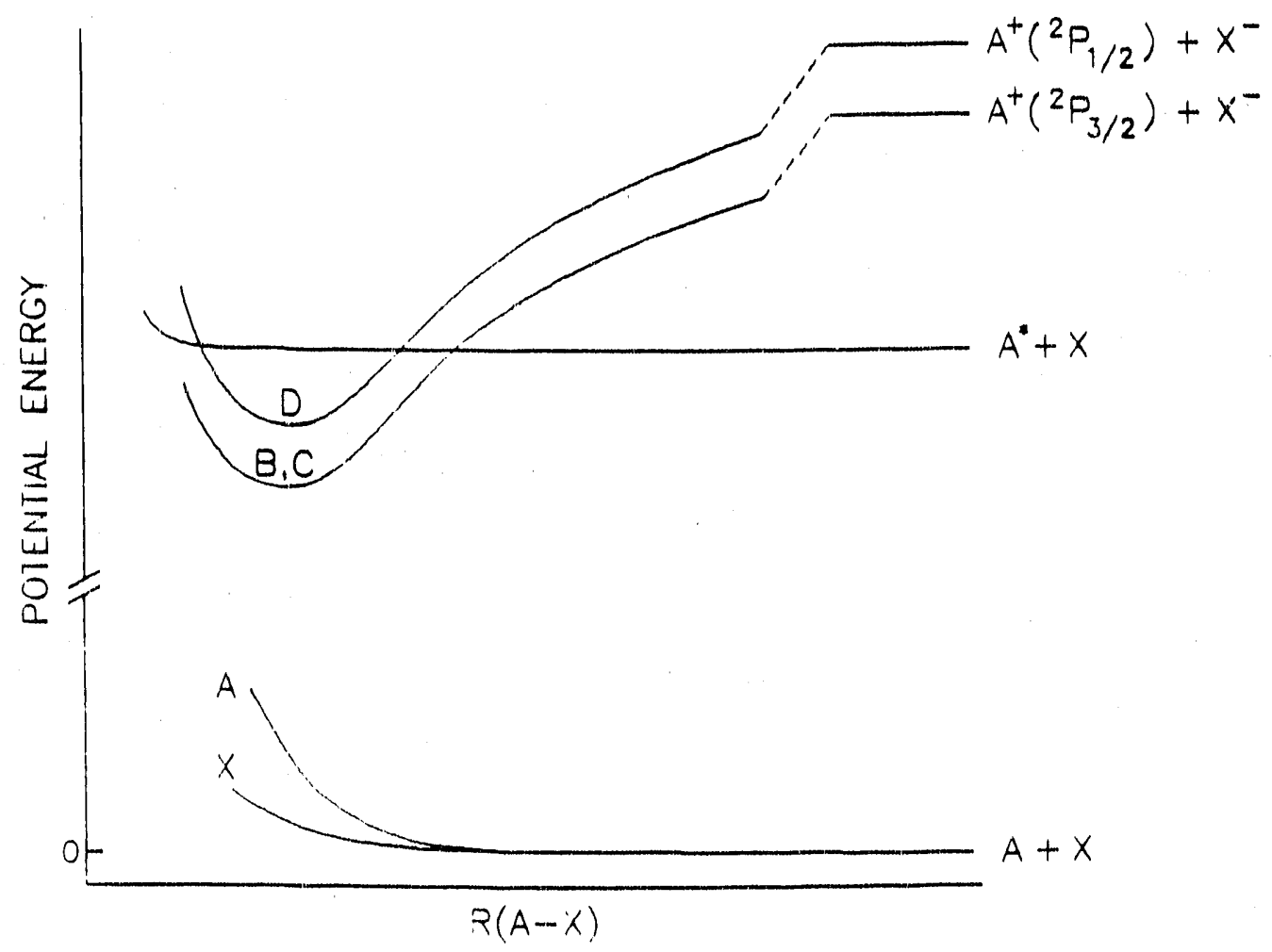

Figure 2. Stylized potential energy curves for rare gas (A) - halogen (X) excimer systems (from ref. 16).

Figure 3 is a spectrum of $\mathrm{XeBr}$ fluorescence taken for this work (experimental conditions will be discussed later). The strong peak at $281.8 \mathrm{~nm}$ is the B-X transition. The broad peak at $320 \mathrm{~nm}$ is the C-A transition. The D-X peak, which should be at $221 \mathrm{~nm}$ [17, pg. 92], is not seen in the spectrum because of the shortwavelength insensitivity of the detector used for these measurements. The very broad peak at $415 \mathrm{~nm}$ is the trimer molecule, $\mathrm{Xe}_{2} \mathrm{Br}^{*}$. ( $\mathrm{Xe}_{2} \mathrm{Br}^{*}$, aiso an excimer, is formed when a $\mathrm{Xe}$ atom combines with $\mathrm{XeBr}^{*}$.) All these spectral features are representative of the rare gas halides, and are fairly well understood. The photodissociation cross-section of $\mathrm{C}_{3} \mathrm{~F}_{7} \mathrm{I}$ is included for reference to show the suitability of $\mathrm{XeBr}$ for pumping this lasant. 


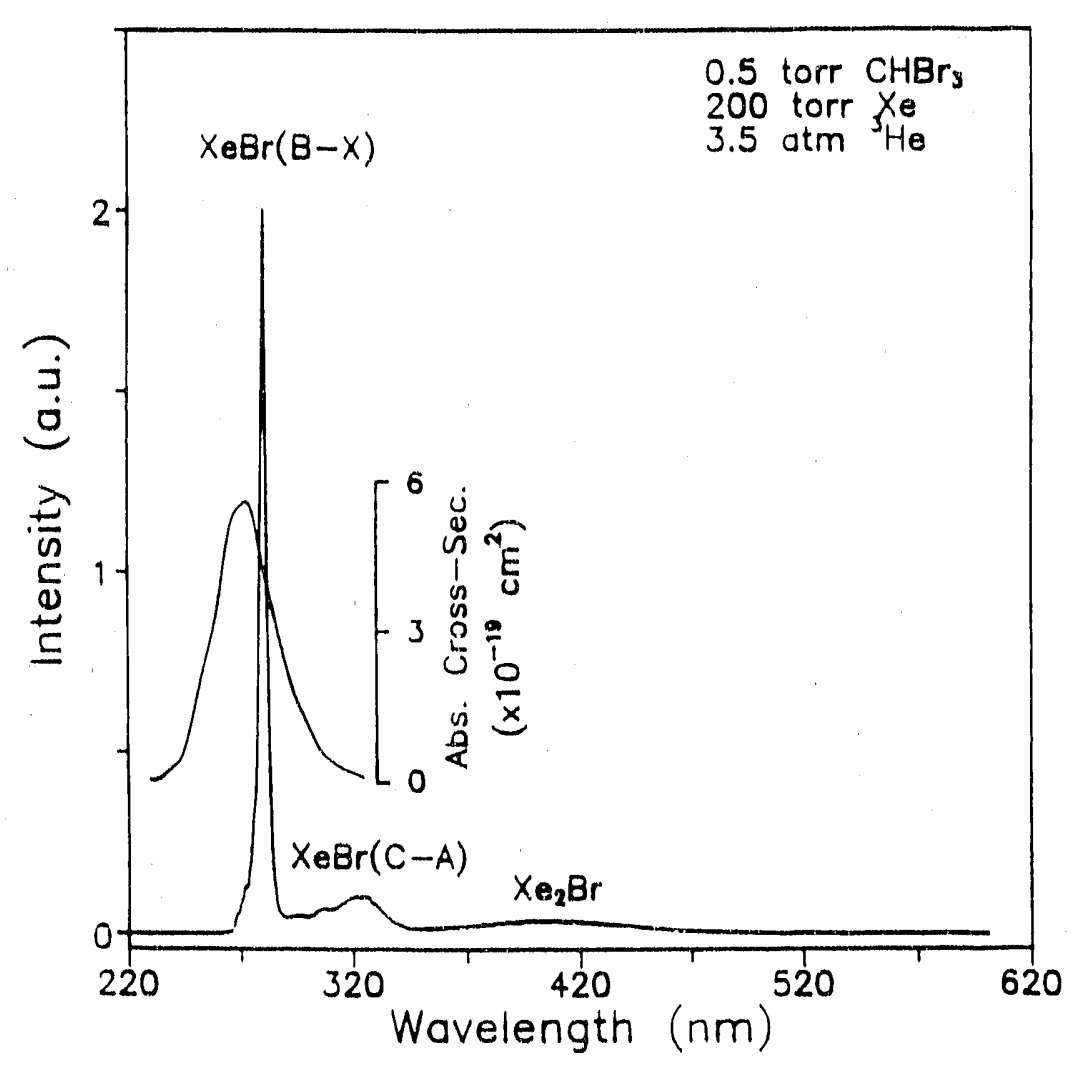

Figure 3. Emission spectrum of $\mathrm{XeBr}$ under nuclear pumping, as measured in these experiments (corrected for spectral sensitivity of the detector), with photodissociation cross-section of $\mathrm{i}-\mathrm{C}_{3} \mathrm{~F}_{7} \mathrm{I}$ superimposed.

2.1.3 Formation Mechanisms. There are two important pathways for formation of the excimer state: the ion channel, and the metastable channel. Referencing Figure 2 , the excimer is formed through the first channel when a positive rare gas ion and a negative halogen ion collide in the presence of a third body (to take away excess energy and allow the excimer pair to "fall down the hill" into the trapped B, C, or D state). The metastable channel occurs when a metastable rare gas atom collides with a halogen-bearing molecule. The rare gas atom attaches itself to it's halogen atom, tearing it from the rest of the molecule (hence, the name "harpoon" reaction).

Both of these channels are present in a rare gas halide plasma. The extent to which one is dominant in the formation of the excimer depends on the pumping 
mechanism. For plasmas in which the energy starts from "the top" and dribbles down, such as in e-beam and nuclear pumping, the ion channel tends to dominate, since many rare gas ions are formed. Conversely, for electrical discharges; excitation comes from relatively low energy electrons (no high energy tail in the electron energy distribution, as in e-beams), so a large number of metastable atoms are formed, and the metastable channel is prominent [20]. These distinctions are approximate, however; accurate knowledge of the formation channels depends on a modeling of the specific gas mixture and pumping conditions. $\mathrm{XeBr}$ does not seem to follow this convention, with the metastable channel being dominant in e-beam plasmas $[7,21,22]$.

The relative strengths of the two channels in nuclear pumping is not well known. Nuclear plasmas are typically considered to be very similar to e-beam generated plasmas for excimer laser pumping considerations [23], suggesting a strong ion channel for most excimers. Prior modeling work for nuclear pumped $\mathrm{XeBr}$ [7] suggests that the metastable channel dominates. Results of modeling in this research corroborated that finding.

2.1.4 Fluorescence Efficiencies. An important characteristic of rare gas halides, and many other excimer systems, is the high efficiency at which energy deposited in the system can be converted into excimer fluorescence, principally on the B-X transition. This efficiency varies from system to system. As examples, efficiencies have been reported of approximately $50 \%$ for rare gas dimers [16, pg. 99;17, pg. 52]; $28 \%$ [24], 8.3\% [25], and $12.5 \%$ [26] for $\mathrm{KrF} ; 4.4 \%$ for ArF [27]; and 11+5\% for $\mathrm{XeBr}[9]$. The kinetic reasons behind such high efficiencies lie in the fast rates at which the excimers are formed in the mixtures, and then the lack of kinetic pathways out of the excimer stat. Hence, energy put into the system channels efficiently into the excimer state. From there, the short lifetime of the state, coupled with moderate quenching rates of the state by most of the gas species, yield a high fluorescence efficiency. This high efficiency is of primary importance in considering excimers as large lasers. Likewise, it is a driving factor in the determination to use an excimer as the nuclear flashlamp gas in the laser system being considered in this research. 


\subsection{XeBr Excimer}

As indicated above, $\mathrm{XeBr}$ is a rare gas halide excimer. It was chosen for these expiriments because: 1 ) it was thought to $b$ ve a good fluorescence efficieng (11\% in e-beam pumped experiments [9]), and 2) its emission wavelength at $281.8 \mathrm{~nm}$ is well within the photoabsorption band of the common perfluoroalkyliodides ( $\mathrm{C}_{3} \mathrm{~F}_{7} \mathrm{I}$ and $\mathrm{CF}_{3} \mathrm{I}$ ) used as parent molecules in the atomic iodine laser (compare Figares 1 and 3).

$\mathrm{XeBr}$ is a fairly well-studied system, and was the first rare gas halide to laven[28]. Various methods have been used to attain lasing, including e-beams $[22,28,20]$, ebeam controlled discharge [29], and electric discharges [30-32]. Stimulated entraion has also been found on the $\mathrm{Xe}_{2} \mathrm{Br}$ trimer using e-beams [33]. Development of this system as a laser, however, has been limited because of self-absorption of the laser line by gas constituents, particularly $\mathrm{Br}_{2}$, and $\mathrm{Xe}_{2}{ }^{+}$. These problems have been avoided to some extent by using alternate bromine donors, such as $\mathrm{HBr}$, and by pumping with an electric discharge where few xenon dimer ions are formed [29,31]. It should be noted this self absorption is significant for a laser (perhaps a few percent per cavity length), but not large enough to effect performance of a flashlamp. (Reference 21 gives an estimated absorption of $0.017 \% / \mathrm{cm}$ at $282 \mathrm{~nm}$ under laser pumping.)

The only nuclear pumping of $\mathrm{XeBr}$ reported to date was a limited experimental study done at the University of Florida [34]. Pumping there was done with a single different gas mixture, somewhat different than found optimum in these results, and at neutron fluxes much lower than utilized in this work $\left(10^{11} \mathrm{vs} 10^{15} \mathrm{n} / \mathrm{cm}^{2} \mathrm{sec}\right)$. A fluorescence efficiency (light out between 280 and $295 \mathrm{~nm}$ divided by energy deposited in the gas) of $0.37 \%$ was reported.

\subsection{Nuclear Pumping Mechanisms.}

Nuclear pumping of the gases in a flashlamp (or in any nuclear purnped laser) utilizes the energy of fast ions produced in neutron-induced nuclear reactions. (The pumping is actually done by the secondary electrons generated by the ions. This 
makes the pumping efficiencies relatively insensitive to the type of ion doing the excitation.) Examples of the reactions typically used are:

$$
\begin{aligned}
& \mathrm{n}+{ }^{235} \mathrm{U} \rightarrow>\mathrm{ff}+200 \mathrm{MeV}(\sigma=582 \mathrm{~b}) \\
& \mathrm{n}+{ }^{10} \mathrm{~B} \rightarrow>{ }^{4} \mathrm{He}+{ }^{7} \mathrm{~L}+2.3 \mathrm{MeV}(\sigma=3837 \mathrm{~b}) \\
& \mathrm{n}+{ }^{3} \mathrm{He} \rightarrow \mathrm{T}+\mathrm{p}+0.8 \mathrm{MeV}(\sigma=5327 \mathrm{~b})
\end{aligned}
$$

The energies indicated are the kinetic energies of the reaction products. A discussion of these reactions follows. The cross-sections $(\sigma)$ in these reaction are for thermal neutron energies, in units of barms $(b)=10^{-24} \mathrm{~cm}^{2}$.

2.3.1 235 U Pumping. Reaction 1 provides the highest pumping power of the three, approximately $300 \mathrm{~W} / \mathrm{cm}^{3}$ for a flux of $3 e^{15}$ (read $3 \times 10^{15}$ ) $\mathrm{n} / \mathrm{cm}^{2} \mathrm{sec}$ (TRIGA pulse peak) because of the high energy release per event and reasonably high cross section for thermal neutrons. It, however, can only be used as a wall coating system (typically 5 micron thick) because gaseous forms of uranium (typically UF 6 ) are kinetically incompatible (iñ significant concentrations) with most gas laser systems. $\mathrm{UF}_{6}$ also has a large photon absorption cross section over much of the visible/UV, so is difficult to use in high concentrations when trying to generate light in this wavelength range. Wall coated uranium was not used in the present experiments because of the handling and disposal difficulties associated with enriched uranium and fission product gases.

2.3.2 ${ }^{10} \mathrm{~B}$ Pumping. The second reaction above, ${ }^{10} \mathrm{~B}(\mathrm{n}, \alpha)^{7} \mathrm{Li}$, is also only used as a wall coating (typically 1 micron thick) for at least one of the same reasons as UF6: kinetic incompatibility of gaseous boron compounds such as $\mathrm{BF}_{3}$. This reaction, however, has a much lower pumping power, measured in these experiments as approximately $12 \mathrm{~W} / \mathrm{cm}^{3}$ for the same flux as above, averaged over the volume of a 1 -inch diameter cell. Like any wall pumping source, ${ }^{10} \mathrm{~B}$ also has a restriction of being able to only pump a relatively small volume because of the limited range of the reaction products in the gas. For example, the range of the product alpha in 1 atm. $\mathrm{He}$ is $1.4 \mathrm{~cm}$, limiting a laser tube to approximately this diameter. This pumping source, however, offers a significant convenience in parametric and proofof-principle experiments because of its low cost and lack of radioactive by-products. 
A boron coated test cell was used in this work for parametric evaluations of $\mathrm{XeBr}$ fluorescence.

2.3.3 3e Pumping. "He is the only commonly used gas phase reactant (third reaction above). It has a significant advantage in being a kinetically oesign species in most laser or fluerescence mixtures, even at atmospheric pressures (except as acting as a third body in three-body reactions). It also is easy to handle and dispose of. (Tritium buildup is not significant in the scale of experiments done for this report, but may be for larger pumping fluences.) It provides a moderate pump power of approximately $60 \mathrm{~W} / \mathrm{cm}^{3}$ for a flux of $3 e^{15} \mathrm{n} / \mathrm{cm}^{2} \sec$ (in $3 \mathrm{~atm} .{ }^{3} \mathrm{He}$ ), and is optically transparent in the visible and UV.

All these considerations together make ${ }^{3} \mathrm{He}$ an excellent pumping source for large volume systems. A possible restriction is the high cost of the gas $(\$ 85 / 1$-atm at this writing). This is due to the rarity of the ${ }^{3} \mathrm{He}$ isotope in nature. (All commercially available ${ }^{3} \mathrm{He}$ comes from decay of weapons stockpiles of tritium.) For a large engineered system this cost may represent a significant capital investment, but replacement cost for the burn-up would be modest (\$.03/MJ energy released). 


\section{Chapter 3}

\section{FLUORESCENCE EXPERIMENTS}

This chapter will detail experiments conducted using the University of lllinois TRIGA reactor to measure nuclear-induced fluorescence of $\mathrm{XeBr}$, and to determing optimum pressures and gas mixtures for laser flashlamp application. A description will first be given of the TRIGA, followed by a discussion of the experimental set up. Results of experiments will next be given. These will includo; first, measurements of pressure rise in the experiments to determine energy deposition in the $\mathrm{XeBr}$ mix; and second, results of $\mathrm{XeBr}$ pumping with ${ }^{10} \mathrm{~B}$ and ${ }^{3} \mathrm{He}$, inchuding spectra and efficiencies. Application of this fluorescence to design of the laser will be considered. Finally, a description of a small effort to measure fluorescence of another excimer, $\mathrm{KrF}$, under ${ }^{3}$ He pumping will be given.

\subsection{TRIGA Reactor}

The TRIGA reactor is a light water research reactor at the University of Illinois at Urbana-Champaign. It is capable of both steady state $(1.5 \mathrm{MW})$ and pulsed (6000 MW peak) operation. A summary of some characteristics of the facility are given in Table 1.

A plan view of the reactor is shown in Figure 4. One of the irradiation facilities of the reactor which make it especially convenient for laser research is the throughport indicated in the figure. This port is a $53 / 8^{\prime \prime}$ diameter tube that runs all the way through the shielding, and directly adjacent to the core. Experiments, such as a laser cell, can be mounted in a "carriage" and loaded in the port right next to the core. This allows the cell to receive a high peak neutron flux during a reactor pulse, while maintaining a reasonably uniform flux over a meter length. (The flux drops by approximately half about 1 foot on either side of the point of peak flux.) This throughport was used in all experiments described herein.

All experiments were done with $\$ 3.00$ pulses from the reactor, giving a peak power 
Table 1. TRIGA reactor characteristics for the throughport [35].

\section{Steady-State Operation}

Power

Thermal Fluxa

Epi-thermal Flux b

Fast Flux ${ }^{\mathrm{C}}$

Dose Rate $\left(\mathrm{SiO}_{2}\right)$

\section{Pulsed Operation}

Pulse Size

Peak Reactor Power

Peak Thermal Flux

Peak Epi-thermal Flux

Peak Fast Flux

Peak Dose Rate $\left(\mathrm{SiO}_{2}\right)$

\section{Typical Pulses}

\section{Pulse Size (\$)}

Peak Reactor Power (MW)

Pulse Duration, FWHM (msec)

Total Fieactor Energy (kW-hr)
$1.5 \mathrm{MW}$

$2.91 \mathrm{e} 12 \mathrm{n} / \mathrm{cm}^{2} \mathrm{sec}$

$2.24 \mathrm{e} 11$

$3.30 \mathrm{e} 11 "$

$7 \mathrm{kRad} / \mathrm{sec}$

aThermal flux: $2200 \mathrm{~m} / \mathrm{s}$ flux. Uncertainty: $\pm 2.72 \%$.

b Epi-thermal flux: $0.5 \mathrm{eV}$ to $0.5 \mathrm{MeV}$. Uncertainty: $\pm 2.52 \%$.

CFast flux: $>2.8 \mathrm{MeV}$. Uncertainty: $\pm 1.86 \%$.

$\mathrm{d}_{\text {Energy in pulse proper only. The tail of the pulse (not }}$ important for these measurements) includes, for example, another $1.1 \mathrm{~kW}$-hr in the $\$ 3.00$ pulse.

of $1600 \mathrm{MW}$ and peak flux of $3.1 \mathrm{e}^{15} \mathrm{n} / \mathrm{cm}^{2} \mathrm{sec}$ for FWHM $12.5 \mathrm{msec}$. (" $\$ 3.00 "$ is a measuru of the reactivity insertion into the reactor core used to initiate the pulse.) As will be discussed below, these pulses provided pump energies of $0.7 \mathrm{~J} / \mathrm{cm}^{3}$ in 2.5 atm. ${ }^{3} \mathrm{He}$ and $0.14 \mathrm{~J} / \mathrm{cm}^{3}$ in a 1 -inch diameter ${ }^{10} \mathrm{~B}$ coated cell at 1 atm. Ar. Respective peak powers were $56 \mathrm{~W} / \mathrm{cm}^{3}$ and $11 \mathrm{~W} / \mathrm{cm}^{3}$.

\subsection{Experimental Set-up}

Also shown in Figure 4 is the set-up used for fluorescence experiments. Two different ceils were constructed for fluorescence measurements, one for ${ }^{10} \mathrm{~B}$ 


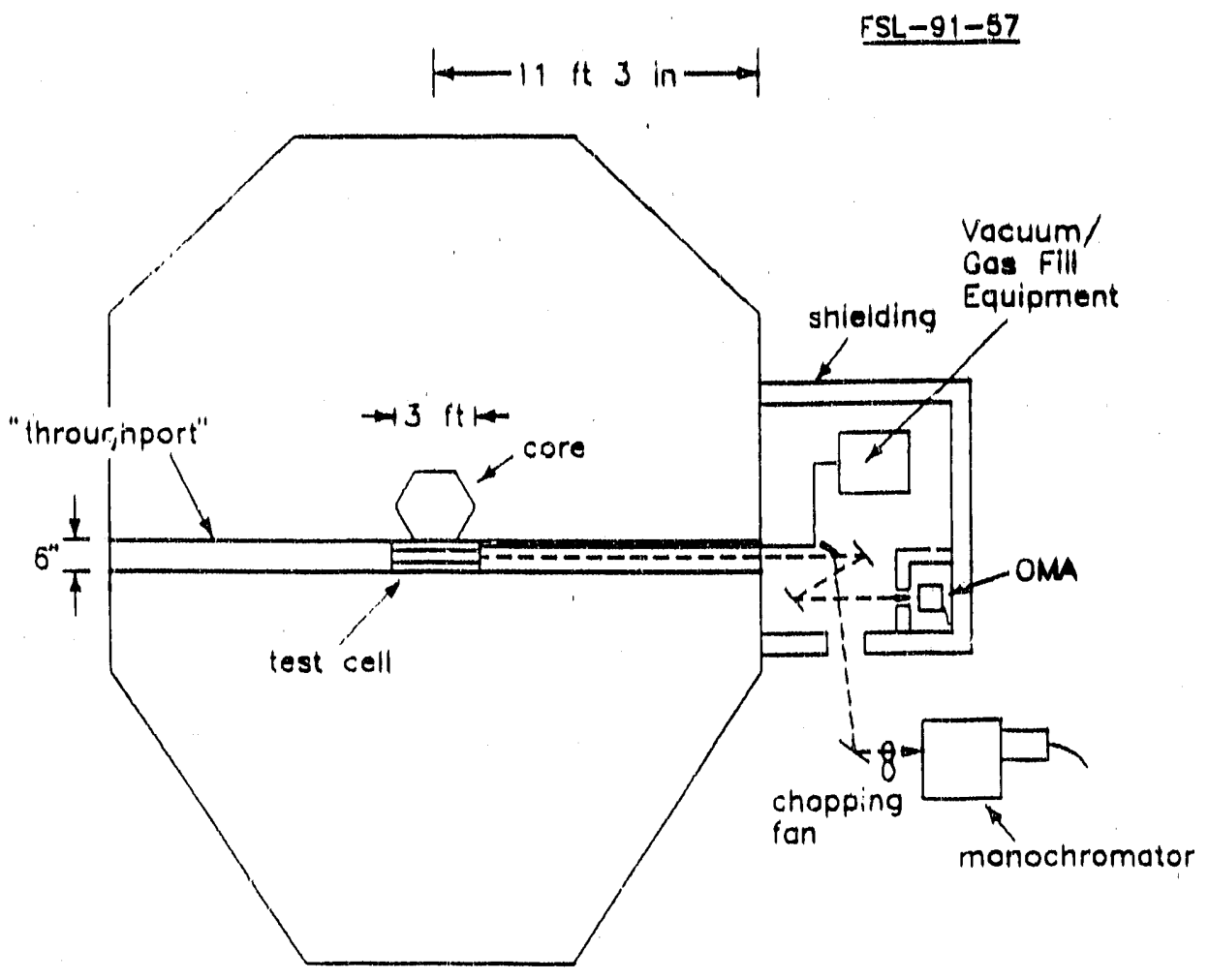

Figure 4. Experimental set-up for fluorescence experiments (not to scale).

pumping, and the other for ${ }^{3} \mathrm{He}$ pumping. Details of the design of these cells will be given later. Both cells were placed on a carriage in the throughport, with vacuum/gas fill lines attached, running out to a gas handling station on one end of the port. Pneumatic valves on the carriage allowed remote control of gas inlet to the cell. Use of these lines allowed the cell to be evacuated and refilled with various gas pressures and mixtures without removing the cell from the reactor. This was necessary because the carriage and cell, though made of materials to minimize activation (mostly aluminum), still become sufficiently "hot" following a pulse of neutrons that they could not be handled without a long decay period (hours).

The following sections will detail the gas handling system, chemicals, and diagnostic equipment used in experiments. Aspects of the laser cell experiments (as opposed 
to fluorescence cell experiments) which pertain to these topics will also be covered here, although a descripti's of the laser cell set-up will be given later.

3.2.1 Gas Handing System. The vacurum system used was a 6-inch diffusion pump; attached to the cell with 1-inch vacuum line. This allowed a vacurum of approximately 1-10 mtorr in the cell for fluorescence experiments. A modified valving design allowed a somewhat better vacuum in the laser cell for laser experiments, of approximately 0.5 mtorr. No vacuum gauges were attached to the test cells or laser during experiments, so all pressures were estimated based on bench top measurements with vacuum gauges either temporarily attached to or put in place of the cells.

Fill gas handling was done through a series of valves, gauges and a gas manifold at the pumping station. Materials in the system to which cell gases were exposed included aluminum tubing and fixtures, buna-n and Viton gaskets, vacuum grease, stainless steel and brass valves, copper and stainless tubing, diffusion pump oil used as a manometer fluid, and possibly other materials inside pressure gauges. All materials had moderate to good resistance to $\mathrm{Br}_{2}$, the most caustic gas used in the experiments.

3.2.2 Chemicals. Chemicals used in experiments included $99.8 \%$ pure ${ }^{3} \mathrm{He}$ (99.994\% ${ }^{3} \mathrm{He}+{ }^{4} \mathrm{He}$ ); research grade $\mathrm{Ar} ; 99.999 \%$ pure $\mathrm{Xe}$; $99+\%$ pure $\mathrm{CHBr}_{3}$; 99.6\% pure $\mathrm{Br}_{2}$; $99.99 \%$ pure $\mathrm{BBr}_{3} ; 97-99 \%$ pure $\mathrm{i}-\mathrm{C}_{3} \mathrm{~F}_{7} \mathrm{I}$; $>97 \%$ pure $\mathrm{CF}_{3} \mathrm{I}$; $>99.995 \%$ pure $\mathrm{Kr}$; and research grade $\mathrm{NF}_{3}$ in $\mathrm{He}$. The liquid compounds $\left(\mathrm{Br}_{2}\right.$, $\mathrm{CHBr}_{3}, \mathrm{BBr}_{3}$, and $\mathrm{C}_{3} \mathrm{~F}_{7} \mathrm{I}$ ) were treated to several freeze/evacuate/thaw cycles with either a dry ice/acetone bath or LN2 to remove dissolved gases. An attempt was also made to freeze out impurities in the ${ }^{3} \mathrm{He}$, since, due to the high $\mathrm{He}$ pressures used, this represented the largest known impurity source in the system. This was done by immersing the ${ }^{3} \mathrm{He}$ lecture bottle in $\mathrm{LN} 2$ during gas filling operations. It was found this precaution had no effect on fluorescence output either as an increase in output, or as a change in emission spectrum. (No impurity lines were ever identified in the spectra taken.) 
32.3 Dimgnostic Equipment. Several diagnostics were implemented in different phases of the experiments. These included two different Optical Multichannel Analyzers (OMA's) to measure fluorescence spectra (intensity versus wavelength): a Princeton Applied Research" model 1450/1452, and a model OMA III 1460/1456 from the same company. The spectrographs attached to both OMA's were Thermo Jarrel Ash Inc. model Monospec 18, with a $150 \mathrm{gv} / \mathrm{mm}$, $450 \mathrm{~nm}$ blaze spectral grating (Aires, Inc.) in the OMA model 1450/1452; and a $300 \mathrm{gv} / \mathrm{mm}, 300 \mathrm{~mm}$ blaze grating in the OMA $1460 / 1456$. Both OMA's were intensity calibrated using a $D_{2}$ light source: Gates Inc. model DCR-30/60 G power supply vith Nassau Inc. model D102F lamp. The lamp was intensity calibrated by EG\&G Gamma Scientifie Inc:

A monochromator/photomultiplier tube (PMT) was used to collect information on the time dependance of the $\mathrm{XeBr}$ fluorescence at the wavelength of interest (282 $\mathrm{nm}$ ). The monochromator was a CGA-McPherson model EU-700 with an RCA 31034 PMT.

An infrared sensitive InAs photodiode (EG\&G Judson, model $\mathbf{J 1 2}$ room temperature) with pre-amp was used to measure laser output. A 1.31 micron bandpass filter was used in front of the detector to allow measurement of only the laser line.

A fast response (20 microsec) pressure transducer used for energy deposition measurements in fluorescence experiments was a Kulite, Inc. model IPT1100 with home-made pre-amp. As explained in the following section, this transducer was attached to the fluorescence and laser cells in the reactor throughport. It was found to operate surprisingly well in the intense radiation field during a pulse, with only a small radiation-induced current in the signal. The transducer lifetime was found to be approximately 6 dozen pulses (7.5 MRad dose) before performance started to degrade, presumably due to radiation-induced damage to the silicon diaphragm in the transducer. This degradation was observed as a discrepancy between fill gas pressures in the cell as registered on filling equipment gauges, as opposed to the readings indicated by the transducer.

Indication of manufacturer is not intended as an endorsement of product. 
Determination of the temporal shape of the neutron pulse was made using an uncompensated ion chamber located near the reactor core. The temporal shope of the neutron pulse as seen by the laser was assumed to be identical (for these purposes) to that recorded by the ion chamber, based on nearness of ther ton chamber to the core. Ion current from the chamber was amplified through a picoammeter (Keithley model 415 ).

A digital oscilloscope (Nicolet 4094/4562) was used for data collection from the ion chamber, monochromator, and photodiode. An AT\&T personal computer was used for some fluorescence data storage.

Correlation of timing between reactor pulse and data collection equipment was done using an adjustable-delay timing circuit constructed by the department electronics shop.

\subsection{OMA Calibration}

The two OMA's used in measurements served to take spectra of the $\mathrm{XeBr}$ fluorescence over the range approximately 200 to $700 \mathrm{~nm}$. In addition, by calibrating the sensitivity of the devices, they were used to measure absolute light output from the fluorescing gas in $W / \mathrm{cm}^{3}$. This, when correlated with the energy deposited in the gas, as measured by the pressure transducer, allowed a determination of the fluorescence efficiency of the excimer.

Determination of the sensitivity of the OMA's in usable units (i.e. counts per $J / \mathrm{cm}^{2}$ incident on the OMA) was found difficult, although attempted, using vendorsupplied data only. A more accurate method, strongly recommended by the manufacturer, is to use a light source of known intensity for calibration. To this end, a $D_{2}$ lamp, which provides continuum radiation in the UV portion of the spectrum, was shipped to a vendor, and calibrated from 200 to $400 \mathrm{~nm}$, such that the intensity in $\mathrm{W} / \mathrm{cm}^{2}$ at a given distance from the lamp was known throughout this wavelength range. The lamp was then placed in front of each OMA at this distance, and an OMA sensitivity could then be determined in OMA counts per $\mathrm{J} /\left(\mathrm{cm}^{2}-\mathrm{nm}\right)$ incident light on the OMA entrance slit. 
This calibration was then applied to spectra obtained from the $\mathrm{XeBr}$ fluorescemee in reactor experiments, and the spectra could be recalculated in terms of light intemsity from the fluorescence incident on the OMA at each wavelength. Light attrmution due to neutral density filters used in front of the OMA had to also be factoredin, using known spectral transmission of the filters. Assuming isotropic fluoreseemedin the excimer, a known cell volume, and careful optical alignment during experimente such that the entire cell volume could be seen by the OMA, a determination of the: excimer fluorescence intensity in unis of $\mathrm{J} /\left(\mathrm{cm}^{3}-\mathrm{nm}\right)$ could be made across the spectrum. Fluorescence data will be shown later using this correction. An exmople of the calibration calculations and application to a fluorescence measuremeat is given in Appendix A.

The uncertainty of the calibration was unclear, due to the lack of knowledge concerning use history of the $\mathrm{D}_{2}$ lamp prior to calibration. Assuming the lamp was fairly new, however, the uncertainty would be $\pm 10 \%$. This uncertainty, and its contribution to overall measurement uncertainty, is discussed in Appendix E.

It should be noted that the $D_{2}$ lamp used for calibration is recommended for determining sensitivity in the UV because its emission is largely in this region of the spectrum, with very little in the visible. The other type of lamp commonly used for intensity calibrations is a tungsten ribbon lamp. It, however, emits much more strongly in the visible than in the UV. If used for UV calibrations, 2nd order light from the visible in the spectrograph will be brighter than 1st order UV, making calibration difficult. This problem was found in this work (and caused significant headache) when initial calibrations were done with a tungsten lamp.

\subsection{Pressure Transducer Measurements}

As indicated above, a piezoresistive pressure transducer was attached to experimental cells to measure energy deposited in the gas. (The operation of this transducer is based on a measurement of the change in resistivity of a silicon diaphragm under stress.) This was done for both fluorescence cells, as well as the laser cell. This measurement technique relies on the fact that a significant amount of energy is deposited in the gas during a pulse, such that the gas heats and, due to 
the closed cell volume, the pressure increases a readily measurable amount. Using an ideal gas heat capacity for the gas mixtures of $C_{V}=3 / 2 R=12.5 \mathrm{~J} /(\mathrm{mol} \mathrm{K})$, the energy deposited in the gas was determined. The method does not account, of course, for deposited energy which is converted to optical emission. In these measurements, emission in the visible and UV was shown to be small (ca. $1 \%$ of the energy deposited). The IR emission was assumed to be negligible, based on normal behavior of rare gas/halide excimers.

This technique has been used for other applications [36,37]. It has a restriction that the pulse length must be shorter than the time it takes for the gas to cool convectively/radiatively against the cell walls. Measurements can also be complicated, however, if the pulse is too short, i.e., short compared to the speed of sound in the gas, so that pressure waves are seen by the transducer. Since the 12 msec pulse is long compared to the transit time for a sound wave across the cell (60 microsec), only cooling of the gas during the pulse was of concern in these measurements, and this was corrected for as explained below.

3.4.1 ${ }^{10} \mathrm{~B}$ Pumping. The pressure rise as measured in the fluorescence cell using ${ }^{10} \mathrm{~B}$ pumping is shown in Figure 5, with the neutron pulse superimposed. This cell

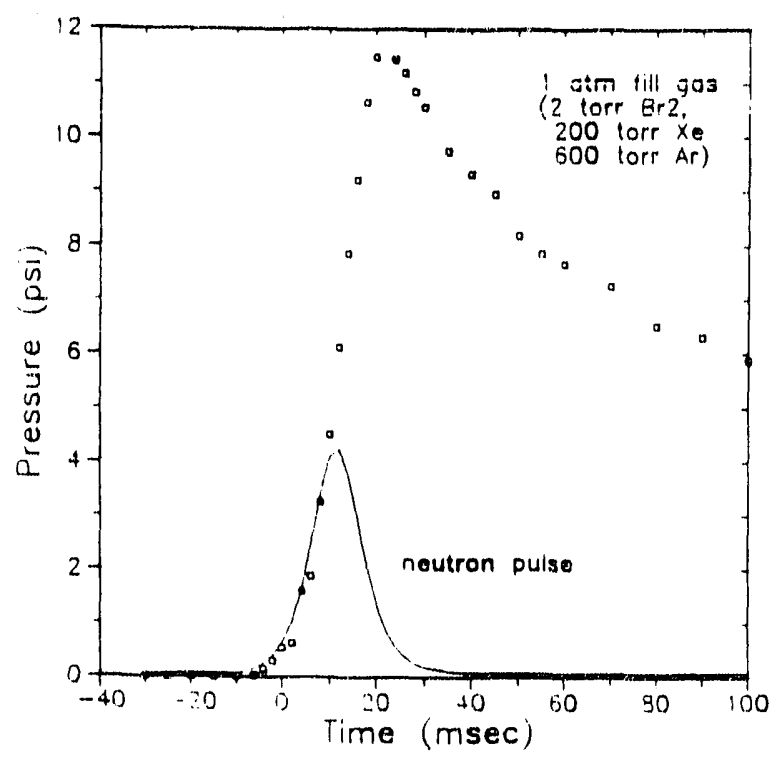

Figure 5. Measured pressure rise during a pulse with the ${ }^{10} \mathrm{~B}$-coated fluorescence cell. 
was 1 -inch inside diameter by 12 inches long, with a thin ${ }^{10} \mathrm{~B}$ coating (approximately 1 micron) on the inside. It can be seen that the pressure increased during the pulse to about 11.5 psi over fill pressure ( 800 torr), but then begins to decrease somewhat before the end of the pulse. This decrease is due to convective and radiative cooling of the gas against the cell walls (which heats only a degree or two due to the $\mathrm{n}-{ }^{10} \mathrm{~B}$ reactions, as well as gamma dose). Because this fall-off occurs before the end of the pulse, the pressure peak had to be corrected to reflect total energy deposited during the pulse.

This correction was done by curve-fitting the fall-off of the pressure to a single exponential, to represent the convective and radiative cooling. The entire rise and fall of the pressure was then modeled as a balance between a Gaussian heat input term of unknown magnitude (the reactor pulse shape), and the exponential heat loss term. A good fit was found, and then the equation was re-calculated assuming no cooling. This calculated pressure rise was $12.6 \mathrm{psi}$, a few percent above the $11.6 \mathrm{psi}$ shown in the figure. This calculation was not repeated for other pressure rise measurements (e.g. ${ }^{3} \mathrm{He}$ experiments). Rather, this fractional correction (12.6/11.6) was used to adjust all measurements. (Details of the calculations in this correction procedure are given in Appendix F.)

It should be noted there was a significant radiation-induced spike in the pressure transducer signal for pulses done on empty cells (approximately a 5 psi equivalent voltage). This radiation-induced effect, however, peaks and dies away before the peak of the pressure rise in a filled cell, so is not subtracted out of energy deposition measurements.

The pressure rise of $12.6 \mathrm{psi}$ was used to calculate an energy deposition of 0.14 $\mathrm{J} / \mathrm{cm}^{3}$. This, however, is an average over the cell volume. Because the alpha particles produced in the $\mathrm{n}^{10} \mathrm{~B}$ reactions have a finite range (approximately $1.4 \mathrm{~cm}$ in $1 \mathrm{~atm} \mathrm{He}$ ), the energy deposition in the cell is spatially non-uniform. This was qualitatively verified in visual observations of the ${ }^{10} \mathrm{~B}$ coated cell in the reactor during low power irradiations. The fluorescence from the cell could be seen to be brighter around the edges of the cell radial cross-section than in the center at pressures used in these experiments. 
As a check on the accuracy of the pressure transducer technique, these results can be partially compared to a calculation performed by A. Chung [38, pg. 14] of the energy deposition in a one inch diameter boron coated cell. Calculation results are shown in Figure 6. The energy deposition scale indicated in the figure is basadon slowing-down calculations for alpha and Li particles in He. Based on this curve; the volume average can be calculated to be approximately $22 \mathrm{keV} / \mathrm{cm}^{3}-\mathrm{sec}$ per unit neutron flux. This would predict an average energy deposition from a TRIGA paise of $0.14 \mathrm{~J} / \mathrm{cm}^{3}$ (in $\mathrm{He}$ ), in agreement with that measured in these experiments $\{0.14$ $\mathrm{J} / \mathrm{cm}^{3}$ ) (in $\mathrm{Ar}$ ).

One would expect, however, the energy deposition in Ar to be somewhat higher than in $\mathrm{He}$, since the range for an alpha particle from the, $\mathrm{n}^{10} \mathrm{~B}$ reaction in $1 \mathrm{~atm}$.

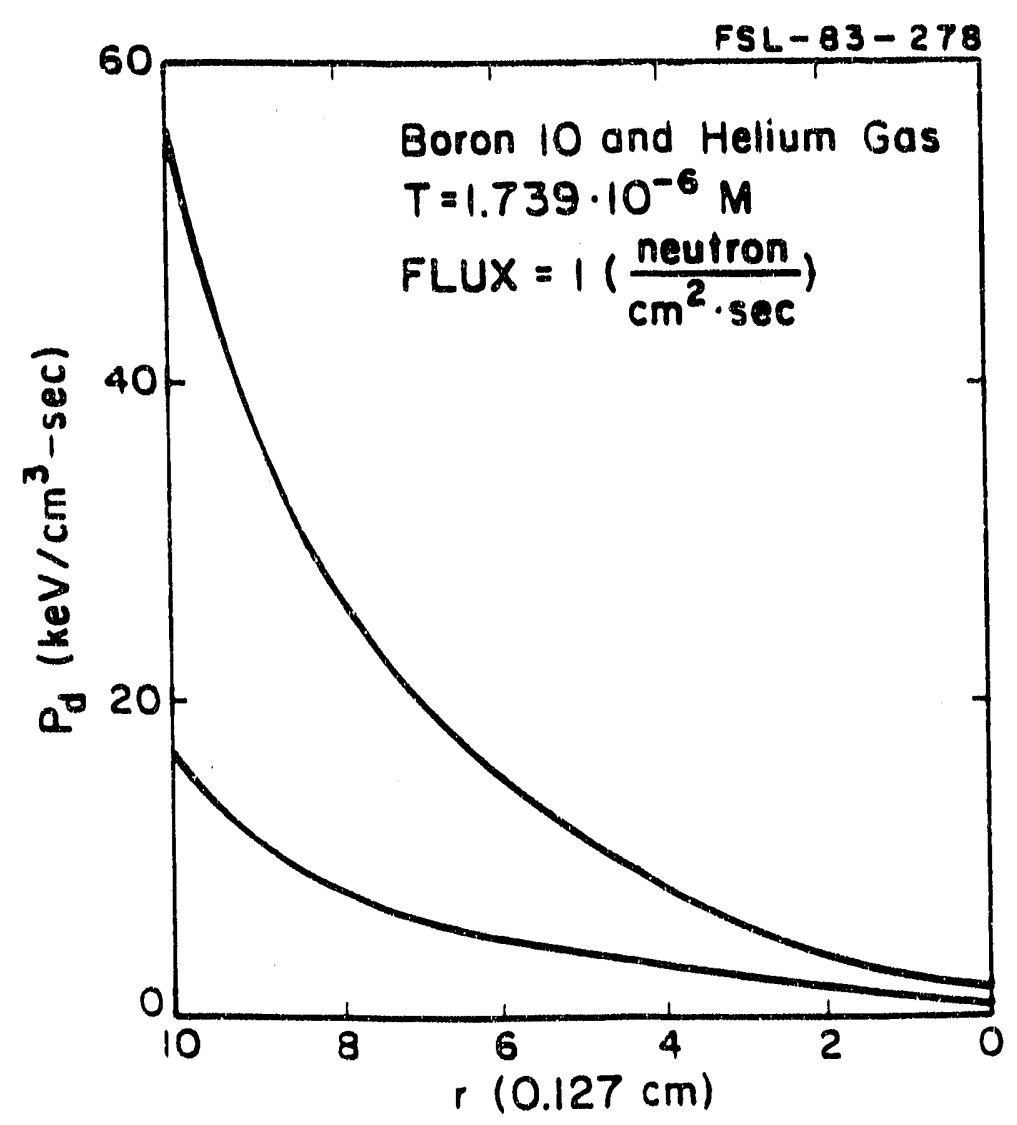

Figure 6. Calculated spatial power deposition as a function of radius for a 1-inch diameter ${ }^{10}$ B-coated cell (from ref. 38 ). 
gas is $0.6 \mathrm{~cm}$ in Ar and $2.5 \mathrm{~cm}$ in He. (For the $2.5 \mathrm{~cm}$ diameter cell, more of the alpha particles would be lost to the wall in He than Ar.) The fact that the calculated energy deposition in He is so close to the measured value in Ar may be due to the fact that the neutron flux in the throughport is not fully uniform along the length of the one-foot long fluorescence cell. The flux at the ends of the cell is approximately $25 \%$ less than at the middle $\left(3.1 \mathrm{e} 15 \mathrm{n} / \mathrm{cm}^{2} \mathrm{sec}\right)$ [35]. This peak flux, however; was. used for the entire cell length in the calculation above; hence, the energy depostition: was overestimated in He. Allowing for this corrected flux would predict the energy deposition in $\mathrm{He}$ to be lower than that measured in Ar. (It should be noted that the measured flux in the throughport is only slightly pertisbed by the this boron coating: $5 \%$ of the neutrons passing through the 1 micron layer are absorbed.) Energy deposition calculations could be done for Ar, or measurements in $\mathrm{He}$, to obtain a more accurate comparison. The fact that the pressure transducer gives approximately accurate results, however, is still inferred from the results above.

Elsayed-Ali and Miley [39], also found results comparable to the pressure transducer using another technique by measuring an average energy deposition of $20.2 \mathrm{keV} / \mathrm{cm}^{3}$-sec per unit flux in a similar cell with 400 torr $\mathrm{O}_{2}$. This was done by quantitatively measuring $\mathrm{O}_{3}$ formation during irradiation.

3.4.2 ${ }^{3}$ He Pumping. Similar types of experiments were conducted measuring pressure rise and fluorescence with ${ }^{3} \mathrm{He}$ pumping in a cell with similar dimensions to the ${ }^{10} \mathrm{~B}$ cell. Figure 7 shows results from several pressure rise measurements on fills of 0.5 torr $\mathrm{CHBr}_{3}, 200$ torr $\mathrm{Xe}$, and the balance ${ }^{3} \mathrm{He}$ up to a pressure of $3.7 \mathrm{~atm}$. Also shown in the figure are several values for the theoretically predicted energy deposition for pure $\mathrm{He}$, based on a know!eoge of the geometry, neutron flux, energy released per absorption, etc. These predicted results were taken from Wilson and DeYoung [40], who did a detailed analysis of energy deposition in ${ }^{3} \mathrm{He}$ pumped lasers for various pressures and cell diameters. Scaling to neutron fluxes in the reactor was based on information given previously in Table 1.

A surprisingly close agreement is shown between the measurements and theory in Figure 7. Similar to the discussion above for ${ }^{10} \mathrm{~B}$ pumping, however, one may expect some difference between the theoretical predictions for energy deposition 


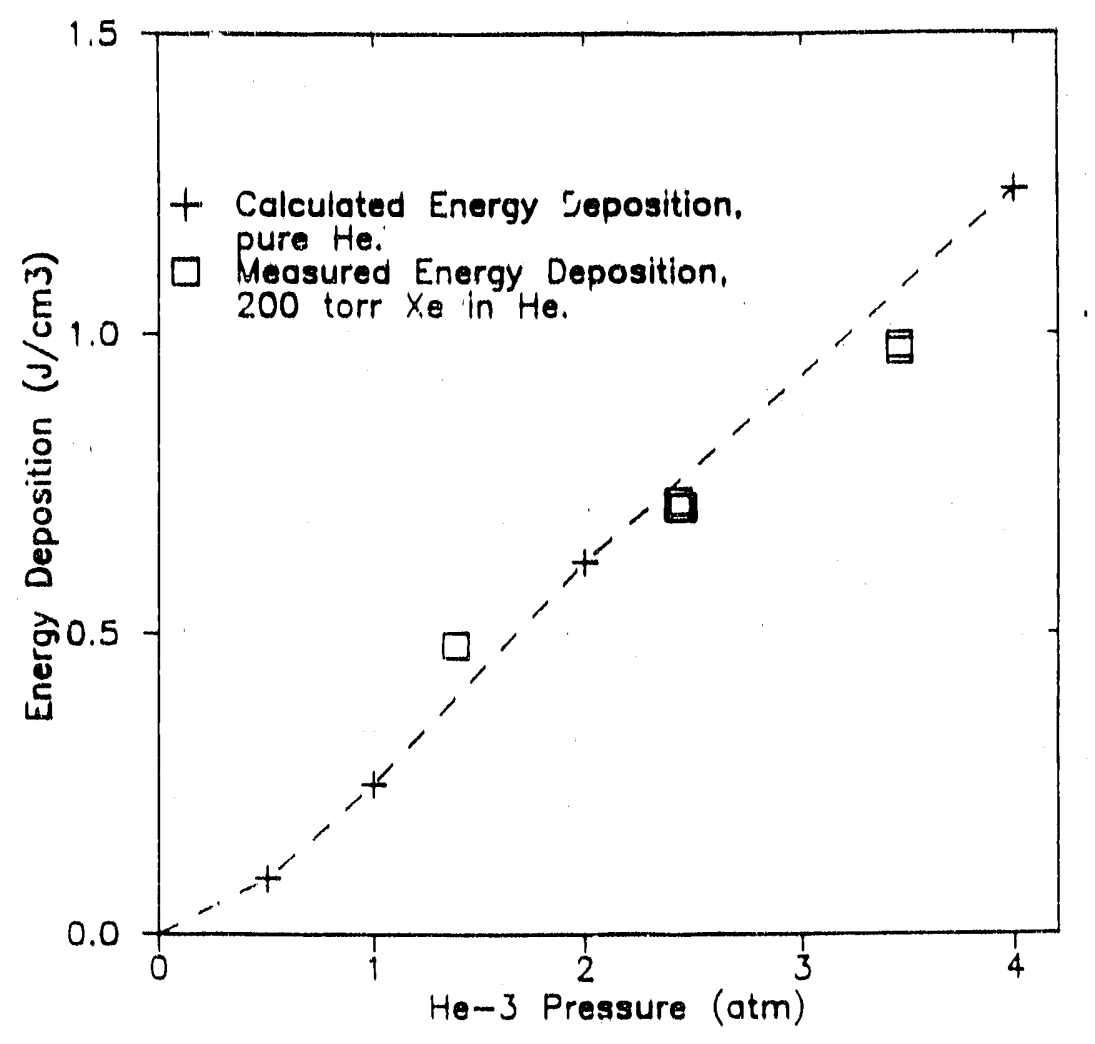

Figure 7. Comparison of energy deposition measured in $\mathrm{He}+200$ torr $\mathrm{Xe}$ vs calculated (from ref. 40) for pure He for the 1-inch diameter test cell.

and measured values because the predictions assumed pure ${ }^{3} \mathrm{He}$, whereas these experiments included 200 torr $\mathrm{Xe}$ in up to $3.5 \mathrm{~atm}{ }^{3} \mathrm{He}$. The range of an $\mathrm{n}-{ }^{3} \mathrm{He}$ reaction proton in $3 \mathrm{~atm}$. He is $1.5 \mathrm{~cm}$, compared to $2.7 \mathrm{~cm}$ in 200 torr Xe. Hence, for the $2 \mathrm{~cm}$ diameter cell, the energy deposition should be somewhat higher with the addition of $\mathrm{Xe}$. The fact that this does not show in the figure may be due to the fact that, as in ${ }^{10} \mathrm{~B}$ pumping, the neutron flux dips at the ends of the cell, which was not taken into account in the calculations. (Depression of the neutron flux by the significant neutron absorption in the $3 \mathrm{~atm} .{ }^{3} \mathrm{He}$ is taken into account in the calculations. This absorption reduces the flux at the cell location by approximately 35\% [40].) Taking this dip into account would place the energy deposition in the $\mathrm{He} / \mathrm{Xe}$ mixture above that for pure $\mathrm{He}$, as expected. Again, calculations for a $\mathrm{He} / \mathrm{Xe}$ mixture (as done in reference 40 for pure $\mathrm{He}$ ), or experiments in pure $\mathrm{He}$, 
would allow a more accurate comparison of theory and measurement: The comparison above, however, as with the $10_{\mathrm{B}}$ results, is sufficient to show the pressure transducer technique is approximately correct. Some discussion of the contribution of this uncertainty to the error in fluorescence efficiency determinations is included in Appendix E.

It should be noted, referencing Figure 7, thit a line drawn through the experimental data points would not pass through the origin, as would be expected. (A line through the theoretical predictions does pass through the origin.) This may be due to an inaccuracy caused by the limited number of data points taken, or may be due to a non-linearity of power deposition with. ${ }^{3} \mathrm{He}$ pressure. Since a non-linearity is not expected, based on the theoretical previctions shown in the figure, it is assumed this discrepancy is due to insufficient data.

3.4.3 ${ }^{3} \mathrm{He}$ vs ${ }^{10} \mathrm{~B}$ Pumping. The energy deposition is seen to be significantly higher under ${ }^{3} \mathrm{He}$ pumping than under ${ }^{10_{\mathrm{B}}}$ pumping, with energy depositions of up to 0.98 $\mathrm{J} / \mathrm{cm}^{3}$ measured with $3.7 \mathrm{~atm}{ }^{3} \mathrm{He}$ (compared to the $0.14 \mathrm{~J} / \mathrm{cm}^{3}$ indicated above for ${ }^{10} \mathrm{~B}$ ). The energy deposition is also much more spatially uniform in ${ }^{3} \mathrm{He}$ pumping than in ${ }^{10} \mathrm{~B}$ since it is a volume source rather than a wall source. Figure 8 shows a calculated energy deposition profile for a $3-\mathrm{cm}$ diameter cell with various pressures of ${ }^{3} \mathrm{He}$ (from ref. 40). Again, this spatial profile was qualitatively verified in visual observations of the cell under irradiations: the fluorescence across the cross-section of the cell appeared uniform in the $1-3 \mathrm{~atm}$. of ${ }^{3} \mathrm{He}$ used in these experiments.

3.4.4 Gas Heating. The $0.98 \mathrm{~J} / \mathrm{cm}^{3}$ measured in ${ }^{3} \mathrm{He}$ experiments is a significant amount of energy, and generates a peak (spatially averaged) gas temperature of approximately $780^{\circ} \mathrm{C}$. This is a significant temperature increase for many gas phase reactions, and has the potential of affecting, either positively or negatively, the fluorescence efficiency of the excimer. Some evidence (to be detailed later) was found that, for these experiments, the fluorescence efficiency was greater on the falling side of the pulse than on the rising side, possibly attributable to a change in gas temperature. 


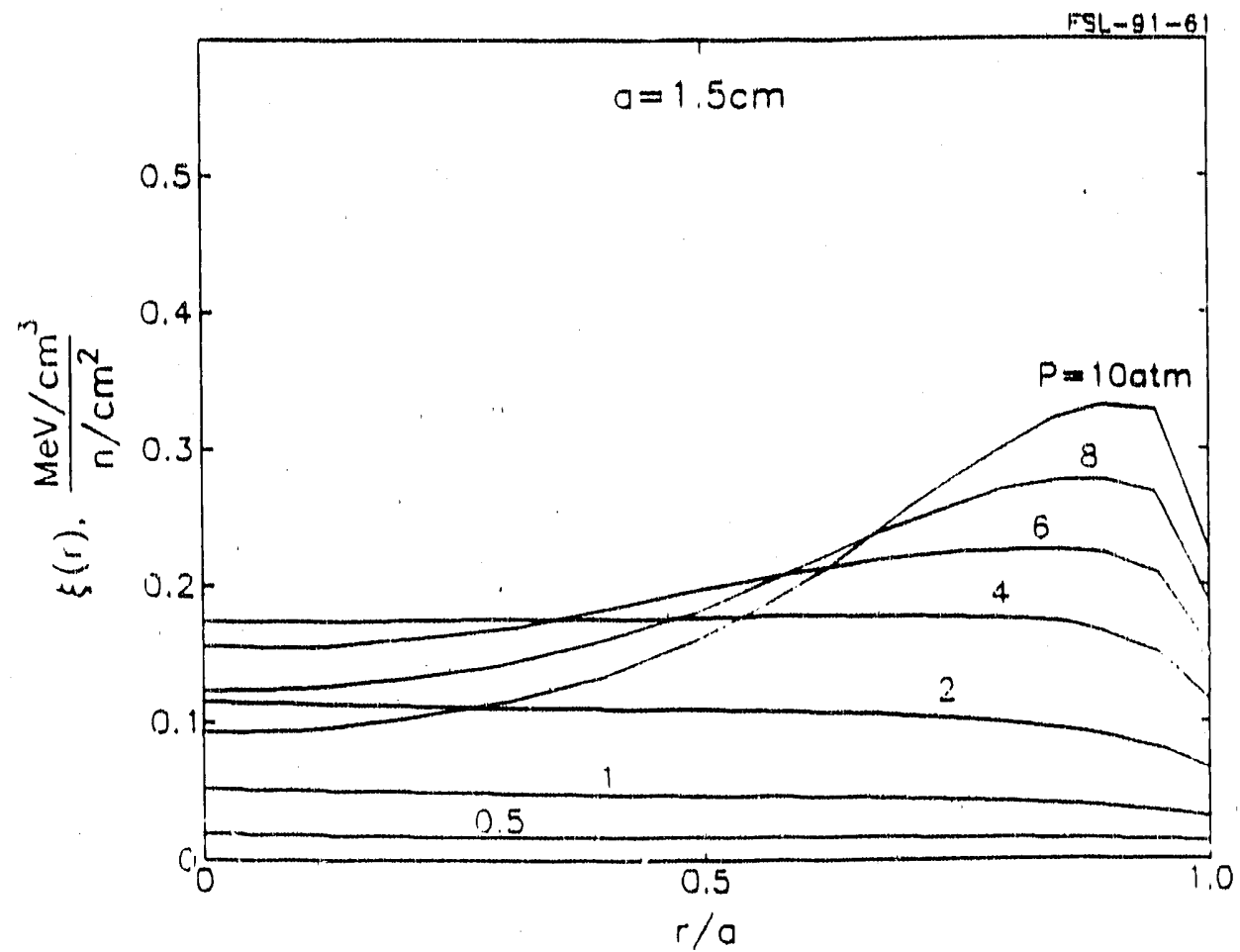

Figure 8. Calculated spatial energy deposition for a $3-\mathrm{cm}$ diameter cell with varying pressures of ${ }^{3} \mathrm{He} . \xi(r)$ is energy deposited per unit neutron fluence (from ref. 40).

\subsection{XeBr Fluorescence under ${ }^{10} \mathrm{~B}$ Pumping}

This section will detail results of measurements of the fluorescence of $\mathrm{XeBr}$ under ${ }^{10} \mathrm{~B}$ excitation, using a test cell constructed especially for this purpose. Measurements taken of fluorescence under ${ }^{3} \mathrm{He}$ excitation will be reported in the following section. The motivation behind these experiments was to determine the optimum $\mathrm{Xe} /$ bromine donor mixture to maximize $\mathrm{XeBr}$ fluorescence at $282 \mathrm{~nm}$, which mixture could then be used in a laser configuration. ${ }^{10} \mathrm{~B}$ was used because of its low cost, as compared to ${ }^{3} \mathrm{He}$, even though it was not planned for use in a final laser design. (The difficulties of efficiently coupling light from a surface source excitation, such as ${ }^{10} \mathrm{~B}$, as well as the significantly lower pump powers attainable with this method required selection of ${ }^{3} \mathrm{He}$ as the pump source for a laser.) 
Measurements were made using three different bromine donor molecules, and with varying pressures of these donors and of $\mathrm{Xe}$ and the buffer gas. Ar was used:as a buffer gas to maximize pump power, as it has a higher stopping power for alphas: than $\mathrm{He}$, so less alphas were lost to the wall of the cell. (The principal purpose of the buffer gas is to stop the alpha particles. It has a weak effect on gas kineticai, as buffer atoms act as third bodies in 3-body reactions. The buffer also increasen the heat capacity of the mix, lessening temperature rise.)

Care was taken in cell design, alignment, and diagnostics for these experimenta, as well as ${ }^{3} \mathrm{He}$ fluorescence experiments, so that the entire fluorescence cell volumo was viewed by optical diagnostics. This was necessary for a determination of absclute fluorescence output. Because of the importance of this requirement, a brief description of the technique used in alignment will be given.

The 1-inch diameter by 12 -inch fluorescence long cell was placed on a carriage next to the core in the throughport such that its centerline axis was parallel to the port, and extended out through a 2-inch diameter hole in the shielding doughnuts which are placed in the port during pulsing. Since the cell was one inch in diameter, the entire volume of the cell was viewable from outside the port at any point within $1 / 2$ inch of this axds. Alignment of diagnostics to be within this prescribed distance was done by first placing an iris on the axis (with the aid of binoculars) outside the port, at a distance of approximately 12 feet from the cell. Then the light from a small bulb mounted behind the rear window of the cell was shone through the interior of the cell, out the port, and through the iris. The light passing through the iris could then be assumed to be within $1 / 2$ inch of the ixis, and diagnostics were aligned on this signal. The iris was removed before pulsing to make sure it was not clipping the view. This technique proved tedious, and required some care in, for example, finding the best method to illuminate the cell in order to find the axis. It was sufficiently straightforward, however, to be considered repeatable and reliable. The contribution of the uncertainty in the technique to the overall fluorescence efficiency uncertainty is discussed in Appendix E. 
A description will now be given of the bromine donors and the experimental cell used in ${ }^{10} \mathrm{~B}$ experiments, followed by results and discussion. (A description of the experimental set-up was given in section 3.2 above.)

3.5.1 Bromine Donors. Three bromine-containing compounds were used in these experiments, $\mathrm{Br}_{2}, \mathrm{CHBr}_{3}$, and $\mathrm{BBr}_{3}$. All three are liquids at room temperature. While extensive measurements were done with the first two materials, only one data point was taken with $\mathrm{BBr}_{3}$ because its reactive nature caused significant handling difficulties. All three materials have low personnel exposure limits, requiring care in experiments.

Choice of these compounds was aided by work reported [21] on the trimer, $\mathrm{Xe}_{2} \mathrm{Br}$. Several bromine donors were utilized in that research. The best, in terms of $\mathrm{XeBr}$ formation rate, was $\mathrm{CBr}_{4}$. This material requires system heating, however, to achieve a sufficient vapor pressure, so was not used for this work. $\mathrm{CHBr}_{3}$ was found to work almost as well.

3.5.2 10 B Fluorescence Cell. A schematic of the cell constructed for these experiments is shown in Figure 9. The tube was $1 \mathrm{~mm}$ wall aluminum (1100). The thickness of the boron coating was not known, but was presumably approximately 1 micron, based on reported experiments using similar tubes [38,39]. Fused silica

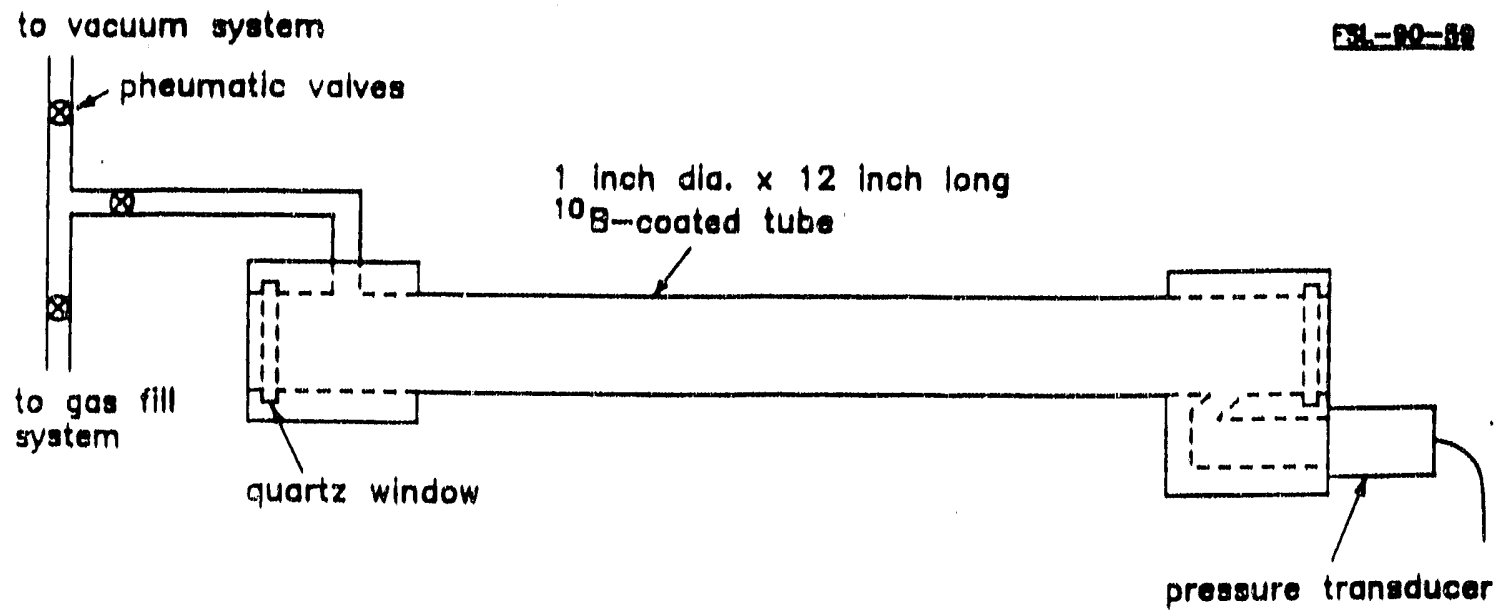

Figure 9. Schematic of ${ }^{10} \mathrm{~B}$-coated test cell (not to scale). 
windows, chosen because they were known from previous experiments [41] to experience minimal darkening under irradiation, were sealed with Viton or bumann o-rings. (The estimated transmission loss through the windows at $282 \mathrm{~nm}$ during a pulse was $<<1 \%$.)

3.5.3 $\mathrm{Br} 2$ Fluorescence Results. A fluorescence spectrum of $\mathrm{XeBr}$ under ${ }^{10} \mathrm{~B}$ excitation, as recorded with ihe OMA 1450/1452 system, is shown in Figure 10. The strong peak of interest for this work is seen at $282 \mathrm{~nm}$. Two other peaks at $320 \mathrm{~nm}$ and $415 \mathrm{~nm}$ are also indicated. Other finer features in the spectrum are thought to be noise, since the fluorescence was relatively 'veak, just on the edge of the detector sensitivity. The spectrum has not been corrected for OMA spectral sensitivity. (That is, the detector is more sensitive to certain wavelengths than others.) The lines observed in this spectrum agree in wavelength with spectra taken of $\mathrm{XeBr}$ by other workers under different pumping mechanisms [9,21,30,42], indicating the three peaks seen can be correctly attributed to $\mathrm{XeBr}$ and $\mathrm{Xe}_{2} \mathrm{Br}$ transitions. The measured linewidth of approximately $3 \mathrm{~nm}$ for the $282 \mathrm{~nm}$ peak was similar to that reported by other workers $(1.6-2.8 \mathrm{~nm}$ in ref. 31$)$.

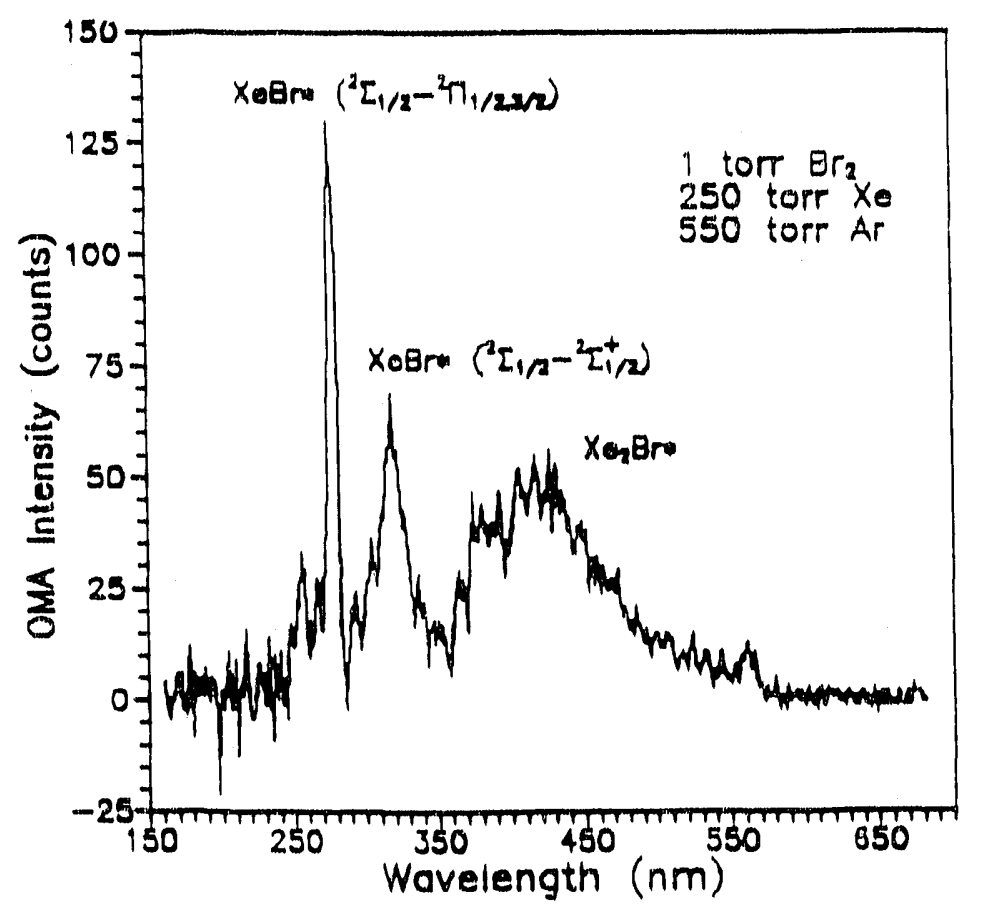

Figure 10. Fluorescence spectrum of $\mathrm{XeBr}$ under ${ }^{10} \mathrm{~B}$ pumping (OMA 1450/1452). 
As the line at $282 \mathrm{~nm}$ was of principle interest for this work, results presented below will focus on the dependance of the intensity of this peak as a function of gas mixture. Before discussing specific results, however, it should be explained thatin several of the figures that follow, lines have been drawn through the experimemal data points. These lines are arbitrary, and are not meant to definitively show treads in the data. Since there was often significant scatter in the results, they were simply added as an aid to the eye to group data points together.

Figures 11-13 show results of measurements done using $\mathrm{Br}_{2}$ as a bromine donor, varying gas parameters to optimize output. Light detection was done using the OMA 1450/1452 system. Measurements varying the Xe pressure, as shown in Figure 11, indicate a very weak dependance on this parameter; likewise for the

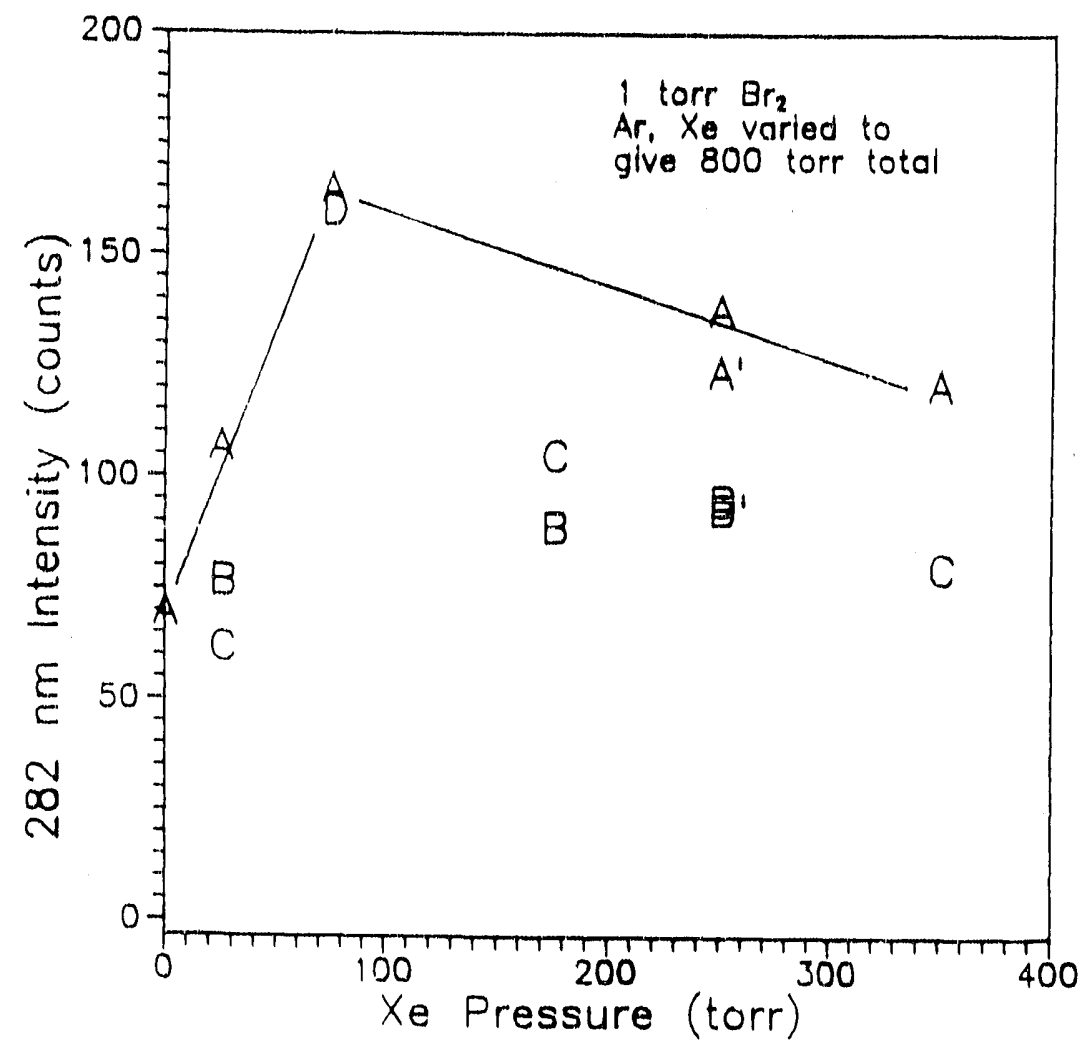

Figure 11. $\mathrm{XeBr}$ emission at $282 \mathrm{~nm}$ as a function of $\mathrm{Xe}$ pressure under ${ }^{10} \mathrm{~B}$ pumping (OMA 1450/1452). Letters represent sequential pulses on the same gas fill. The unidentified emission at zero torr Xe had a wavelength of ca. $289 \mathrm{~nm}$. 


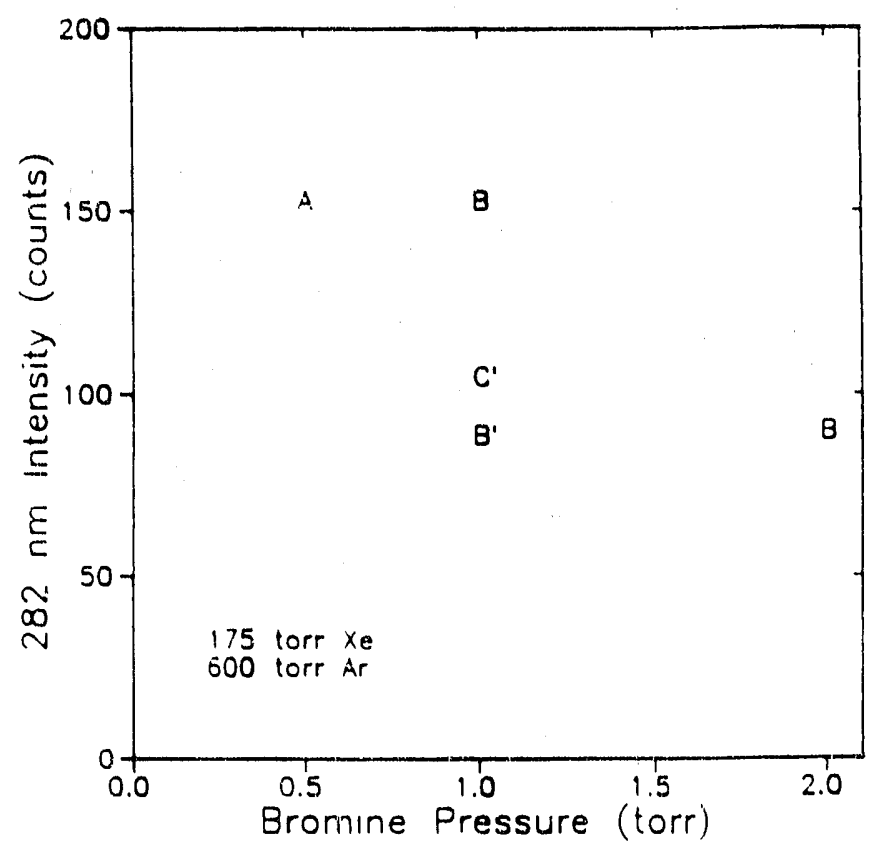

Figure 12. XeBr emission at $282 \mathrm{~nm}$ as a function of $\mathrm{Br} 2$ pressure under ${ }^{10^{0}} \mathrm{~B}$ pumpirig (OMA 1450/1452). Letters represent sequential pulses on the same gas fill.

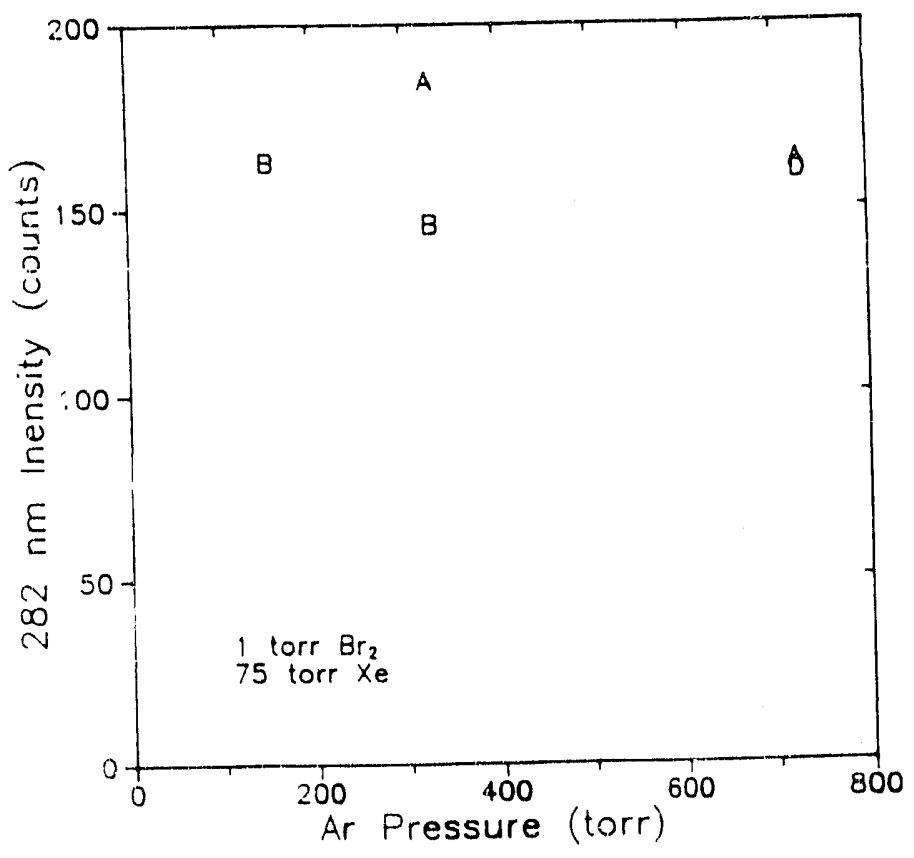

Figure 13. $\mathrm{XeBr}$ emission at $282 \mathrm{~nm}$ as a function of Ar pressure under ${ }^{10} \mathrm{~B}$ pumping (OMA 1450/1452). Letters represent sequential pulses on the same gas fill. 
variation in $\mathrm{Br}_{2}$ and $\mathrm{Ar}$ pressures shown in Figures 12 and 13. The fluorescence at zero $\mathrm{Xe}$ pressure in Figure 11 was not $\mathrm{XeBr}$ fluorescence, as it was shifted in wavelength from $282 \mathrm{~nm}$ to approximately $289 \mathrm{~nm}$. The origin of this fluorescence was unclear. It is close enough in wavelength, however, to the $\mathrm{XeBr}$ transition to be useful for iodine pumping, so is included in the figure.

The letters (A-D) in Figure 11 represent sequential pulses on the same fill of gas. That is, letter A represents the first pulse, letter B, the second, etc. (Data from some pulses were lost due to radiation effects on the OMA, so some sequences are incomplete; e.g., there is no pulse $A$ at $\mathbf{1 7 5}$ torr Xe in Figure 11. Also, two fills were done at 250 torr Xe: hence, the primed notation.) What appears to be a decreasing output with added pulsing may be the effect of impurities being driven from the boron coating into the gas on each pulse, contaminating the mixture. It may, however, simply be scatter in the data due to a difficulty found in making reproducible measurements with this OMA (1450/1452) system. This alternative is considered the more likely, considering the larger randomness in results from sequential pulses presented in other figures that follow.

The reason for this difficulty in making repeatable measurements was not fully identified; efforts to solve the problem deserve some discussion. The intensities given in the figures are from the spectra as recorded by the OMA during pulsing. The peak heights would simply change from pulse to pulse. This variance in measured fluorescence intensity appeared as a wide scatter in all the results with this OMA (1450/1452), and appeared to involve the synchronization of the pulsed fluorescence $(30 \mathrm{msec})$ with the exposure timing of the OMA (100 msec). Under ordinary circumstances, this timing would not have been difficult. There may have been a complication in this case, however, due to radiation effects on the OMA.

That is, in order to maximize the detected light, the OMA detector head was placed as close to the fluorescence cell as possible, approximately 5 meters. Unfortunately, the detector head contains integrated circuits with high sensitivity to ionizing radiation. To minimize the effect of the radiation, large quantities of shielding (lead and cement bricks) were placed around the detector in a trial and error fashion. Even still, in perhaps half of all pulses, all or part of the spectral data were lost 
(giving, for example, only a third of the spectrum). Given that the radiation was affecting the detector so significantly as to lose data, it was also considered possible that the scan timing was also being affected, though in an unmonitorable fashion. Fortunately, after some sets of experiments, another OMA (1460/1456) was acquired, which was more sensitive, and so could be placed farther from the throughport entrance. Data was rarely lost with this OMA, and was more reproducible (though still not completely so). In summary, no firm reason was found for the inability to make repeatable measurements of the fluorescence, either on separate, identical gas fills, or from sequential pulses on the same fill. The data was still considered good enough, however, to allow selection of a gas mixture for use in the laser, and to measure an approximate fluorescence efficiency. The effect of this scatter on the uncertainty in the fluorescence efficiency calculations is discussed in Appendix E.

Based on these measurements, an optimum gas mixture using $\mathrm{Br}_{2}$ as a bromine donor was determined to be approximately 1 torr $\mathrm{Br}_{2}$ and 100 torr $\mathrm{Xe}$ in Ar. The term "optimum", however, is used loosely, here given the weak dependance found in fluorescence for variations in both $\mathrm{Xe}$ and $\mathrm{Br}_{2}$ pressures. The significant scatter in the data also makes accurate determination of an optimum difficult. An effort was made to take a large number of data points to help offset this uncertainty, with marginal success.

3.5.4 CHBr3 Fluorescence Results. Figures 14 through 16 give fluorescence results for experiments using $\mathrm{CHBr}_{3}$ and $\mathrm{BBr}_{3}$ as bromine donors. Figures 14 and 16 were taken with the OMA $1460 / 1456$ system; Figure 15 was taken with the OMA $1450 / 1452$ system.

The dependance on fluorescence output as a function of $\mathrm{CHBr}_{3}$ pressure is shown in Figure 14. The optimurin pressure found here of 0.1-0.2 torr is somewhat lower than the 1 torr reported in ef. 21 for investigations of $\mathrm{Xe}_{2} \mathrm{Br}$. This may be due to the fact that these exper ments were done with measurements at the higher pressures first, followed by the low pressure measurements. Consequently, there may have $\mathrm{CHBr}_{3}$ adsorbed on the cell walls (on the boron coating) which contributed to the fluorescence at the low partial pressures, giving anomalously high 


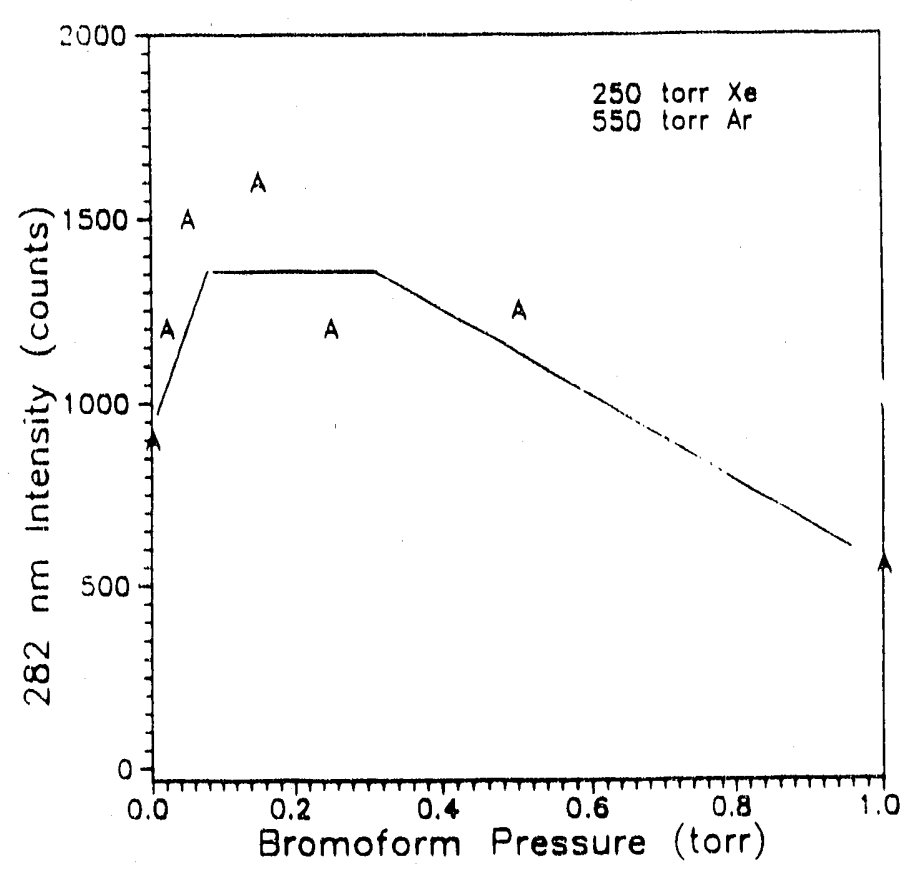

Figure 14. $\mathrm{XeBr}$ emission at $282 \mathrm{~nm}$ as a function of $\mathrm{CHBr}_{3}$ pressure under ${ }^{10} \mathrm{~B}$ pumping (OMA 1460/1456). Letters represent sequential pulses on the same fill of gas. The emission at zero torr $\mathrm{CHBr}_{3}$ is attributed to $\mathrm{CHBr}_{3}$ adsorbed on the cell wall.

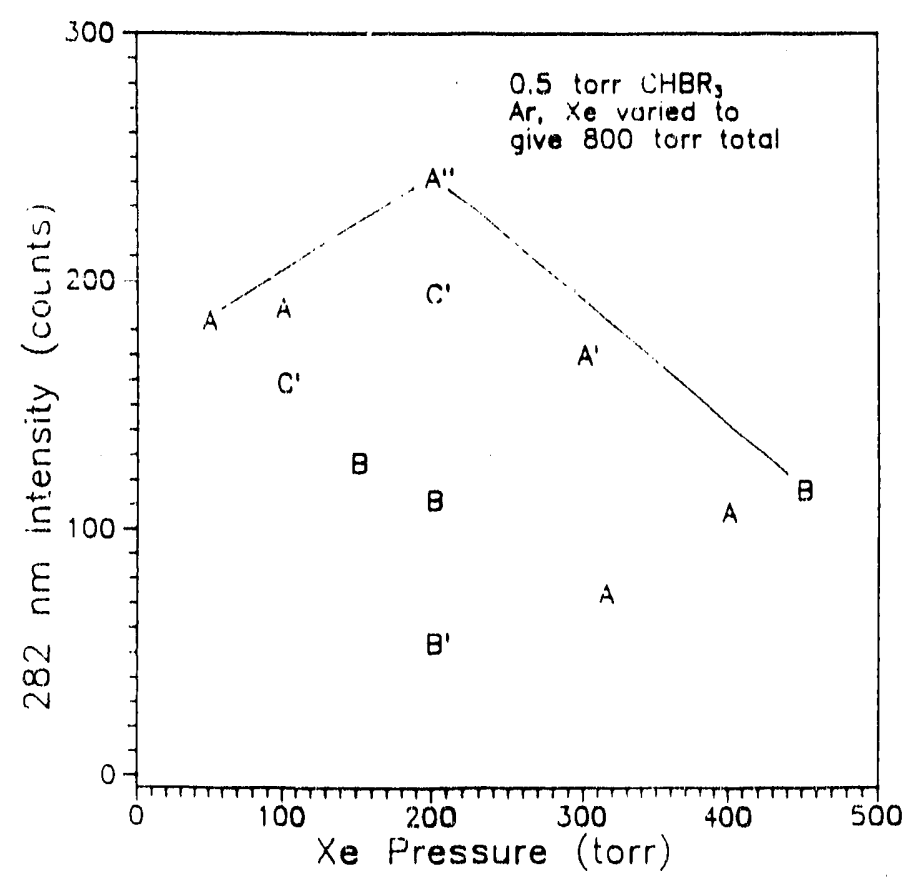

Figure 15. $\mathrm{XeBr}$ emission at $282 \mathrm{~nm}$ as a function of Xe pressure under ${ }^{10} \mathrm{~B}$ pumping (OMA 1450/1452). Letters represent sequential pulses on the same gas fill. 


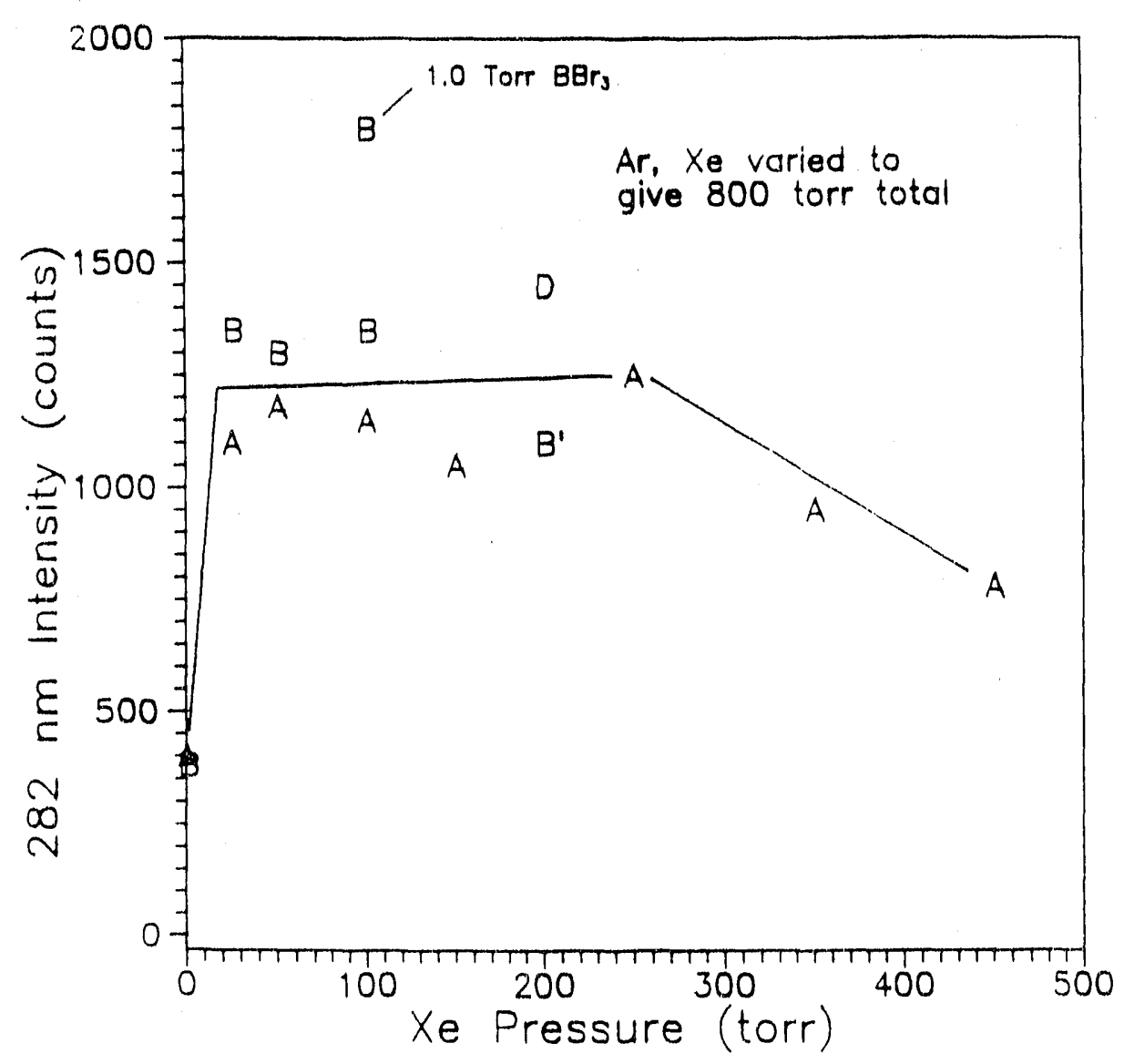

Figure 16. $\mathrm{XeBr}$ emission at $282 \mathrm{~nm}$ as a function of Xe pressure under ${ }^{10} \mathrm{~B}$ pumping (OMA 1460/1456). Bromine donor: 0.5 torr $\mathrm{CHBr}_{3}$, except as noted. Letters represent sequential pulses on the same gas fill. The unidentified emission at zero torr Xe had a wavelength of approximately $286 \mathrm{~nm}$.

readings. The $282 \mathrm{~nm}$ fluorescence seen at zero $\mathrm{CHBr}_{3}$ pressure is thought to have been due to this effect. Because of the difficuity in measuring pressures beiow 0.5 torr with the equipment used, a $\mathrm{CHBr}_{3}$ pressure of 0.5 torr was used in laser experiments, even though a lower pressure may have been preferable.

Figure 15 gives the $\mathrm{XeBr}$ fluorescence with varying $\mathrm{Xe}$ partial pressure for 0.5 torr $\mathrm{CHBr} 3$. As explained above for the $\mathrm{Br}_{2}$ results, the scatter in the data is attributed to a difficulty in coordinating the timing of the pulse and the OMA $1450 / 1452$ system. Figure 16 shows similar data taken with the OMA 1460/1456 system, with 
much smaller scatter. (The emission at zero torr $\mathrm{Xe}$ had a wavelength of approximately $286 \mathrm{~nm}$. Its origin was unidentified. $\left[\mathrm{Br}_{2}^{*}\right.$ is $291 \mathrm{~nm}$.] At this wavelength, however, it was still considered suitable for pumping iodine.) Taking both figures together, an "optimum" Xe pressure of 200 torr was indicated from the figures for 0.5 torr $\mathrm{CHBr}_{3}$.

One data point is shown in Figure 16 for $\mathrm{BBr} 3$. Unfortunately, only one measurement on this gas was successful in a full day of pulsing. No clear explanation was found for failure of the other attempts. It was likely associated with the difficulties in injecting this highly reactive material into the test cell, given the materiais in the system. ( $\mathrm{BBr} 3$, for example, reacts vigorously with moisture in the air to form $\mathrm{HBr}$, a strong acid.) No further tests were done because the performance of the $\mathrm{CHBr}_{3}$, an easier compound to work with, was adequate for these proof-of-principle experiments.

The conclusion of these experiments with ${ }^{10} \mathrm{~B}$ pumping was a determination of an $\mathrm{XeBr}$ mixture for use in a laser of 0.5 torr $\mathrm{CHBr}_{3}$ and 200 torr $\mathrm{Xe}$. This mixture was considered approximately optimum, although the fluorescence output dependance on pressure for both of these gases was not strong. A determination was also made of the fluorescence efficiency with this pumping mechanism. A discussion of the fluorescence efficiency results, however, will be postponed until after a discussion of $3^{3}$ He measurements.

\subsection{XeBr Fluorescence under ${ }^{3} \mathrm{He}$ Pumping}

Following this determination of a gas mixture from ${ }^{10} \mathrm{~B}$ experiments, a test cell was constructed to determine fluorescence efficiencies of this mixture under ${ }^{3} \mathrm{He}$ excitation, as would be used in a laser. A description will be given of the test cell, followed by results and discussion.

3.6.1 ${ }^{3}$ He Fluorescence Cell. A schematic of the cell used in these experiments is shown in Figure 17. The cell was aluminum with fused silica windows sealed with orings. Vacuum and gas filling of $\mathrm{CHBr}_{3}$ and $\mathrm{Xe}$ were done through one port on the cell, and ${ }^{3} \mathrm{He}$ filling through another. The cell was constructed so the inside 


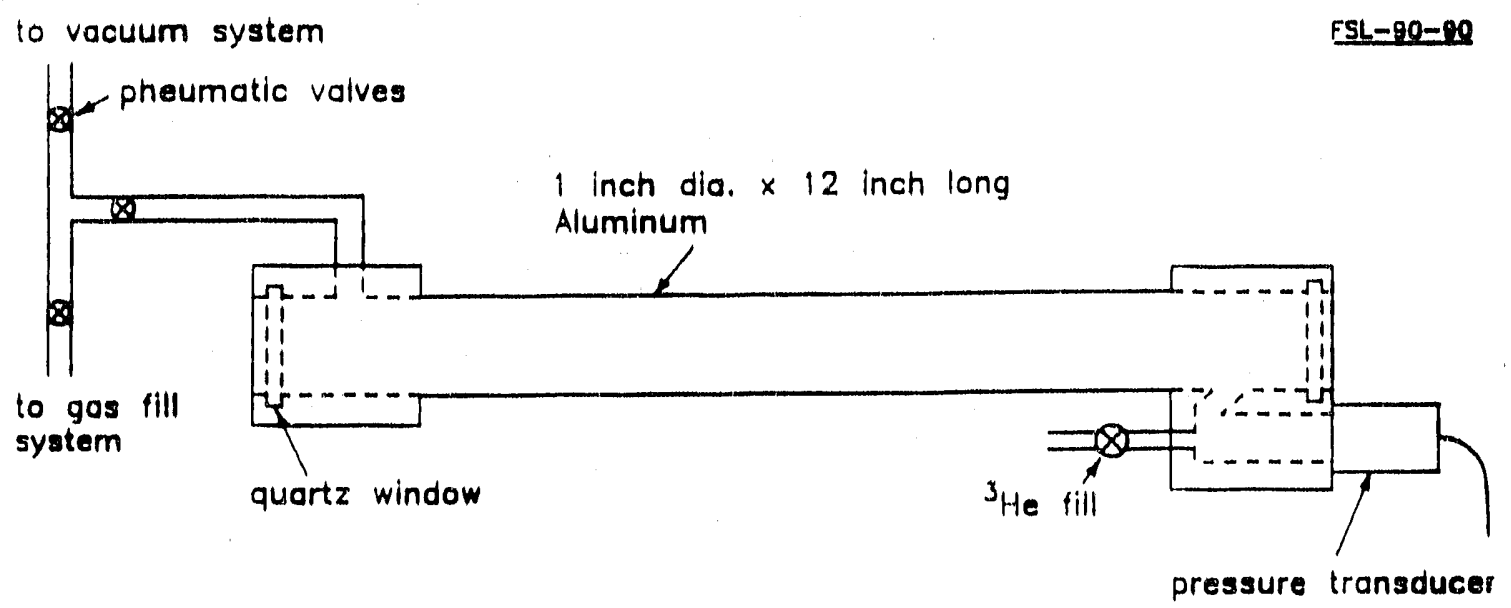

Figure 17. Schematic of ${ }^{3} \mathrm{He}$ test cell (not to scale).

diameter tapered from a diameter of $0.93^{\prime \prime}$ on one end to $0.652^{\prime \prime}$ on the other (not shown in figure). This facilitated viewing of the entire cell volume when in the throughport, necessary for accurate determinations of fluorescence efficiencies.

3.6.2 Fluorescence Results. All ${ }^{3} \mathrm{He}$ fluorescence measurements were taken with the OMA $1460 / 1456$ system. A spectrum as observed during a reactor pulse is shown in Figure 18. This spectrum has not been corrected for spectral response, and is significantly distorted. That is, the $\mathrm{XeBr}$ fluorescence at $282 \mathrm{~nm}$ is actually much stronger than the other two emissions at 320 and $415 \mathrm{~nm}$, so in order to make good measurements of all peaks, a $1 / 16^{n}$ piece of Pyrex glass was used in front of the OMA as a filter. Spectrophotometer measurements had been taken on the glass, showing a transmission at $282 \mathrm{~nm}$ of $6.2 \%$, but approaching $80 \%$ at $320 \mathrm{~nm}$ and $92 \%$ at $415 \mathrm{~nm}$. When used in these measurements the filter served to reduce the $\mathrm{XeBr}$ peak onto the scale of the other two peaks. Experiments had shown that without the Pyrex, all three peaks could not be accurately recorded on the same scale, making a determination of an accurate spectrum and of the light energy emitted under the small peaks difficult (the small peaks were lost in the noise). As will be discussed in the next section, knowledge of the filter transmitivities and OMA spectral response allowed reconstruction of a correct spectrum. 


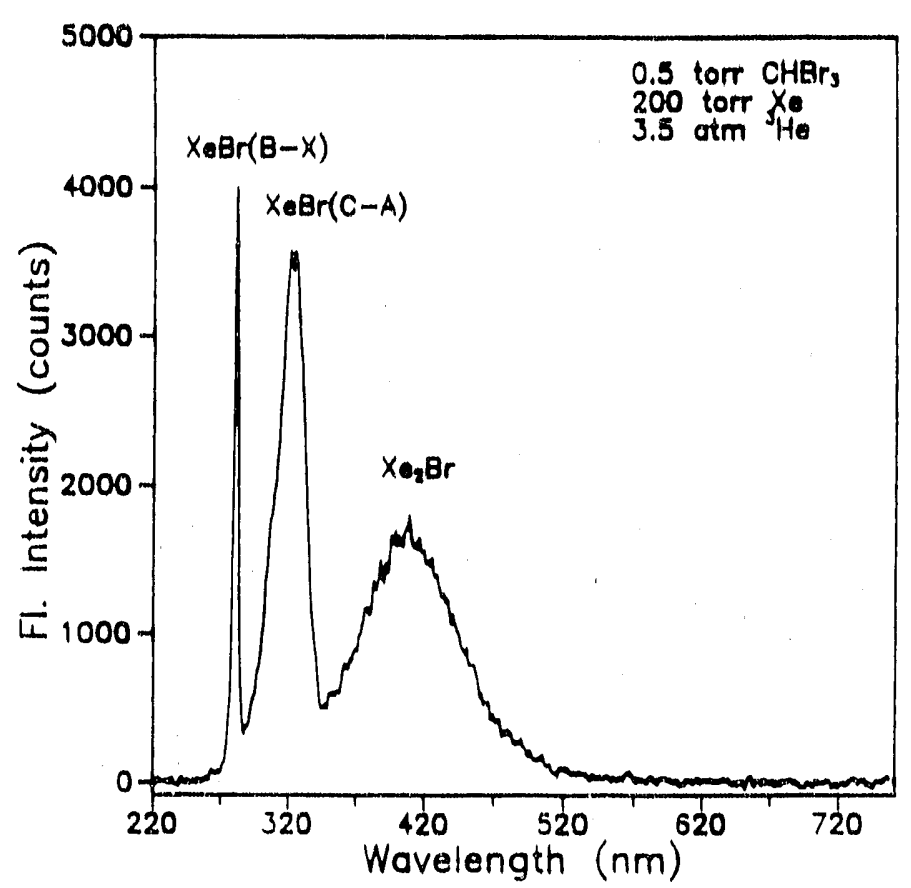

Figure 18. Spectrum of $\mathrm{XeBr}$ fluorescence under ${ }^{3} \mathrm{He}$ pumping, not corrected for wavelength sensitivities of OMA and filters (OMA 1460/1456).

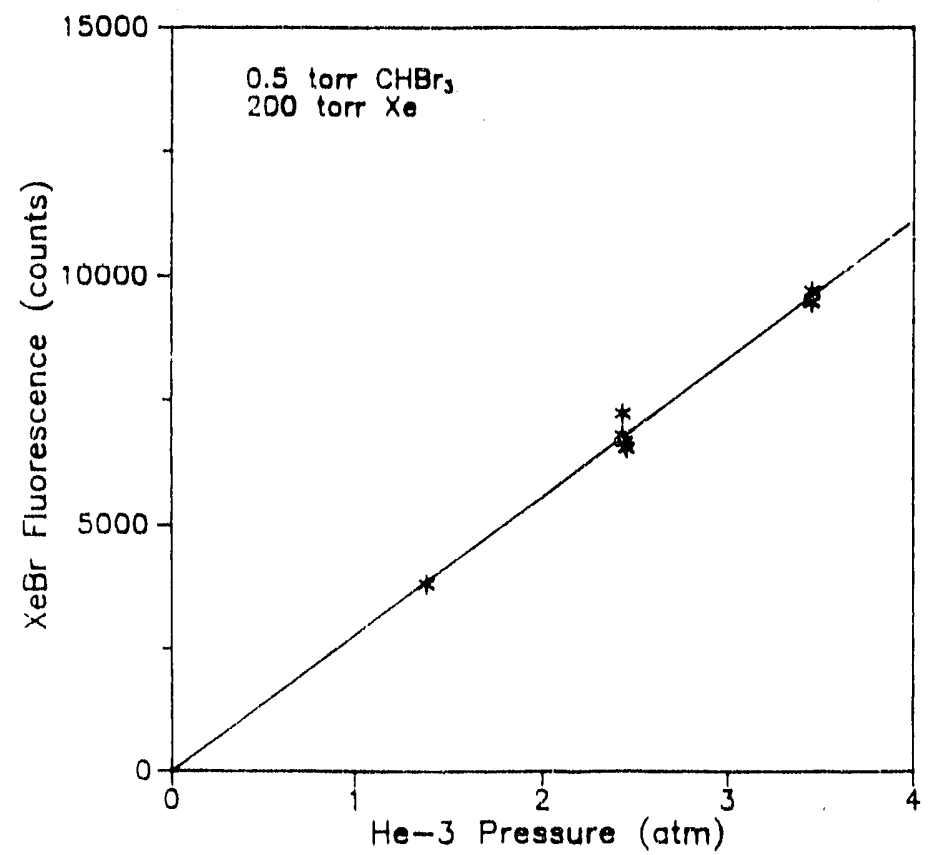

Figure 19. $\mathrm{XeBr}$ emission at $282 \mathrm{~nm}$ as a function of ${ }^{3} \mathrm{He}$ pressure (OMA $1460 / 1456)$. 
Fluorescence measurements were taken with 0.5 torr $\mathrm{CHBr} 3$ and 200 torr Xe with ${ }^{3} \mathrm{He}$ to total pressures of $1.6 \mathrm{~atm}$ to $3.7 \mathrm{~atm}$. Figure 19 shows results at three pressures. A new gas fill was used for each pulse shown. A linear least squares fit through the data (solid line) goes through the origin, indicating a linear outputwith ${ }^{3} \mathrm{He}$ pressure in this regime, and for this test cell. (Changing ${ }^{3} \mathrm{He}$ pressure would. affect both the pumping power as well as the gas kinetics, so a linear dependence with pressure could not necessarily have been anticipated. A linearits or superlinearity would be desirable for scale-up considerations.)

3.6.3 Fluorescence Temporal Dependance. In most fluorescence experiment both: with ${ }^{3} \mathrm{He}$ pumping, as well as ${ }^{10} \mathrm{~B}$ pumping, a measure of the temporal dependence of the fluorescence at $282 \mathrm{~nm}$ was taken using a monochromator/PMT. A trace of the fluorescence, with neutron pulse superimposed, is shown in Figure 20. The chopping in the signal is due to a chopping fan placed in front of the monochromator to allow subtraction of radiation-induced noise in the PMT. This noise is seen in the figure as the small increase in the chopped signal above zero during the $10-20 \mathrm{msec}$ around the peak of the pulse. The load resistor used on the line between the PMT and oscilloscope was 50 kilo-ohm.

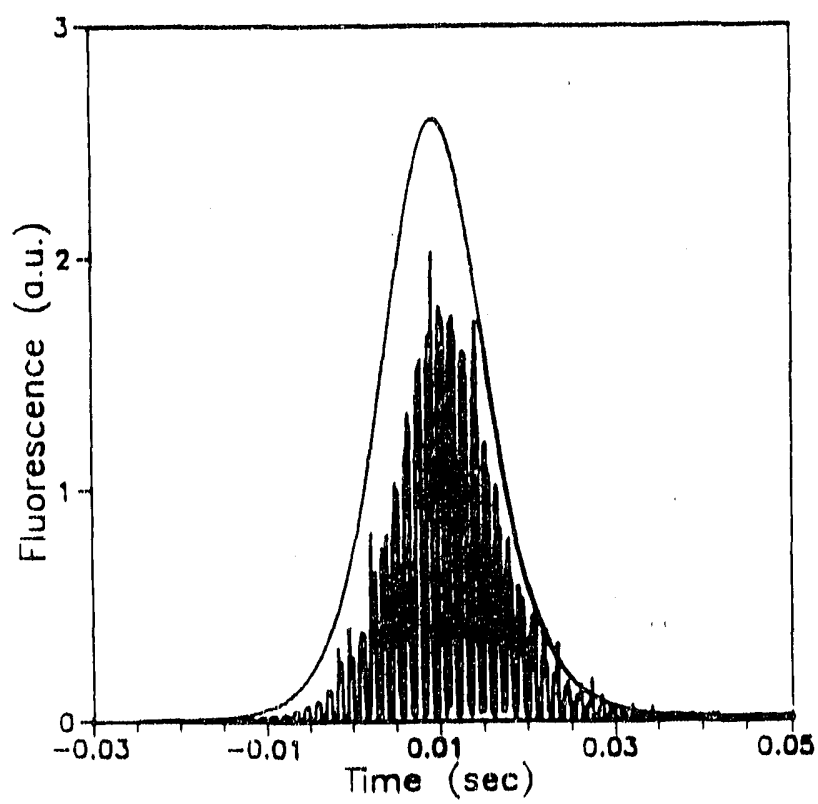

Figure 20. XeBr emission at $282 \mathrm{~nm}$ during a pulse from a $\$ 3.00$ pulse (chopped signal) with reactor pulse shape superimposed. 
A time shift of approximately $1 \mathrm{msec}$ is apparent in the data shown in the figure, with the neutron flux peaking ahead of the fluorescence. This time shift wes seen consistently in the data, and even seemed to be present (though not definitely) in pulses on an empty cell, when the only PMT signal was radiation-induced noise:-

No adequate explanation has been found for this effect. Such a shift could be physically explained by either a long excimer formation time or decay time (in the case of fluorescence measurements), or by a saturation effect in the ion chamber. (Only the latter would explain shifts in the radiation-induced PMT noise.) Regarding the possibility of ion chamber saturation consideration of the specifications for the ion chamber and the picoammeter used to amplify the signal indicated the system was operating in a linear regime, suggesting this was not the source of the problem. Likewise, regarding excimer formation and decay, the 1 msec time shift is an extremely long time in these kinetics, limiting the likelihood of this being the source of the shift. (Kinetic modeling, to be discussed in chapter 4, also supported this conclusion, with no time shift predicted.) The shift was not due to a neutron propagation time delay, as the ion chamber is located farther from the core than the throughport, so any propagation delay should have put the fluorescence pulse ahead of the ion chamber signal, instead of behind.

The effect of increasing temperature on the gas kinetics during pulse could also conceivably cause this time shift (better fluorescence with higher temperature). This possibility was difficult to evaluate, however, without a detailed knowledge of the temperature dependence of important kinetic reactions (temperature dependance was not included in modeling). No literature references were found describing the temperature dependence for this excimer, either.

Finally, measurements to look for problems in internal timing in the digital oscilloscope used for the measurements were negative, although they were not done in the pulsed radiation environment of the experiments.

In summary, the reason for time shift has not been found. In calculations explained below comparing the fluorescence with reactor power in time, this time shift was subtracted out, since the time shift, real or artificial, would not have a direct bearing 
on system efficiency. (That is, the light still comes out, even if it is held up for a msec.)

Aside from this time shift, the fluorexcence was found to be generally in phase and symmetrical with the neutron pulse. This is evidence that little bromine donor depletion occurs. Depletion had been a concern in planning the experiments due to the relattvely large pulse energies involved. In a few experiments with 1 torr Brz in 75 torr $\mathrm{Xe}$ with little to no Ar buffer, a definite asyinmetry in $\mathrm{XeBr}$ fluorescence occurred. The fluorescence was seen to peak well before the reactor power, and the temporal shape was distorted, with the fluorescence having a fast rise time, and then a much longer decay. This was very likely due to $\mathrm{Br} 2$ depletion, since the recombination of $\mathrm{Br}$ atoms into $\mathrm{Br} 2$ requires a third body, usually a buffer gas atom.

3.6.4 Fluorescence Linearity with Power. An important consideration in the scaling of these fluorescence resulis for application in a large laser system with much higher neutron flux is the linearity of the fluorescence intensity with pumping power. Because the pulse is essentially Gaussian in time, rather than a square wave, some measure of this linearity over a limited power range can be ascertained from examination of the ratio of fluorescence intensity to reactor power at different times (powers) during the pulse. To this end, the data shown in Figure 20 was analyzed by dividing the measured fluorescence signal by the reactor power (as given by the neutron flux) at several points in time, and then by graphing this ratio against the normalized reactor power at those time points. The results are shown in Figure 21. Data is shown for times during both increasing and falling reactor power. The lines drawn through the points are simply polynomial fits, and are only meant as visual aids.

Special care was taken in the pulse used for this data that the ion chamber and connected picoammeter used to monitor reactor power, as well as the PMT used to monitor fluorescence intensity, were all operating in a fully linear regime. In the case of the ion chamber, measurements were taken with reactor power at $50 \mathrm{~kW}$, and ion chamber current measured, to determine that the current was linear between $50 \mathrm{~kW}$ and $1500 \mathrm{MW}$, the peak of the pulse. In the case of the PMT, the 


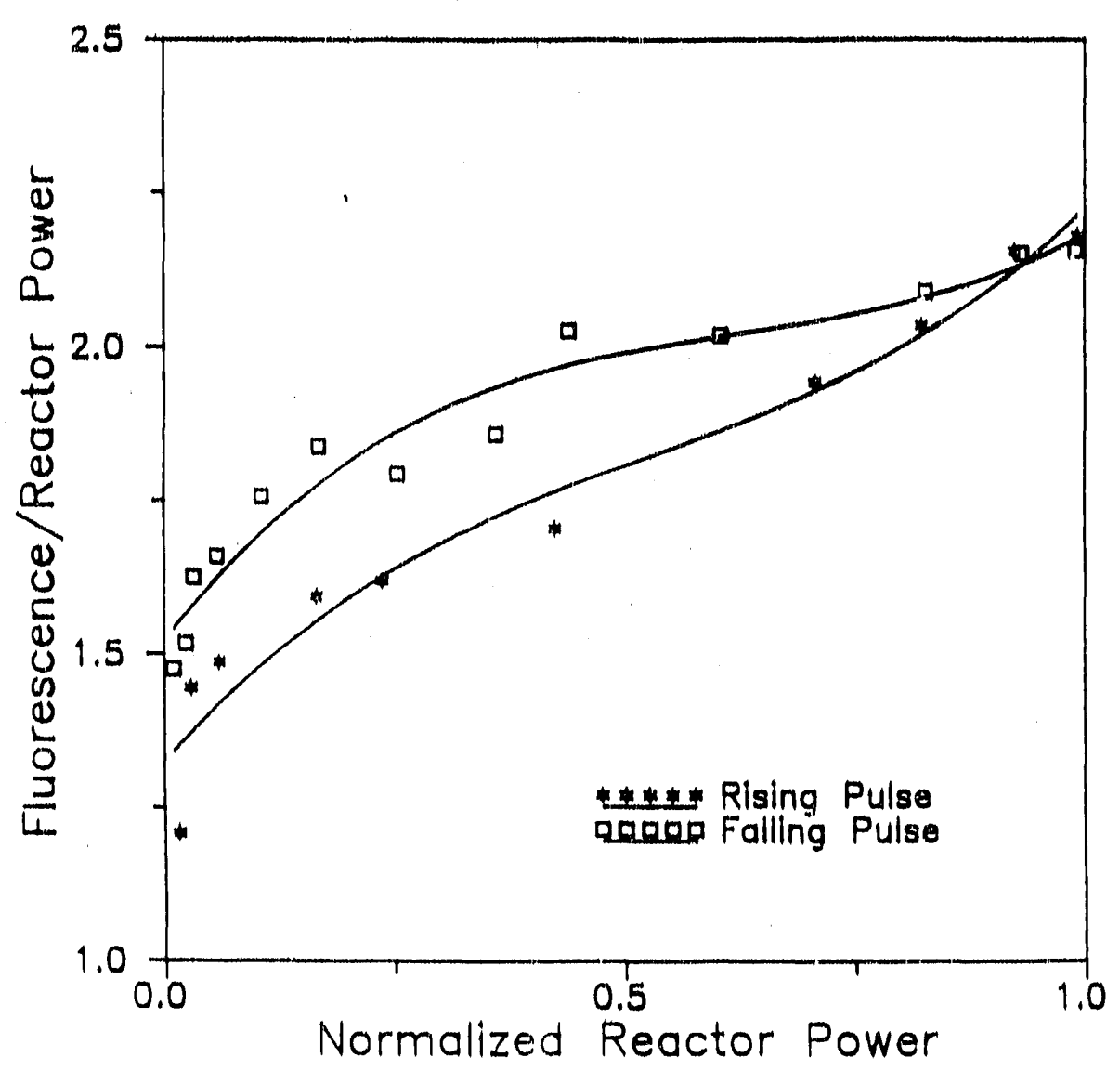

Figure 21. Ratio of instantaneous fluorescence intensity at $282 \mathrm{~nm}$ divided by reactor power, plotted versus normalized reactor power $(1.0=$ pulse peak $)$. The solid curves are included as visual aids only. (Data from Figure 19.)

fluorescence voltage was such as to keep a voltage output from the PMT less than two volts, in which region the PMT was assumed to behave linearly.

Two interesting points are seen in considering this figure. The most important is an apparent non-linearity with pumping power, with the ratio of fluorescence to pumping power, a measure of fluorescence efficiency, increasing with pumping power. As will be explained below, absolute fluorescence efficiencies measured in this work were significantly lower than were expected. This increase in efficiency with pump power would have good implications for the scale-up of this flashlamp to higher power systems. 
The second point to note is that the ratio seems somewhat higher on the falling side of the pulse than on the rising side. A possible explanation for this is that; as indicated earlier, the fluorescing gas heats significantly during the pulse, and this change in efficiency may be due to a difference in gas temperature.

\subsection{Fluorescence Emciencies}

The purpose of the fluorescence measurements using an OMA, in addition to taking fluorescence spectra, was to determine absolute fluorescence efficiencies, defined as fluorescence light out around $282 \mathrm{~nm}$ divided by energy deposited in the game. The fluorescence efficiency obviously has important implications for scale up of these. results to larger flashlamp systems. In this section a discussion of the methodiused in determining fluorescence efficiencies is given, followed by results. A comparison of these results to other literature values will be postponed to sections 4.4 and 4.5, following a discussion of kinetics modeling.

(It should be noted that the small amount of light emilied at other wavelengths besides $282 \mathrm{~nm}$ (e.g. 320 and $415 \mathrm{~nm}$ ) is not of interest, as it cannot be used to pump the iodine laser, so is not included in the fluorescence efficiency. It does represent energy deposited in the gas, however, which is not recorded by the pressure transducer, so its magnitude must be known. It is assumed there is little or no fluorescence outside the wavelength window monitored by the OMA, an assumption based on typical emission characteristics of rare gas halide excimers.)

3.7.1 Fluorescence Emciency Determination. A determination of fluorescence efficiency of $\mathrm{XeBr}$ under both ${ }^{10} \mathrm{~B}$ and ${ }^{3} \mathrm{He}$ pumping was made by comparing intensity-calibrated spectral data with energy deposition results. As discussed in section 3.3 and in Appendix A, intensity calibrations of the spectra were done by correcting spectral data taken with the OMA's by their respective sensitivities, as determined in calibration measurements, and by correcting for known transmissivities of filters used in experiments (neutral density and Pyrex). A knowledge of the distance from test cells to detector, and of the volume of the test cells allowed a determination of absolute fluorescence energy generation within the cell gas, averaged over cell volume and integrated over the pulse duration. (The 
peak fluorescence power is this fluorescence energy, divided by the pulse duration, 12.5 msec FWHM.) In all calculations, the fluorescing volume was viewed as a point source located at the center of the cell. This approximation is valid because the cell is small ( 1 foot in the case of fluorescence cells, and two feet in the care of the laser cell) compared to the distance from the cell to the detector ( 24 feet).

3.7.2 Corrected Spectra. Results of such a correction are shown for one spectra in Figure 22, in units of $J /\left(\mathrm{cm}^{3} \mathrm{~nm}\right)$. (This is the same data as represented in Figure 18.) With correction made for the detector spectral sensitivity, this spectrum shows the much higher oscillator strength of the $\mathrm{B}-\mathrm{X}$ transition at $282 \mathrm{~nm}$ in $\mathrm{XeBr}$. (It should be mentioned that the accuracy of the correction below $270 \mathrm{~nm}$ is questionable because the transmissivity of the Pyrex filter used in measurements is

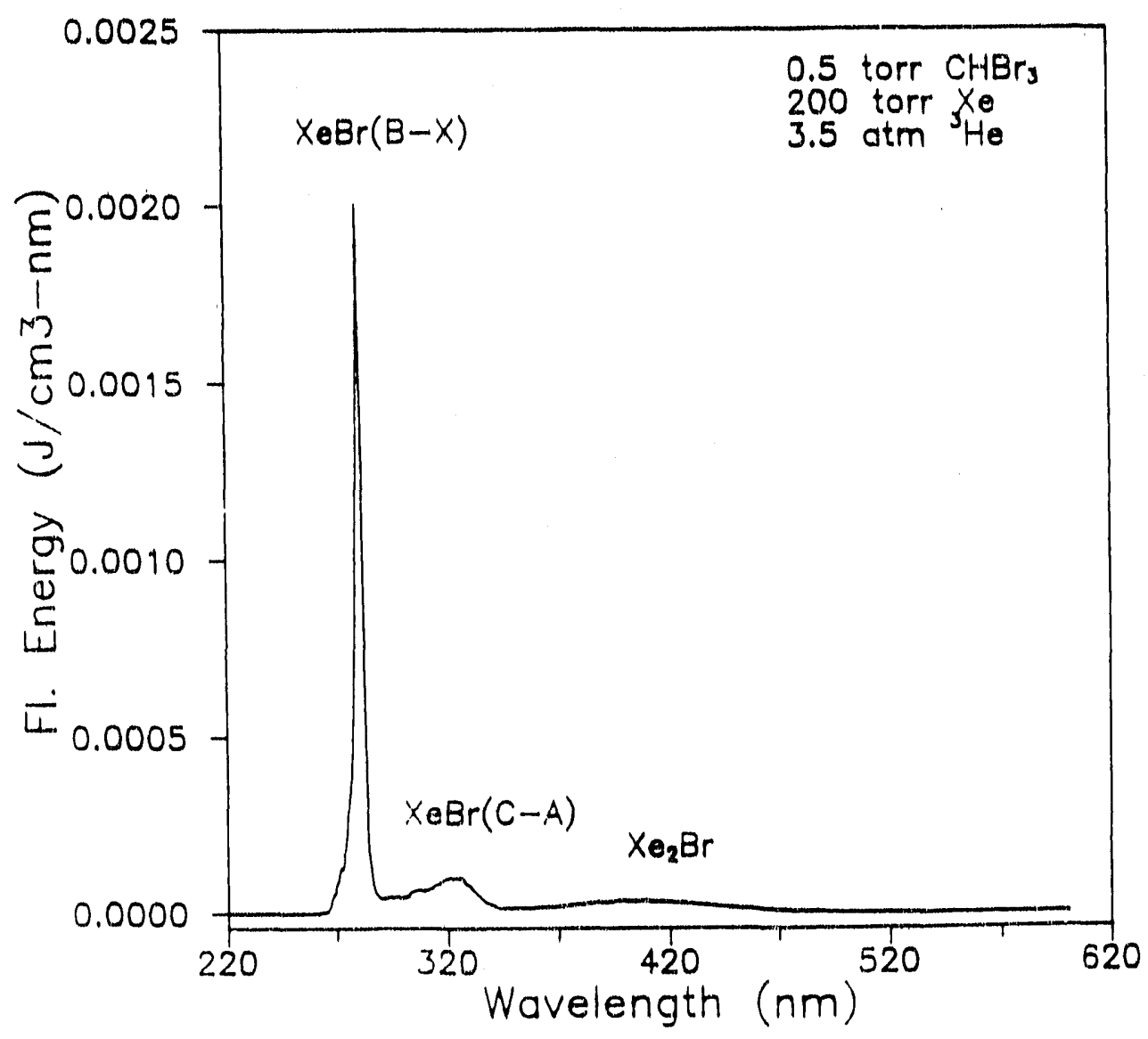

Figure 22. Fluorescence spectrum under ${ }^{3} \mathrm{He}$ pumping as shown in Figure 17, corrected for spectral sensitivities of the OMA and transmitting/reflecting optics. 
very low at these wavelengths, and was not well known. Likewise, above $400 \mathrm{~nm}$ the detector sensitivity had to be extrapolated from shorter wavele 1 gths because the $\mathbf{D}_{\mathbf{2}}$ lamp used in calibrations did not extend out this far in the spectrum.)

3.7.3 ${ }^{10} \mathrm{~B}$ and ${ }^{3}$ He Pumping Results. Fluorescence efficiency is determimed by integrating under the $282 \mathrm{~nm}$ peak, and dividing by the energy deposited in the cell. Efficiency calculations were made for experiments on ${ }^{10} \mathrm{~B}$ pumping, ${ }^{3} \mathrm{He}$ teell pumping, and the pumping of $\mathrm{XeBr}$ with ${ }^{3} \mathrm{He}$ as the flashlamp in the laser cell. Table 2 lists efficiencies for several fluorescence measurements. For ${ }^{10_{B}}$ pamping.

Table 2. Summary of Fluorescence Efficiency Results.

\begin{tabular}{|c|c|c|c|c|c|}
\hline $\begin{array}{l}\text { Pumping } \\
\text { Mechanism }\end{array}$ & $\begin{array}{l}\text { Fluorescing } \\
\text { Mixture }^{\mathrm{a}}\end{array}$ & $\begin{array}{l}\text { OMA } \\
\text { System }\end{array}$ & $\begin{array}{l}\text { Energy } \\
\text { Depos. } \\
\left(\mathrm{J} / \mathrm{cm}^{3}\right)\end{array}$ & $\begin{array}{l}\text { Fluor. } \\
\text { Energy } \\
\left(\mathrm{J} / \mathrm{cm}^{3}\right)\end{array}$ & $\begin{array}{l}\text { Fluor. } \\
\text { Eff. } \\
(\%)\end{array}$ \\
\hline $\begin{array}{c}10_{\mathrm{B} \text { Test }} \\
\text { Cell }\end{array}$ & $\begin{array}{l}1 \mathrm{Br}_{2} \\
75 \mathrm{Xe} \\
725 \mathrm{Ar}\end{array}$ & $\begin{array}{r}1450 / \\
1452\end{array}$ & 0.14 & 0.0014 & 1.0 \\
\hline $\begin{array}{l}{ }^{10} \text { B Test } \\
\text { Cell }\end{array}$ & $\begin{array}{l}0.5 \mathrm{CHBr} 3 \\
200 \mathrm{Xe} \\
600 \mathrm{Ar}\end{array}$ & $\begin{array}{l}1450 / \\
1452\end{array}$ & 0.14 & 0.002 & 1.4 \\
\hline $\begin{array}{l}{ }^{10} \mathrm{~B} \text { Tesi } \\
\text { Cell }\end{array}$ & $\begin{array}{l}0.5 \mathrm{CHBr} 3 \\
200 \mathrm{Xe} \\
600 \mathrm{Ar}\end{array}$ & $\begin{array}{l}1460 / \\
1456\end{array}$ & 0.14 & 0.0016 & 1.1 \\
\hline $\begin{array}{l}{ }^{3} \mathrm{He} \text { Test } \\
\text { Cell }\end{array}$ & $\begin{array}{l}0.5 \mathrm{CHBr} \\
200 \mathrm{Xe} \\
2.4 \mathrm{~atm}^{3} \mathrm{He}\end{array}$ & $\begin{array}{l}1460 / \\
1456\end{array}$ & 0.71 & 0.0062 & 0.87 \\
\hline $\begin{array}{l}{ }^{3} \mathrm{He} \\
\text { Laser } \\
\text { Cell }\end{array}$ & $\begin{array}{l}0.5 \mathrm{CHBr} 3 \\
200 \mathrm{Xe} \\
3 \mathrm{~atm}^{3} \mathrm{He}\end{array}$ & $\begin{array}{l}1460 / \\
1456\end{array}$ & 0.54 & $(0.0019)^{b}$ & $(0.35)^{b}$ \\
\hline
\end{tabular}

apressure in torr, unless otherwise noted.

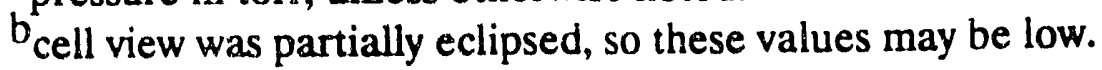


the best of the tiluorescence results (recalling the scatter in the data) are reported. In all fluorescence efficiency measurements, the uncertaint is estimated as $\pm 50 \%$ of the stated value (see Appendix E).

The efficiency in the ${ }^{10} \mathrm{~B}$ pumping experiments was somewhat higher than that in the ${ }^{3} \mathrm{He}$ pumping results. This may be associated with the use of $\mathrm{Ar}$ as the buffer gas, instead of ${ }^{3} \mathrm{He}$. Slightly less energy is required to generate an ion pair infir/Xe mixtures than in $\mathrm{He} / \mathrm{Xe}$ mixtures $(24.2 \mathrm{eV}$ in 200 torr $\mathrm{Xe} / 600$ torr $\mathrm{Ar}$ vs $28.1 \mathrm{eV}$ in 200 torr $\mathrm{Xe} / 2000$ torr $\mathrm{He}$ ), so more of the energy deposited in the system cand up in the excimer. The higher concentration of He also speeds 3-body reactum in the gas kinetics, an important one of which de-excites the excimer state. These two considerations may help explain the lower efficiency in ${ }^{3} \mathrm{He}$ pumping ${ }^{10} 0_{\mathrm{B}}$ pumping. Also, the efficiency of ${ }^{3} \mathrm{He}$ pumping as measured in the laser cell was somewhat lower than that in the ${ }^{3} \mathrm{He}$ test cell. The most likely cause of this discrepancy is an inaccuracy of fluorescence intensity measurements on the laser cell. As will be indicated later, the fluorescence was viewed through a small port on the end of the laser cell. In performing measurements, the view of this port was partially obscured by a valve on the carriage, and it was difficult to tell acrurately what percentage of the port was seen by the detector. An attempt was made to allow a full view, but part of the fluorescence may have been cut off, rsducing the calculated efficiency.

3.7.4 ${ }^{3} \mathrm{He}$ Pressure Dependance. Consideration was also made of the effect of ${ }^{3} \mathrm{He}$ pressure on fluorescence efficiency. Efficiencies for the ${ }^{3} \mathrm{He}$ experiments represented in Figure 19 are shown in Figure 23. The efficiency possibly exhibits a slight increase with pressure, though the limited data makes a definitive conclusion difficult.

Two factors are presented simultaneously in these results, the effect of changing pump power (due to higher ${ }^{3} \mathrm{He}$ pressure) on the efficiency, and the effect of more He atoms on the kinetics (which effects efficiency). It is not possible to distinguish between these two effects, nor determine their contributions from these results. If the efficiency increase shown in Figure 23 can be believed, however, it can be inferred, given the positive effect of increasing pump power discussed in section 


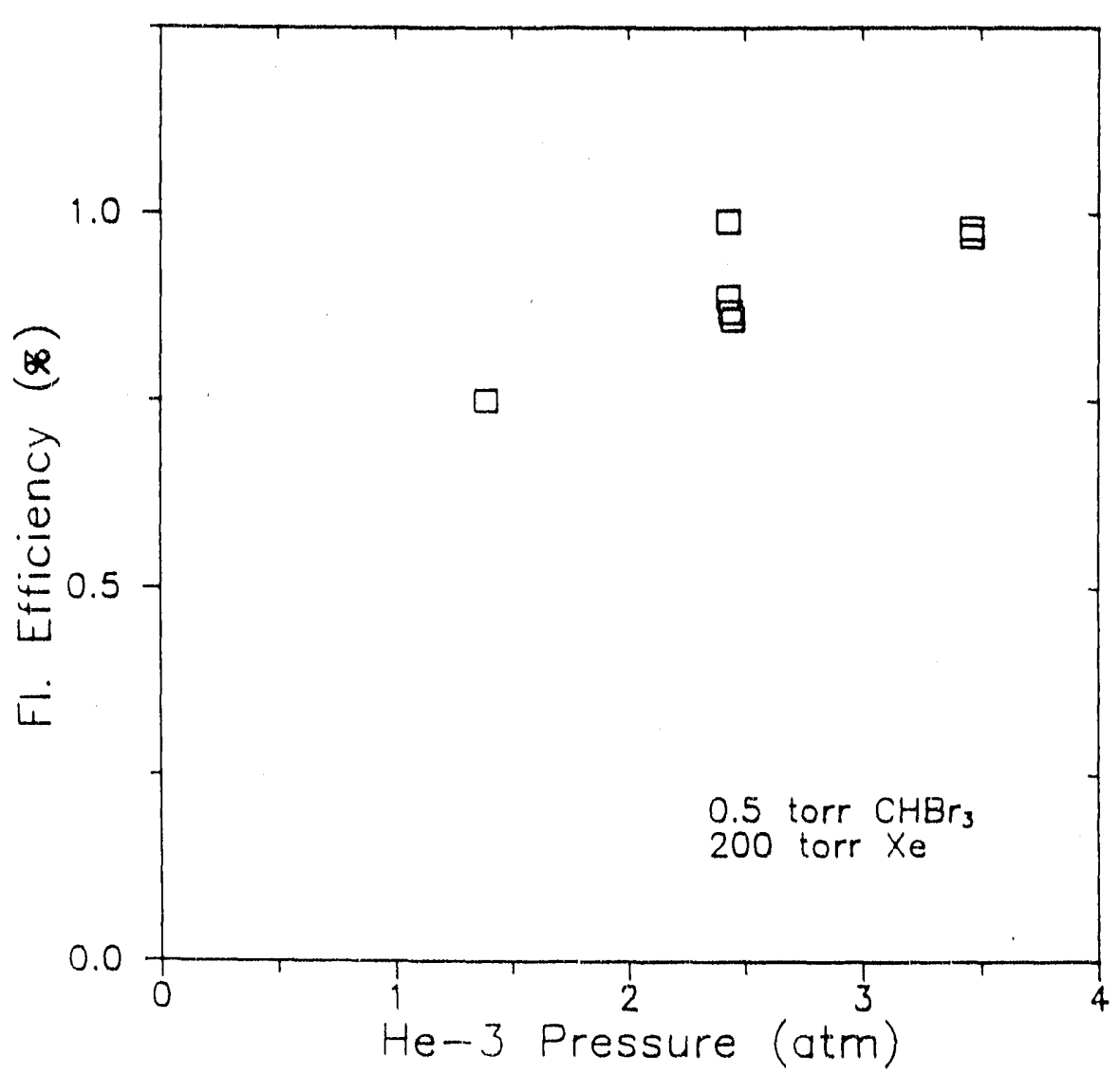

Figure 23. $\mathrm{XeBr}$ " fluorescence efficiency as a function of ${ }^{3} \mathrm{He}$ pressure. (Data from Figure 18.)

3.6.4, that increasing $\mathrm{He}$ atom concentration must have only a small (positive or negative) effect on fluorescence efficiency. (If that is the case, the higher buffer pressure in ${ }^{3} \mathrm{He}$ vs ${ }^{10} \mathrm{~B}$ experiments cannot explain the difference in efficiencies between the two cases, as suggested in the previous section.)

\subsection{Application of XeBr Fluorescence to a Laser}

Given the above results from $\mathrm{XeBr}$ fluorescence studies, there was still the question of whether enough fluorescence can be generated in a TRIGA pulse to pump an iodine laser. Determination of this was done by calculating the power of UV fluorescence which could be deposited in the lasant, given the geometry of the 
proposed laser cell, and comparing this to the pump power threshold for the iodine laser, as reported in the literature.

A pressure of $3 \mathrm{~atm}$. ${ }^{3} \mathrm{He}$ was considered for laser pumping as a compromise between attaining good pump powers and minimizing use of ${ }^{3} \mathrm{He}$. Referencing Figure 23, a fluorescence efficiency of $0.8-0.9 \%$ was expected for this pressure, with a peak pump power of $\left(0.7 \mathrm{~J} / \mathrm{cm}^{3}\right) /(.012 \mathrm{sec})=60 \mathrm{~W} / \mathrm{cm}^{3}$. The laser system used in the experiments (see section 5.3.1) had a fluorescer volume of $2550 \mathrm{~cm}^{3}$, and a laser volume of $153 \mathrm{~cm}^{3}$. It was calculated that the fluorescence could be coupled into the lasant with an efficiency of approximately $15 \%$ (see section 5.1). Combining these factors, a pump power into the lasant of $1.2 \mathrm{~W} / \mathrm{cm}^{3}$ is predicted. By way of comparison, the threshold for lasing has been reported $[43,44]$ as 0.06 $\mathrm{W} / \mathrm{cm}^{3}$, well below this predicted pumping power. The fluorescer pump power of $60 \mathrm{~W} / \mathrm{cm}^{3}$ given above, however, was measured on a 1-inch diameter cell. A significant reduction in the average pump power would be expected in the laser cell configuration, with a cell diameter of 3 inches. (This is due to the neutron attenuation through a cell that size filled with $3 \mathrm{~atm} .{ }^{3} \mathrm{He}$.) Hence, the expected pumping power attainable in the lasant would be somewhat lower than the 1.2 $\mathrm{W} / \mathrm{cm}^{3}$ given above, but still large enough (as shown by experiments) to attain lasing.

(It should be mentioned for the sake of historical accuracy that these calculations were not done completely until after laser experiments had already been completed. This was because fluorescence efficiencies determined from fluorescence experiments were originally grossly overestimated, due to a misinterpretation of vendor supplied data on OMA sensitivities. [Calibrations with the $D_{2}$ lamp were not done until later.] Hence, it was anticipated that fluorescence intensities would be well over threshold values necessary for lasing, so the laser cell was not designed to fully maximize the coupling efficiency, as it might have been. It was only after the laser was found to be operating so close to threshold that the $\mathrm{D}_{2}$ lamp detector calibrations were done and the it was realized that the original estimates were in error.) 


\subsection{Fluorescence Studies with KrF}

When results of fluorescence studies of $\mathrm{XeBr}$ showed relatively low fluoreacence efficiencies for this system, two experiments were done to study the fluorescence of $\mathrm{KrF}$ under ${ }^{3} \mathrm{He}$ excitation, as this excimer is also potentially suitable for pumping: the iodine laser (emission wavelength of $248 \mathrm{~nm}$ ).

These studies were conducted in two experiments by replacing the $\mathrm{XeBr}$ fluorescing mixture in the laser cell with varying mixtures of $\mathrm{Kr}, \mathrm{NF}_{3}$ in $\mathrm{He}$, and ${ }^{3} \mathrm{He}$. Pressures of 0.3 to 10 torr $\mathrm{NF}_{3}$ and 10 to 200 torr $\mathrm{Kr}$ were used in up to $3 \mathrm{~atm}{ }^{3} \mathrm{He}$. (Theese mixtures were based on published $\mathrm{KrF}$ e-beam pumping studies [24,45-50]). Results in both experiments were unsuccessful in generating $248 \mathrm{~nm} \mathrm{KrF}$ fluorescence. Other emissions were seen, but not identified, including lines at approximately 317 , $346,353,382,406$, and $450 \mathrm{~nm}$.

The reasons for the lack of $\mathrm{KrF}$ emission were not determined. Microwave pumping of $\mathrm{KrF}$ at pump powers similar to that utilized in these experiments yielded $8-12 \%$ fluorescence efficiencies $[25,26]$. As will be discussed in section 4.5 below, it is possible an experimental condition unique to this work (e.g. inadequate cell passivation) caused these negative $\mathrm{KrF}$ results as well as the low $\mathrm{XeBr}$ fluorescence efficiencies measured. This has not been verified, however. 


\section{Chapter 4}

\section{FLUORESCENCE MODELING}

This section will discuss a kinetics computer code developed to model the $\mathbf{X e B r}$ system under nuclear pumping. This effort was undertaken after the experimental. work was completed in an attempt to understand the low fluorescence efficiencies which were measured. A description will first be given of the code, followred by calculation results, and comparison of these results to experimental measuremanta.

\subsection{Kinetics Code}

As is normally done in kinetic modeling, the approach taken in these calculations was to solve a set of equations representing the chemical reactions occurring in the nuclear plasma. Each equation represented the time rate of change of concentration of a particular species, with each term in the equation being a source or sink reaction involving that species. Twenty reaction species were followed, interacting in 57 reactions with known or estimated rate constants. The species and reactions are shown in Table 3. The symbol " $\mathrm{M}$ " in some reactions represents any third body ( $\mathrm{He}, \mathrm{Xe}$, or $\left.\mathrm{Br}_{2}\right)$.

Originally, consideration was given to solving these equations for steady-state conditions, since excimer kinetics are generally fast compared to the length of the reactor pulse. There is a difficulty, however, encountered in mathematically obtaining a steady-state solution, in that a few transient species, especially atomic bromine, have relatively long recombination times (msec). This makes a steadystate approximation invalid, so this approach was abandoned. (Such a solution can be obtained by using educated guesses to artificially increase slow, but unimportant reactions, or by neglecting them altogether. Choosing such approximations, however, requires a stronger background in the area than the author felt he had.)

Alternately, it was decided to solve the set of 17 non-linear differential equations numerically (i.e., retaining time-dependance). This was accomplished using an 
Table 3. XeBr Kinetic Model

Model Species: $\mathrm{He}^{+}, \mathrm{He}_{2}^{+}, \mathrm{Xe}^{+}, \mathrm{Xe}_{2}^{+}, \mathrm{He}^{*}, \mathrm{He}_{2}^{*}, \mathrm{Xe}^{*}, \mathrm{Xe}_{2}^{*}, \mathrm{Br}_{2}^{+}, \mathrm{Br}_{2}^{*}, \mathrm{Br}^{+}$, $\mathrm{Br}^{-}, \mathrm{Br}, \mathrm{Br}{ }^{*}, \mathrm{XeBr}{ }^{*}, \mathrm{Xe}_{2} \mathrm{Br}^{*}, \mathrm{e}, \mathrm{Br}, \mathrm{Xe}, \mathrm{He}$

\section{REACTION}

\section{RATE CONSTANI}

\section{Charge Transfer}

1. $\mathrm{He}^{+}+\mathrm{Br}_{2}$ r.5-> $\mathrm{He}+\mathrm{Br}_{2}^{+}$

$$
\text { L.5-> } \mathrm{He}+\mathrm{Br}^{+}+\mathrm{Br}
$$

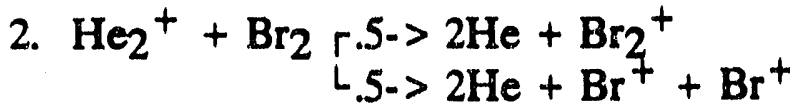

3. $\mathrm{He}^{+}+\mathrm{Xe} \rightarrow \mathrm{He}+\mathrm{Xe}^{+}$

$1 e-9$ b,c

4. $\mathrm{He}_{2}^{+}+\mathrm{Xe}->2 \mathrm{He}+\mathrm{Xe}^{+}$

5. $\mathrm{He}_{2}^{+}+\mathrm{Xe}+\mathrm{M} \rightarrow 2 \mathrm{He}+\mathrm{Xe}^{+}+\mathrm{M}$

6. $\mathrm{Xe}^{+}+\mathrm{Br}_{2} \rightarrow \mathrm{Xe}+\mathrm{Br}_{2}^{+}$

7. $\mathrm{Xe}_{2}^{+}+\mathrm{Br}_{2} \rightarrow 2 \mathrm{Xe}+\mathrm{Br}_{2}+$

$1 e-9^{b, c}$

$7 \mathrm{e}-12^{\mathrm{c}}$

$2 \mathrm{e}-12^{\mathrm{b}}$

$2 \mathrm{e}-2 g^{\mathrm{d}}$

$9 \mathrm{e}-11^{\mathrm{e}}$

$1 e-11^{c}$

\section{Penning Ionization}

8. $\mathrm{He}^{*}+\mathrm{Xe}->\mathrm{He}+\mathrm{Xe}^{+}+\mathrm{e}$

9. $\mathrm{He}^{*}+\mathrm{Br}_{2}>\mathrm{He}+\mathrm{Br}_{2}^{+}+\mathrm{e}$

10. $\mathrm{Xe}^{*}+\mathrm{Xe}^{*} \rightarrow \mathrm{Xe}^{+}+\mathrm{Xe}+\mathrm{e}$

11. $\mathrm{Xe}_{2}^{*}+\mathrm{Xe}_{2}^{*} \rightarrow \mathrm{Xe}_{2}^{+}+2 \mathrm{Xe}+\mathrm{e}$

$1.5 e-10^{b}$

$1 \mathrm{e}-10^{\mathrm{b}}$

$5 \mathrm{e}-10^{\mathrm{f}}$

$3.5 e-10^{f}$

\section{Electron Attachment}

12. $\mathrm{Br}_{2}+\mathrm{e}->\mathrm{Br}^{-}+\mathrm{Br}$

$1 e-11 g$

\section{Dimerization}

13. $\mathrm{He}^{+}+\mathrm{He}+\mathrm{M}>\mathrm{He}_{2}{ }^{+}+\mathrm{M}$

14. $\mathrm{Xe}^{+}+\mathrm{Xe}+\mathrm{M} \rightarrow \mathrm{Xe}_{2}^{+}+\mathrm{M}$

15. $\mathrm{Xe}^{*}+\mathrm{Xe}+\mathrm{Xe}->\mathrm{Xe}_{2}^{*}+\mathrm{Xe}$

$5 e-32^{b}$ 
Table 3 (Cont.)

16. $\mathrm{Xe}^{*}+\mathrm{Xe}+\mathrm{He}->\mathrm{Xe}_{2}{ }^{*}+\mathrm{He}$

$1.4 \mathrm{e}-32^{\mathrm{b}}$

17. $\mathrm{Br}+\mathrm{Br}+\mathrm{M} \rightarrow \mathrm{Br}_{2}+\mathrm{M}$ $1 e-31^{b}$

\section{Excimer Formation}

18. $\mathrm{Xe}^{*}+\mathrm{Br}_{2}>\mathrm{XeBr}+\mathrm{Br}$ $4 \mathrm{e}-10^{\mathrm{i}}$

19. $\mathrm{Xe}_{2}{ }^{*}+\mathrm{Br}_{2}>\mathrm{XeBr}^{*}+\mathrm{Br}+\mathrm{Xe}$ $4 \mathrm{e}-10 \mathrm{j}$

20. $\mathrm{Xe}^{+}+\mathrm{Br}^{-}+\mathrm{Xe} \rightarrow \mathrm{XeBr}^{*}+\mathrm{Xe}$ $1 \mathrm{e}-25^{\mathrm{b}}$

21. $\mathrm{Xe}^{+}+\mathrm{Br}^{-}+\mathrm{He}->\mathrm{XeBr}{ }^{*}+\mathrm{He}$ $2 \mathrm{e}-26^{\mathrm{b}}$

22. $\mathrm{Xe}_{2}^{+}+\mathrm{Br}^{-}+\mathrm{Xe}>\mathrm{XeBr}^{*}+2 \mathrm{Xe}$ $1 e-25^{b}$

23. $\mathrm{Xe}_{2}^{+}+\mathrm{Br}^{-}+\mathrm{He}->\mathrm{XeBr}^{*}+\mathrm{Xe}+\mathrm{He}$

$2 \mathrm{e}-26^{\mathrm{b}}$

\section{Electronic Recombination}

24. $\mathrm{He}^{+}+2 \mathrm{e}->\mathrm{He}^{*}+\mathrm{e}$

25. $\mathrm{He}_{2}^{+}+\mathrm{e}->\mathrm{He}^{*}+\mathrm{He}$

26. $\mathrm{He}_{2}^{+}+\mathrm{e}+\mathrm{M} \rightarrow \mathrm{He}_{2}{ }^{*}+\mathrm{M}$

27. $\mathrm{He}_{2}{ }^{+}+2 \mathrm{e}->\mathrm{He}_{2}{ }^{*}+\mathrm{e}$

28. $\mathrm{Xe}^{+}+\mathrm{e}+\mathrm{M}>\mathrm{Xe}^{*}+\mathrm{M}$

29. $\mathrm{Xe}^{+}+2 \mathrm{e}>\mathrm{Xe}^{*}+\mathrm{e}$

30. $\mathrm{Xe}_{2}^{+}+\mathrm{e}->\mathrm{Xe}^{*}+\mathrm{Xe}$

31. $\mathrm{Br}^{+}+\mathrm{c}+\mathrm{M} \rightarrow \mathrm{Br}^{*}+\mathrm{M}$

32. $\mathrm{Br}^{+}+2 \mathrm{e} \rightarrow \mathrm{Br}^{*}+\mathrm{e}$

$(6 \pm 2) e-21^{b}$

$1.8 \mathrm{e}-8^{\mathrm{b}}$

$(5 \pm 1) e-27^{b}$

$(4 \pm 0.5) \mathrm{e}-20^{\mathrm{b}}$

$1 \mathrm{e}-26^{\mathrm{b}}$

$2.2 \mathrm{e}-19^{\mathrm{b}}$

$(2.3+0.2) e-6^{b}$

$1 \mathrm{e}-26^{\mathrm{b}}$

$1 e-19^{b}$

33. $\mathrm{Br}_{2}^{+}+\mathrm{e}->\mathrm{Br}^{*}+\mathrm{Br}$

$1 e-7^{b}$

\section{Ionic Recombination}

34. $\mathrm{He}^{+}+\mathrm{Br}^{-}+\mathrm{Xe}->\mathrm{He}+\mathrm{Br}+\mathrm{Xe}$

$2 \mathrm{e}-25^{\mathrm{b}}$

35. $\mathrm{He}^{+}+\mathrm{Br}^{-}+\mathrm{He}->2 \mathrm{He}+\mathrm{Br}$

$2 \mathrm{e}-26^{\mathrm{b}}$

36. $\mathrm{He}_{2}^{+}+\mathrm{Br}^{-}>2 \mathrm{He}+\mathrm{Br}$

$4 \mathrm{e}-7^{\mathrm{b}}$

37. $\mathrm{Br}^{+}+\mathrm{Br}^{-}+\mathrm{Xe}->\mathrm{Br}_{2}{ }^{*}+\mathrm{Xe}$

$2 \mathrm{e}-25^{\mathrm{b}}$

38. $\mathrm{Br}^{+}+\mathrm{Br}^{-}+\mathrm{He} \rightarrow \mathrm{Br}^{*}+\mathrm{He}$

$2 \mathrm{e}-26^{\mathrm{b}}$

39. $\mathrm{Br}_{2}^{+}+\mathrm{Br}^{-}>3 \mathrm{Br}$

$4 \mathrm{e}-7^{b}$

40. $\mathrm{Br}^{+}+\mathrm{Br}^{-}+\mathrm{Xe}->3 \mathrm{Br}+\mathrm{Xe}$

$4 \mathrm{e}-25^{\mathrm{b}}$ 
Table 3 (Cont.)

41. $\mathrm{Br}_{2}^{+}+\mathrm{Br}^{-}+\mathrm{He}->3 \mathrm{Br}+\mathrm{He}$

$2 e-26^{b}$

\section{Quenching}

42. $\mathrm{XeBr}^{*}+\mathrm{Br}_{2}->\mathrm{Xe}+3 \mathrm{Br}$

43. $\mathrm{XeBr}{ }^{*}+\mathrm{e}->\mathrm{Xe}+\mathrm{Br}^{\prime \prime}$

44. $\mathrm{XeBr}^{*}+\mathrm{Xe}->2 \mathrm{Xe}+\mathrm{Br}$

45. $\mathrm{XeBr}{ }^{*}+\mathrm{Xe}+\mathrm{M}->\mathrm{Xe}_{2} \mathrm{Br}^{*}+\mathrm{M}$

46. $\mathrm{Xe}_{2} \mathrm{Br}^{*}+\mathrm{Br}_{2}>2 \mathrm{Xe}+3 \mathrm{Br}$

47. $\mathrm{Xe}_{2} \mathrm{Br}^{*}+\mathrm{e}->2 \mathrm{Xe}+\mathrm{Br}^{-}$

48. $\mathrm{Xe} 2 \mathrm{Br}^{*}+\mathrm{Xe}>3 \mathrm{Xe}+\mathrm{Br}$

49. $\mathrm{He}+\mathrm{e}->\mathrm{He}+\mathrm{e}$

50. $\mathrm{He}_{2}+\mathrm{e}->2 \mathrm{He}+\mathrm{e}$

51. $\mathrm{Xe}+\mathrm{e}->\mathrm{Xe}+\mathrm{e}$

52. $\mathrm{Xe}_{2}+\mathrm{e}->2 \mathrm{Xe}+\mathrm{e}$

53. $\mathrm{Br}^{2}+\mathrm{e}->\mathrm{Br}+\mathrm{e}$

54. $\mathrm{Br}_{2}^{*}+\mathrm{e}->\mathrm{Br}_{2}+\mathrm{e}$

$6 e-10^{k}$
$1 e-7^{b}$
$3.2 e-12^{f}$
$3 e-31^{l}$
$3.3 e-10^{1}$
$1 e-7^{b}$
$2.8 e-13^{l}$
$(4.2 \pm 0.6) e-9^{b}$
$1 e-9^{m}$
$1 e-9^{n, 0}$
$1 e-9^{b}$
$1 e-8^{p}$
$3 e-7^{q}$

\section{Radiative Decay}

55. $\mathrm{XeBr}^{*} \rightarrow \mathrm{Xe}+\mathrm{Br}+\mathrm{hv}$

56. $\mathrm{Xe}_{2} \mathrm{Br}^{*} \rightarrow 2 \mathrm{Xe}+\mathrm{Br}+\mathrm{hv}$

57. $\mathrm{Xe}_{2}^{*} \rightarrow 2 \mathrm{Xe}+\mathrm{hv}$

aUnits: 2-body, $\mathrm{cm}^{3} / \mathrm{sec} ; 3$-body, $\mathrm{cm}^{6} / \mathrm{sec}$; rad. decay, $\mathrm{sec}^{-1}$. The notation of, for example, 1e-9 represents $1 \times 10^{-9}$ : ${ }^{b}$ Ref. 7. ${ }^{c_{R}}$ Ref. $51 .{ }^{d}$ Ref. $52 .{ }^{e^{2}}$ Estimate from

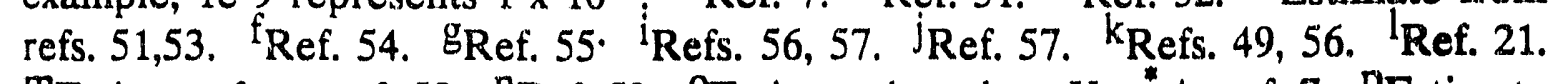
mEstimate from ref. 58. ${ }^{n}$ Ref. 59. ${ }^{\circ}$ Estimate based on $\mathrm{Xe}_{2}{ }^{*}$ in ref. 7. PEstimate based on $\mathrm{Kr}^{*}$ in ref. $60 .{ }^{9}$ Estimate based on $\mathrm{Cl}_{2}$ in ref. $54 .{ }^{\mathrm{r}}$ Ref. 28.

equation solving package called "LSODE" (originally developed at Lawrence Livermore National Lab). This routine is capable of solving the stiff differential 
equations normally encountered in kinetics calculations. The term "stiff" refers to a situation where some terms in the equations change at a much faster rate in time than other terms; i.e., some reactions occur much faster than others. Rather than choosing the fastest reaction as limiting the time step for all reactions in the system as the equations are solved numerically, the routine chooses appropriate time steps for each reaction. While increasing the complexity of the code, this greatly decreases computing time. A program was written in FOR'TRAN listing the differential equations and calling the LSODE subroutines. A copy of program is given in Appendix B. Computations were done on a PC (286/287), and required $<10$ minutes per run.

\subsection{Rate Equations}

The rate equations used were mostly taken from Wilson [7], following the modeling he had done for this system for a fast burst reactor. (This is the only previous kinetic modeling done on $\mathrm{XeBr}$ known to the author.) There were several modifications to his published approach, however, both in general, and in applying it to a TRIGA pulse environment.

The principal modification was the development of a numerical, time-dependant solution to the equations. Wilson had developed a steady-state solution (method not detailed in published results). While requiring more computation, a timedependant solution yields more information on the effect of changing gas pressures and pumping rates on species concentrations, and is not subject to the uncertainties introduced in a steady-state approximation.

Other modifications included correcting a few (ten) rate constants by comparisons to both Wilson's original sources and other published literature. Most corrections were less than an order of magnitude. Three significant changes, however, involved apparent typographical errors in the spontaneous fluorescence rates of $\mathrm{XeBr}^{*}$ (the species of most interest in this work), $\mathrm{Xe}_{2} \mathrm{Br}^{*}$, and $\mathrm{Xe}_{2}{ }^{*}$. Rates listed by Wilson were $6.8 \mathrm{e}-8,1 \mathrm{e}-7$, and $6 \mathrm{e}-7$, respectively, when they should have been $5.7 \mathrm{e}+7,4 \mathrm{e}+6$, and $6 e+7$ (see Table 3 for references). 
Another modification involved decreasing the pump power utllized by Wilson's model to correspond to the lower neutron flux generated by the TRIGA (vs a fast burst reactor). The $10^{17} \mathrm{n} / \mathrm{cm}^{2}$ sec peak flux in $1 \mathrm{~atm}$. of ${ }^{3} \mathrm{He}$ in a fast burst reactor corresponds to an approximate $800 \mathrm{~W} / \mathrm{cm}^{3}$ powe) deposition [40]. The 3015 $\mathrm{n} / \mathrm{cm}^{2}$ sec peak flux in a TRIGA pulse corresponds to approximately $40 \mathrm{~W} / \mathrm{cm}^{3}$, as measured in these experiments.

For temporal considerations, a Gaussian pulse of length $12 \mathrm{msec}$ FWHM was used to represent the TRIGA pulse. The inaccuracy in the fit between the Gaussian and an actual pulse is estimated to be less than 5\%. As mentioned, Wilson reported a steady-state solution, so no pulse width was involved in that work.

Finally, some consideration was given as to the energy input terms for the equations. That is, as energy is dumped into the system during a pulse from the fast $\mathrm{a}^{3}{ }^{3} \mathrm{He}$ reaction products, this energy goes into the formation of lons and excited atoms. This energy input is represented in the modeling equations as source terms for these ions and excited atoms. The magnitude of these source terms, proportional to instantaneous pumping power, is determined by partitioning the energy into the various ions and excited states. Wilson did this according to a model which weighted the $\mathrm{W}$ values (ev/ion pair) of the gas constituents by the range of the particies in these gas constituents [6,7,61]. For the work being reported here, a partitioning method reported by Kushner [62], based on Monite Carlo slowing down calculations of electrons in gases, was used, as well as that used by Wilson. The two methods gave very similar results in these calculations.

In addition to checking all rate constants in original sources for $\mathrm{XeBr}$, as an additional check, the model equations were also compared to lists of equations published models for the $\mathrm{XeCl}$ excimer laser [54,63], a similar kinetic system. The model was also modified to represent, in addition to a TRIGA pulse, a fast burst reactor pulse, such as modeled by Wilson, and an e-beam pumped system, representative of the experiments done by Swingle, et al. [9]. These modifications were done to allow bench-marking of the code. 
As will be observed on inspection of the rate constants in Table 3, no temperature dependence was included in this modeling. Aside from the difficulty of adding this complexity to the model, this was neglected because experimental results had shown little indication of a strong temperature effect on the kinetics. (That is, the $\mathrm{XeBr}$ fluorescence was symmetrical with the pulse, even through the gas temperature changed several hundred degrees from the beginning of the pulse to the end.)

Some comment should be made as to the selection of the $\mathrm{Br}_{2}$-electron dissociative attachment rate constant ( $\mathrm{xnn} \# 12$ in Table 3 ). Literature values $[55,56]$ for this constant range from $8.2 \mathrm{e}-13$ to $6 \mathrm{e}-10 \mathrm{~cm}^{3} / \mathrm{sec}$. The value of $1 \mathrm{e}-11 \mathrm{~cm}^{3} / \mathrm{sec}$ was chosen from reference 55 as the electron temperature in those experiments was estimated as $350 \mathrm{~K}$. The electron temperature in these nuclear pumped plasmas were expected to have a similar low temperature. The variation of this constant effected the modeling results only modestly. For example, for a TRIGA pulse on 0.5 torr $\mathrm{CHBr}_{3} / 200$ torr $\mathrm{Xe} / 2000$ torr ${ }^{3} \mathrm{He}$ (corresponding to the mixture used in these experiments), a rate of $1 \mathrm{e}-11 \mathrm{~cm}^{3} / \mathrm{sec}$ yielded a fluorescence efficiency of $2.4 \%$, whereas a rate of $6 \mathrm{e}-10 \mathrm{~cm}^{3} / \mathrm{sec}$ indicated $3.7 \%$ for this parameter. This weak dependency is due to the fact that this reaction mainly effects the $\mathrm{XeBr}$ " concentration by controlling the formation of $\mathrm{Br}^{-}$. Since the $\mathrm{XeBr}$ " forination channel involving the ions $\left(\mathrm{Br}^{-}\right.$and $\left.\mathrm{Xe}^{+}\right)$is weak in this excimer (see section 2.1.2), this reaction does not strongly effect the overall kinetics.

It should also be mentioned that this rate for electron attachment in $\mathrm{Br}_{2}$ is significantly slower than might have been expected based on familiarity with the electron attachment rate in $\mathrm{F}_{2}$ (ca. $\left.10^{-9}[55,56,6]\right)$.

\subsection{Modeling Results}

Full modeling results, represented as the time-dependant concentration of each species for a TRIGA pulse, a fast burst reactor pulse, and an e-beam pulse are shown in Figures 24-26. Two interesting items can be seen from the figures. First, the challenge discussed previously in modeling the system with a steady-state approximation is noted. Some species, especially atomic bromine, have long lifetimes, and their concentration variance is not coincident with the pulse, hence, a 
steady-state assumption must be made carefully. ( $\mathrm{XeBr}$ " fluorescence seems fairly coincident.) Second, because of this slow bromine recombination, a deprescion in $\mathrm{Br}_{2}$ concentration can be seen, especially for the faster pulses. This bromine donor depletion is important for small bromine concentrations, and effects overall efficiencies.

Figure 27 shows the model predictions for $\mathrm{XeBr}$ " Iluorescence efficiency (light from $\mathrm{XeBr}{ }^{*}$ emission divided by energy deposited in the cell during the pulse) for the three different pulse types, with $\mathrm{Xe}$ pressure as a variable. These particular mixtures and puises were chosen as representative of the fast burst modeling reported by Wilson [7], the e-beam experiment reported by Swingle, et al. [9], and the TRIGA experiments reported in this work. Pumping conditions are the same as indicated in Figures 23.25 , vis. a $12.5 \mathrm{msec} / 40 \mathrm{~W} / \mathrm{cm}^{3}$ peak TRIGA pulse; a 200 microsec $/ 800 \mathrm{~W} / \mathrm{cm}^{3}$ peak fast burst pulse; and a 1 microsec $/ 44 \mathrm{~kW} / \mathrm{cm}^{3}$ peak ebeam pulse. Comparisons of the model to these data will be considered in the next section.

A few data points were calculated to generate each curve in Figure 27, sufficient to show trends. Two important items should be pointed out. First, comparable fluorescence efficiencies (maxima of approximately 10\%) are indicated for the three pulses of widely different pumping powers (ranging over three orders of magnitude). Second, for all three curves, a Xe pressure of 5-25 torr Xe is preferred. As will be discussed below, results reported herein of TRIGA measurements indicated much lower fluorescence efficiencies than that predicted by the model. Also, the experimental results did not indicate the optimum at low Xe pressures predicted by the model.

The model was valuable in determining the energy flow in the system; that is, how energy is channeled into and out of the excimer state. Both excimer formation channels explained in section 2.1.3, the harpoon reaction of $\mathrm{Xe}^{*}$ with $\mathrm{Br}_{2}$, and the ionic recombination of $\mathrm{Xe}^{+}$and $\mathrm{Br}^{-}$, could be followed in the model. The former was almost completely dominant ( $>95 \%$ ) for all three pulses modeled. 


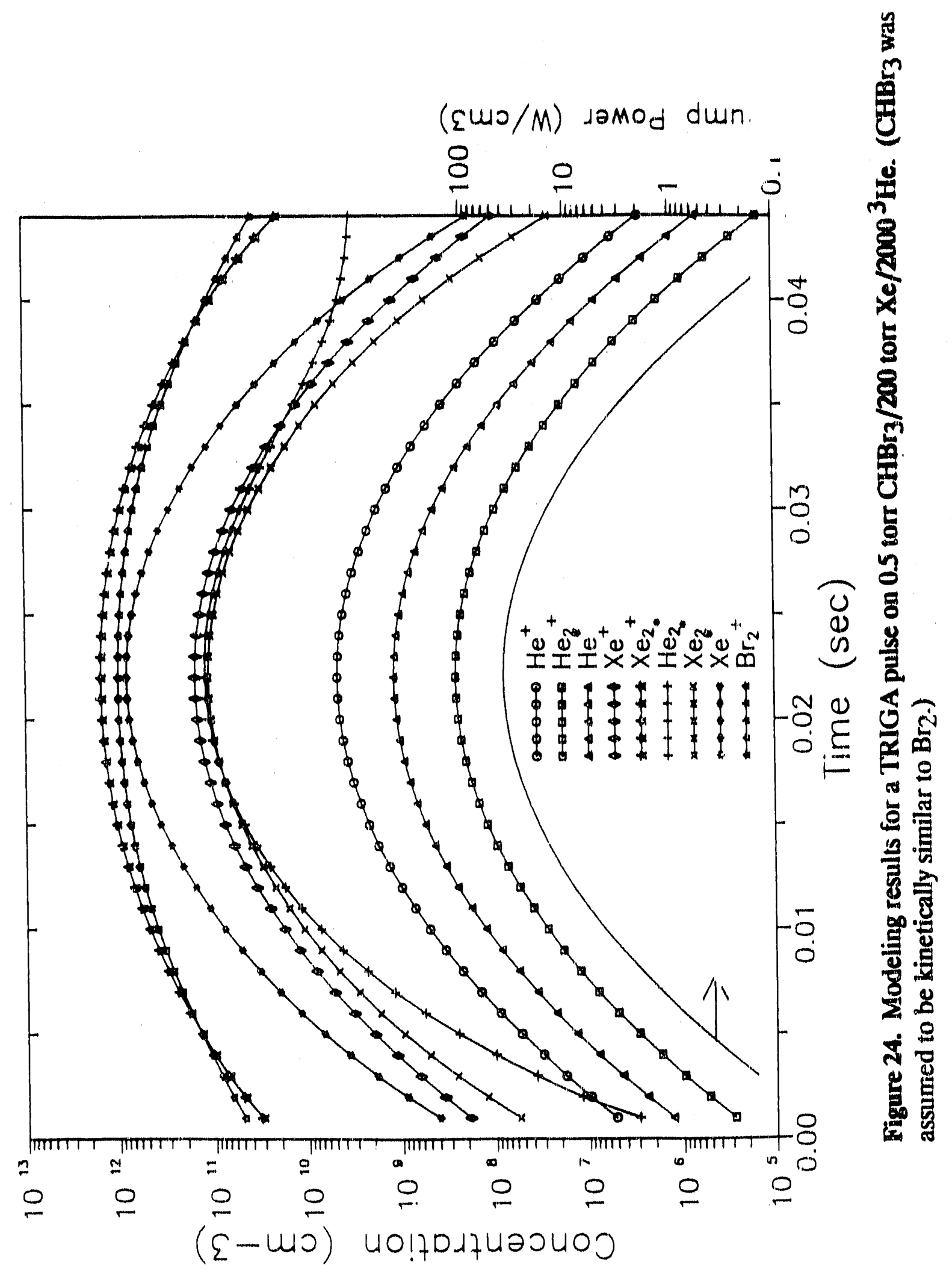




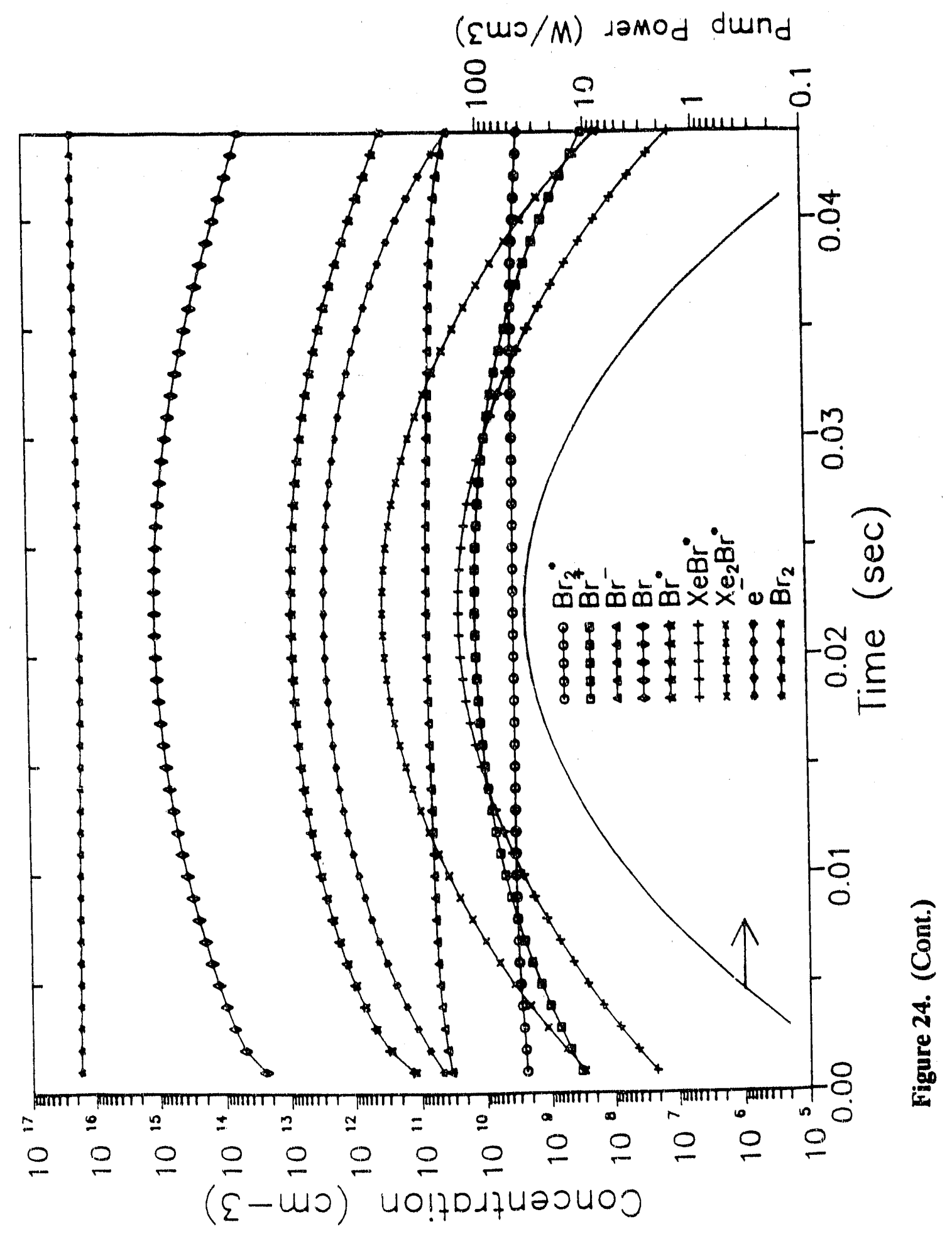




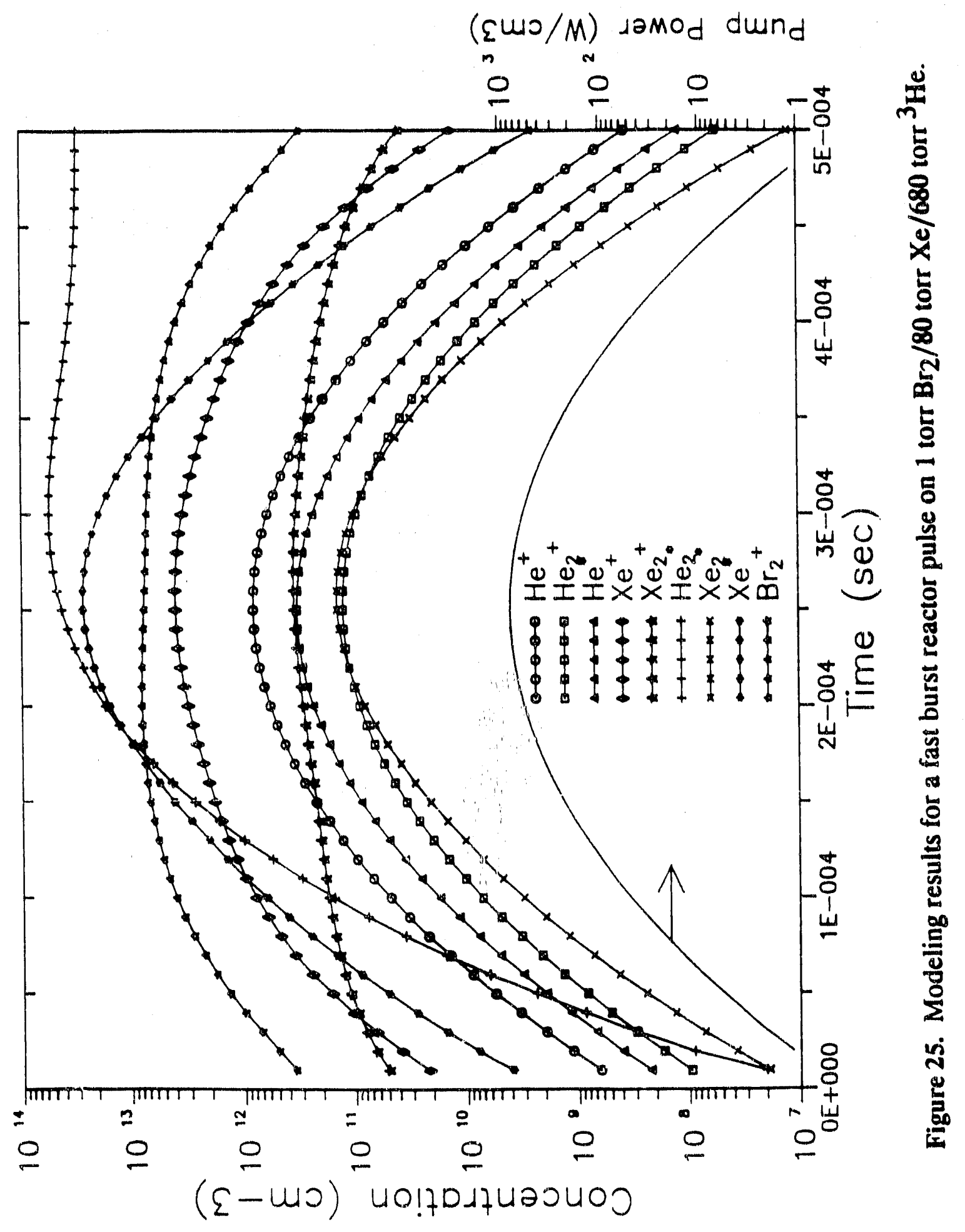




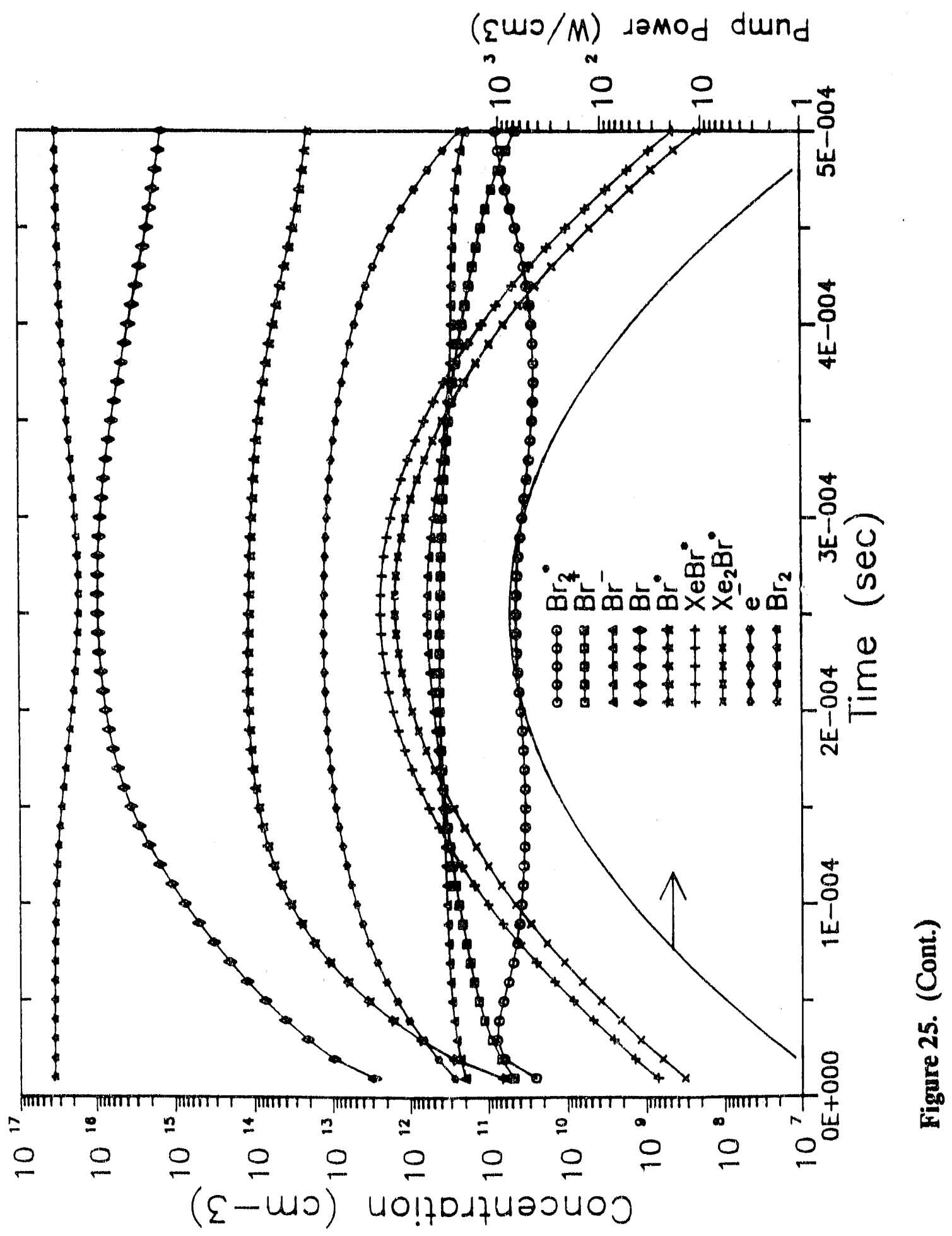




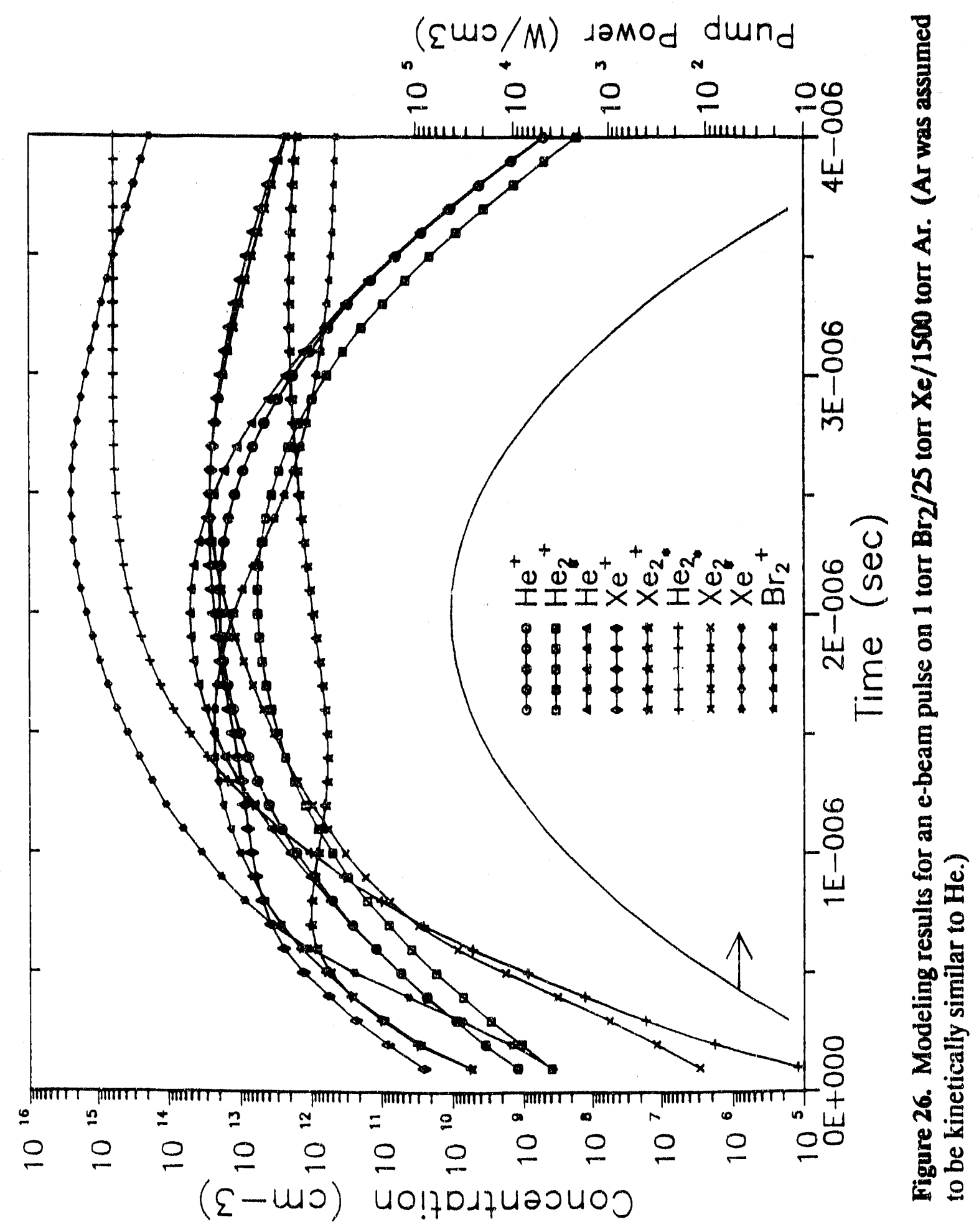




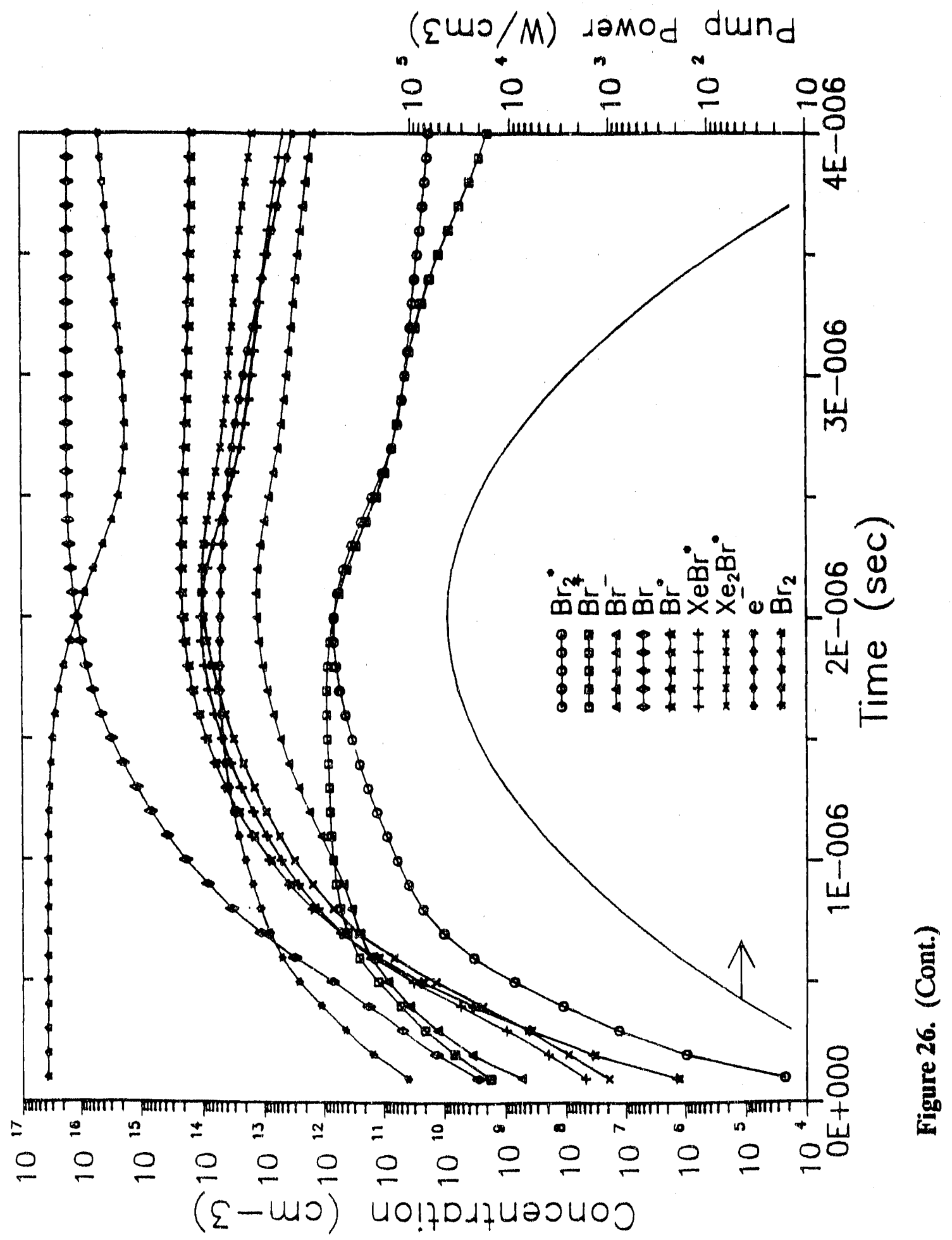




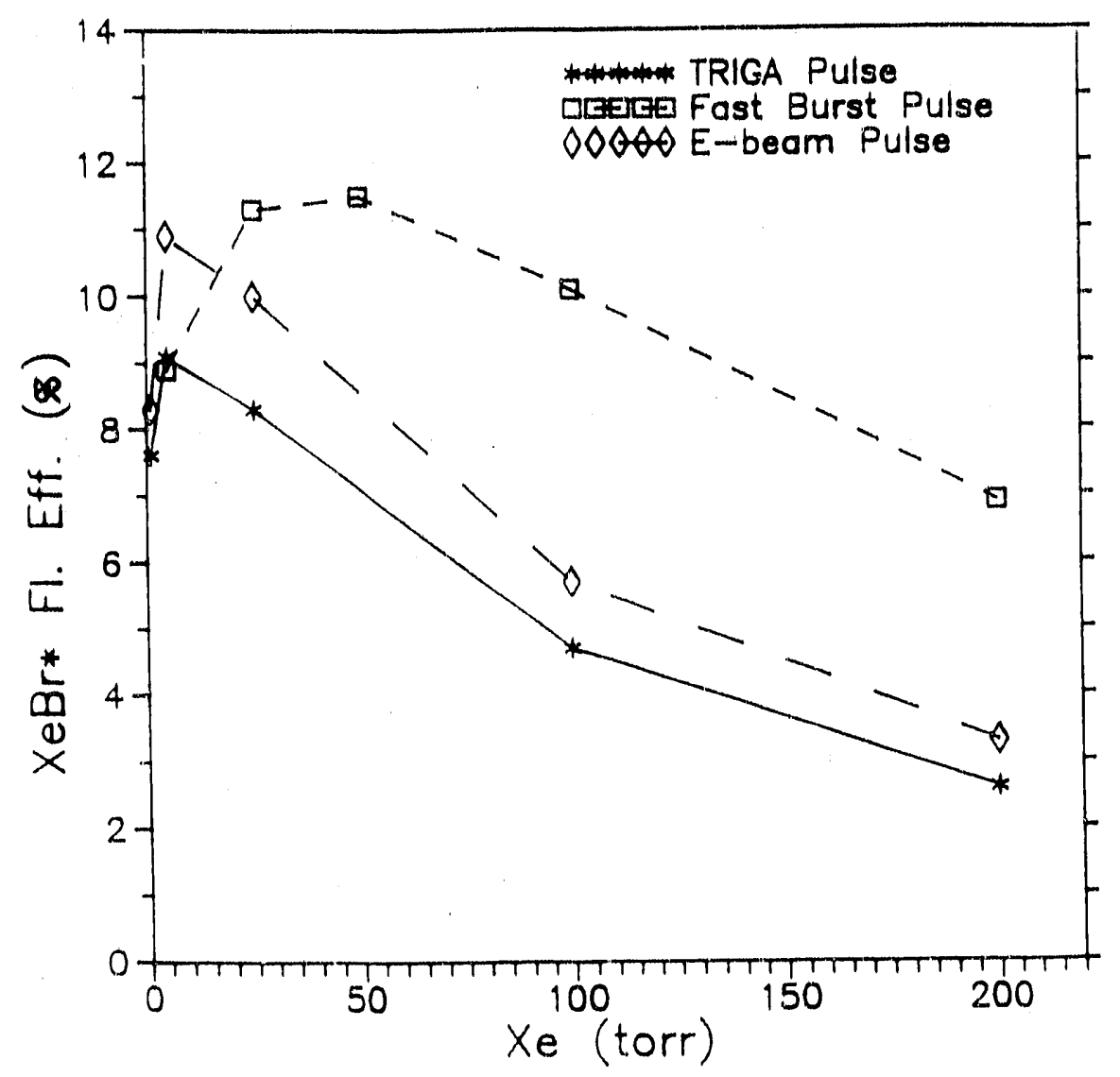

Figure 27. Comparison of $\mathrm{XeBr}$ " fluorescence efficiency from the three kinetic models as a function of Xe pressure. Other parameters: 1) TRIGA pulse: 0.5 torr $\mathrm{Br}, \mathrm{Xe}+{ }^{3} \mathrm{He}$ to 2000 torr; 2) fast burst pulse: 1 torr $\mathrm{Br} 2, \mathrm{Xe}+{ }^{3} \mathrm{He}$ to 760 torr; 3) ebeam pulse: 1 torr $\mathrm{Br}_{2}$, $\mathrm{Xe}+\mathrm{Ar}$ to 1500 torr.

This energy flow pattern is summarized in Figure 28 for a TRIGA pulse on 0.5 torr $\mathrm{CHBr}_{3}, 200$ torr Xe, and 2000 torr ${ }^{3} \mathrm{He}$. The preference for low Xe pressures can be seen, as $\mathrm{Xe}$ acts to both quench $\mathrm{XeBr}^{*}$, as well as channeling $\mathrm{Xe}$ " atoms into the $\mathrm{Xe}_{2}$ " dimers, rather into the excimer. Likewise, the preference for low $\mathrm{Br}_{2}$ concentration is seen in that this molecule is a quencher for $\mathrm{XeBr}^{*}$. The percentages in the figure indicate the fraction of the atoms/molecules in one state which go into forming the product species. 
FSL $-91-60$

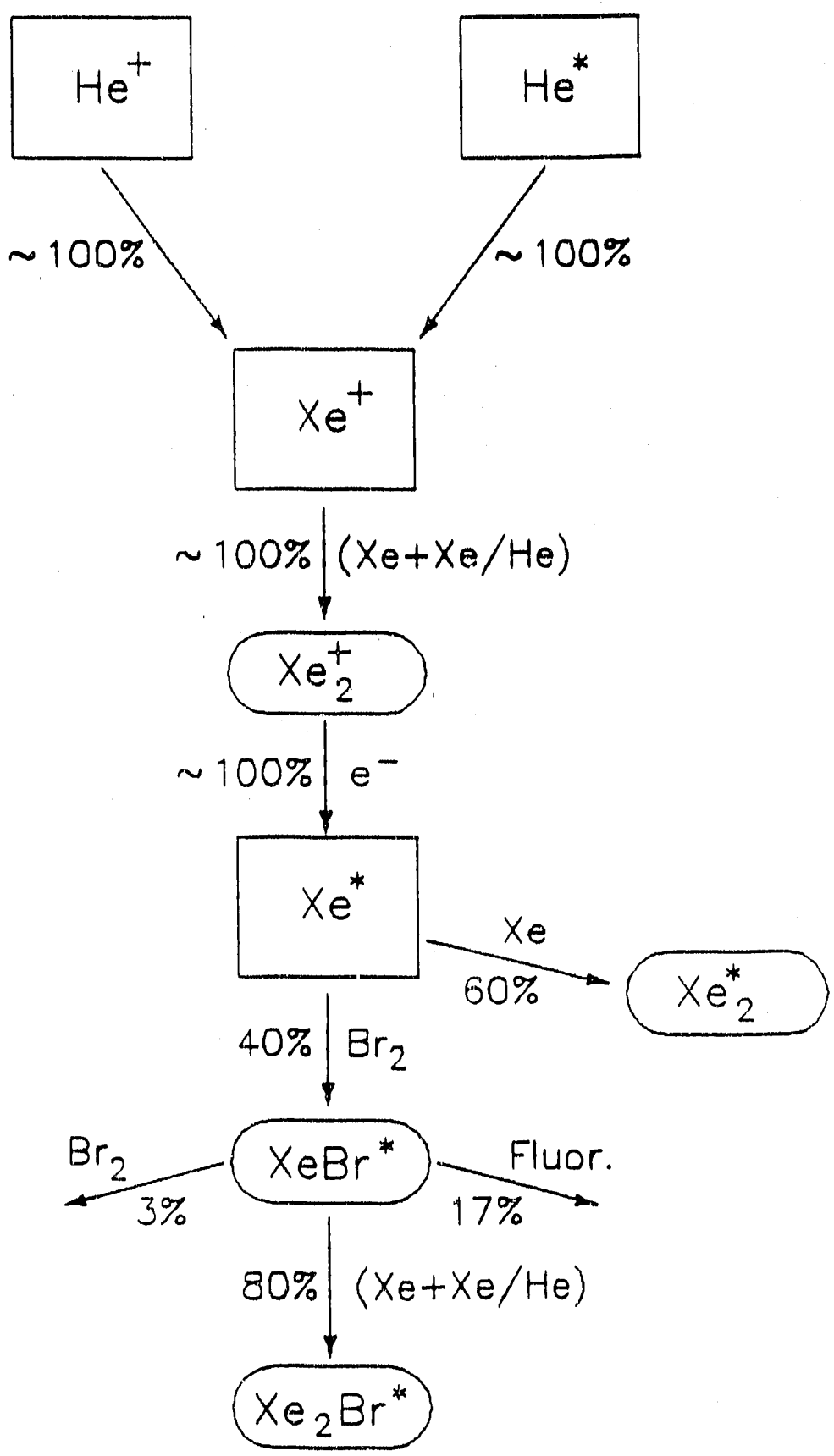

Figure 28. Energy flow pattern into and out of excimer state for 0.5 torr $\mathrm{CHBr} 3 / 200$ torr $\mathrm{Xe} / 2000$ torr ${ }^{3} \mathrm{He}$ in a TRIGA pulse. Species in square boxes are directly pumped by nuclear reaction products. 


\subsection{Comparison of Published Results to Modeling Results}

The modeling results described above can be compared against both experiments. done for this report in the TRIGA, as well as both experimental and modaling results reported in the literature. The latter will be considered first.

A good comparison is found against e-beam pumping experiments on Xebie by Swingle, et al. [9]. There, a fluorescence efficiency of $11+5 \%$ was reported at an optimum Xe concentration of 25 torr in 1 torr $\mathrm{Br}_{2}$ and 1500 torr Ar. (Efficiencies at other Xe pressures were not presented.) As shown in Figure 27, thein predicted $10 \%$ efficiency for these conditions, with a peak near 25 torr.

Likewise, a good comparison is found against Wilson's modeling results [7]. There, he reported a peak efficiency of $13-15 \%$ with a preference for low Xe partial pressures. Modeling shown in Figure 27 indicated a maximum of $11 \%$ efficiency, peaking at low Xe pressures.

Finally, these results can be favorably compared against experiments done at the University of Florida under ${ }^{3} \mathrm{He}$ nuclear pumping of $\mathrm{XeBr}$ [34]. In those experiments a mixture of 534 torr ${ }^{3} \mathrm{He}, 195$ torr $\mathrm{Ar}, 12$ torr $\mathrm{Xe}$, and 6 torr $\mathrm{Br} 2$ were irradiated with a steady-state neutron flux of $10^{11} \mathrm{n} / \mathrm{cm}^{2} \mathrm{sec}$, giving a modespump power of $3.7 \mathrm{~mW} / \mathrm{cm}^{3}$. No effort to determine an optimum mixture was reported. A fluorescence efficiency of $0.37 \%$ was found, most of this (perhaps $75 \%$ ), however, being $\mathrm{Br}_{2}$ "fluorescence at $291.2 \mathrm{~nm}$. Exact modeling for this mixture and pump power by the present code was not possible, in that the $\mathrm{Br}_{2}$ " fluorescence is not calculated in the code. The calculated $\mathrm{XeBr}^{*}$ fluorescence efficiency, however, was still a low $0.4 \%$. This is a little higher than the experimental results, given that most of the measured $0.37 \%$ was not $\mathrm{XeBr}^{*}$ (rather, $\mathrm{Br}_{2}{ }^{\prime \prime}$ ). It does, however, indicate that a low efficiency should be expected with this mixture, as was observed in experiments (too much $\mathrm{Br}_{2}$ ).

One consideration in applying the code to the above experiments is that the code was not fully set up to model Ar, which was used as a buffer gas in the e-beam and nuclear pumping experiments. In order to model these conditions, the source terms 
were modified to reflect the $W$ value and proton range for Ar, as opposed to $\mathrm{He}$, and then Ar was assumed to behave similarly enough to $\mathrm{He}$ in the kinetic reactions to allow utilization of the He rate constants. It is felt this approximation is accurate enough for the purpose of bench-marking the code against experiments.

Likewise, in comparisons below of TRIGA experiments with CHBr3 as the bromine: donor, it was assumed this material is kinetically similar enough to $\mathrm{Br} 2$ to allow. utilization of the appropriate $\mathrm{Br}_{2}$ reactions in the modeling. It would likely have been very difficult to find the necessary reaction rates invoiving $\mathrm{CHBr}$.

It is useful to consider the average $W$ values of the mixtures in these modely and how they reflect on the predicted efficiencies. For example, for the fast burst model (25 torr Xe in 735 torr ${ }^{3} \mathrm{He}$ ) an average $\mathrm{W}$ value of $33 \mathrm{eV} / \mathrm{i} . \mathrm{p}$. is calculated. (W values ior the mixtures used in all three models were near this value). Each $\mathrm{XeBr}$ * fluorescence photon is $4.5 \mathrm{eV}$. At most, 1.4 photons are created per ion pair (one from the ion, and 0.4 from the metastable Xe or Ar also formed), giving a maximum fluorescence efficiency of $19 \%$. Kinetic loss pathways (e.g. $\mathrm{Xe}_{2}{ }^{*}$ or $\mathrm{Xe}_{2} \mathrm{Br}$ formation) reduce this efficiency to the $11 \%$ predicted by the model; but, overall, the system is quite efficient at channeling all energy possible into the excimer state, and releasing this as light.

In summary, a reasonably good comparison of the code predictions against published results, both experimental and theoretical, was found. Predicted behaviors were in-line with those expected for a rare gas halide excimer (high efficiencies, low rare gas and halogen donor pressures).

\subsection{Comparison of TRIGA Results to Modeling Results}

Comparison of the model to measurements done for this reportdid not show as good of agreement as discussed above for published results. Several comparisons will be noted, with discussion to follow.

Figure 29 compares calculated results and an approximate fit to experimental data (from Figure 16, modified to reflect efficiencies) for $\mathrm{XeBr}$ fluorescence efficiency vs 


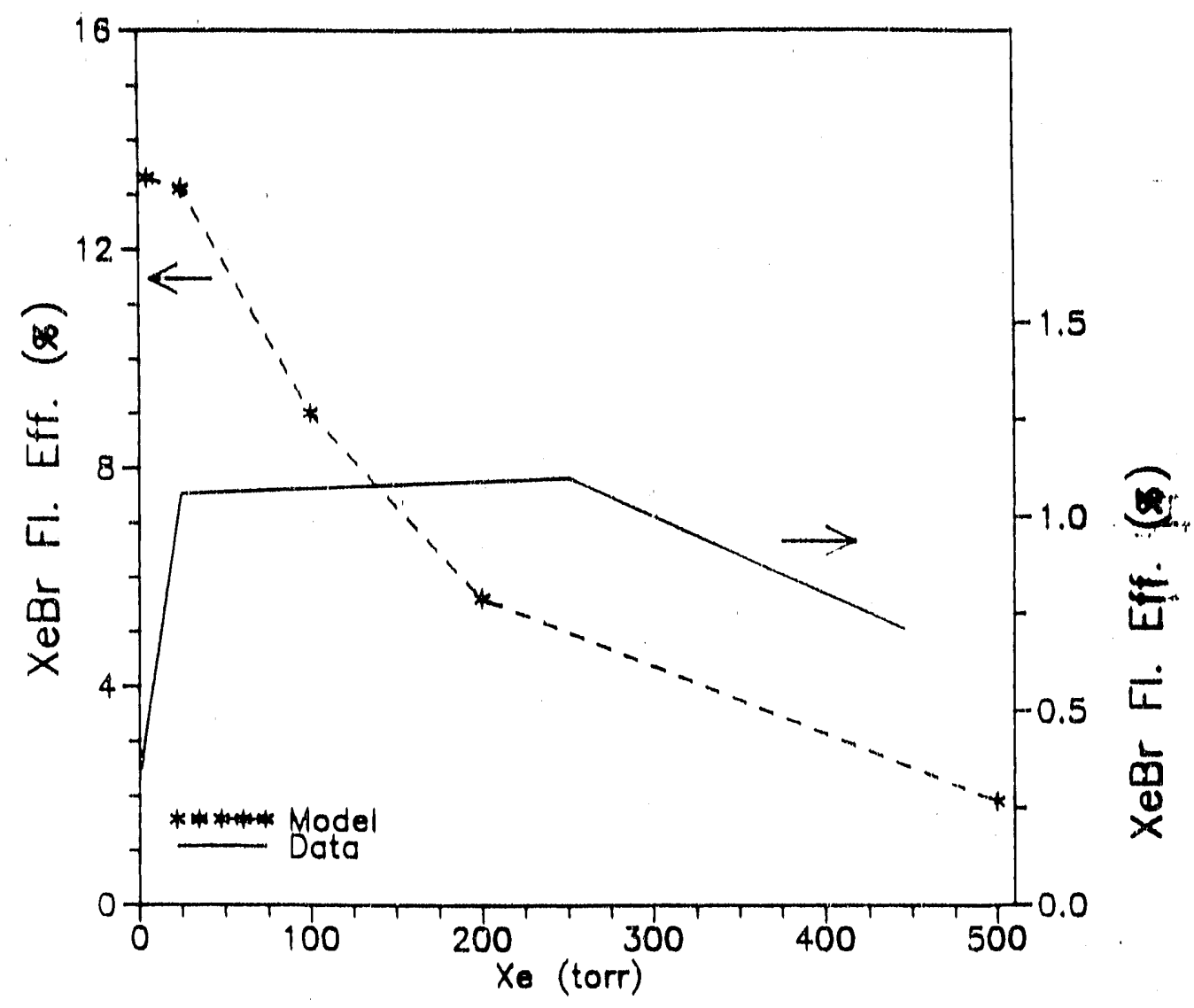

Figure 29. Comparison of modeling and experimental results of $\mathrm{XeBr}$ fluorescence vs $\mathrm{Xe}$ pressure.

Xe pressure. A gas mixture of $0.5 \mathrm{CHBr}_{3}$ in 800 torr total of $\mathrm{Xe}$ and $\mathrm{Ar}$ was considered, excited by ${ }^{10} \mathrm{~B}$ pumping in a TRIGA pulse at $12 \mathrm{~W} / \mathrm{cm}^{3}$ peak pump power. Two major discrepancies are noted. First, the modeling predicts significantly higher fluorescence efficiencies than measured (as much as an order of magnitude difference). Second, the experimental results do not show the preference for low Xe pressure as the model does.

Modeling of the ${ }^{3} \mathrm{He}$ gas mixture used in laser pumping showed moderate agreement with experimental results. The mix considered was 0.5 torr $\mathrm{CHBr}, 200$ torr Xe, and 2000 torr ${ }^{3} \mathrm{He}$, pumped by a TRIGA pulse (approximately $60 \mathrm{~W} / \mathrm{cm}^{3}$ peak power). Experimental results yielded an efficiency of approximately $1 \%$, while 
the code predicted $2.6 \%$ (cf. Figure 27). No Xe pressure dependance measurements were done with ${ }^{3} \mathrm{He}$ pumping due to ${ }^{3} \mathrm{He}$ expense, so a comparison of this parameter was not possible.

A comparison of experimental results and calculated predictions for $\mathrm{Br}_{2}$ concentration dependance is shown in Figure 30. The experimental data were taken from Figure 12. While the experimental data are skimpy, both it and modeling results seem to show a preference for low $\mathrm{Br}_{2}$ concentration. (This was also found in experiments for $\mathrm{CHBr} 3$ in Figure 14.)

An evaluation of the instantaneous fluorescence efficiency during a TRIGA pulse showed some discrepancy between experiment and model. Experiments had shown an approximate doubling in efficiency during a pulse, with the peak efficiency being at the pulse peak (see Figure 21). Modeling showed no such dependance, with a constant efficiency all through the pulse.

On a somewhat different note, some comparison can also be made of the ratio of $\mathrm{Xe}_{2} \mathrm{Br}^{*}$ fluorescence to $\mathrm{XeBr}{ }^{*}$ fluorescence measured during e-beam pumping and TRIGA pumping against models of the two experiments. That is, as shown in Figure 22, the excimer gas mixture under excitation emits broad band visible light centered at $415 \mathrm{~nm}$ from the trimer, $\mathrm{Xe}_{2} \mathrm{Br}^{*}$, as well as the $282 \mathrm{~nm}$ UV from $\mathrm{XeBr}$. This visible emision has been studied under e-beam pumping for utilization as a tunable laser [21,33]. In the results given in ref. 21 the ratio of light emitted in the visible band divided by that emitted in the UV $\left(\mathrm{XeBr}^{*}\right)$ was reported. This ratio was approximately 3 for a mixture of 1.5 torr $\mathrm{CHBr}_{3}, 200$ torr $\mathrm{Xe}$, and 6 atm Ar. Modeling results for this mixture yielded a ratio of 1.3. (The model was calculated with a pumping pulse of $44 \mathrm{~kW} / \mathrm{cm}^{3}$ peak, 1 microsec duration. The pump power in ref. 21 was unreported, but likely considerably higher.) Modeling with a TRIGA pulse on the same gas mix yielded a ratio of 1.1. By comparison, experimental results in the TRIGA yielded a ratio of approximately $0.2-0.3$.

(It should be noted that there was some discrepancy in the peak of this $\mathrm{Xe}_{2} \mathrm{Br}^{*}$ broadband visible emission between published results and these experiments. Ref. 21 indicates the peak at $440 \mathrm{~nm}$; these experiments showed the peak closer to 415 


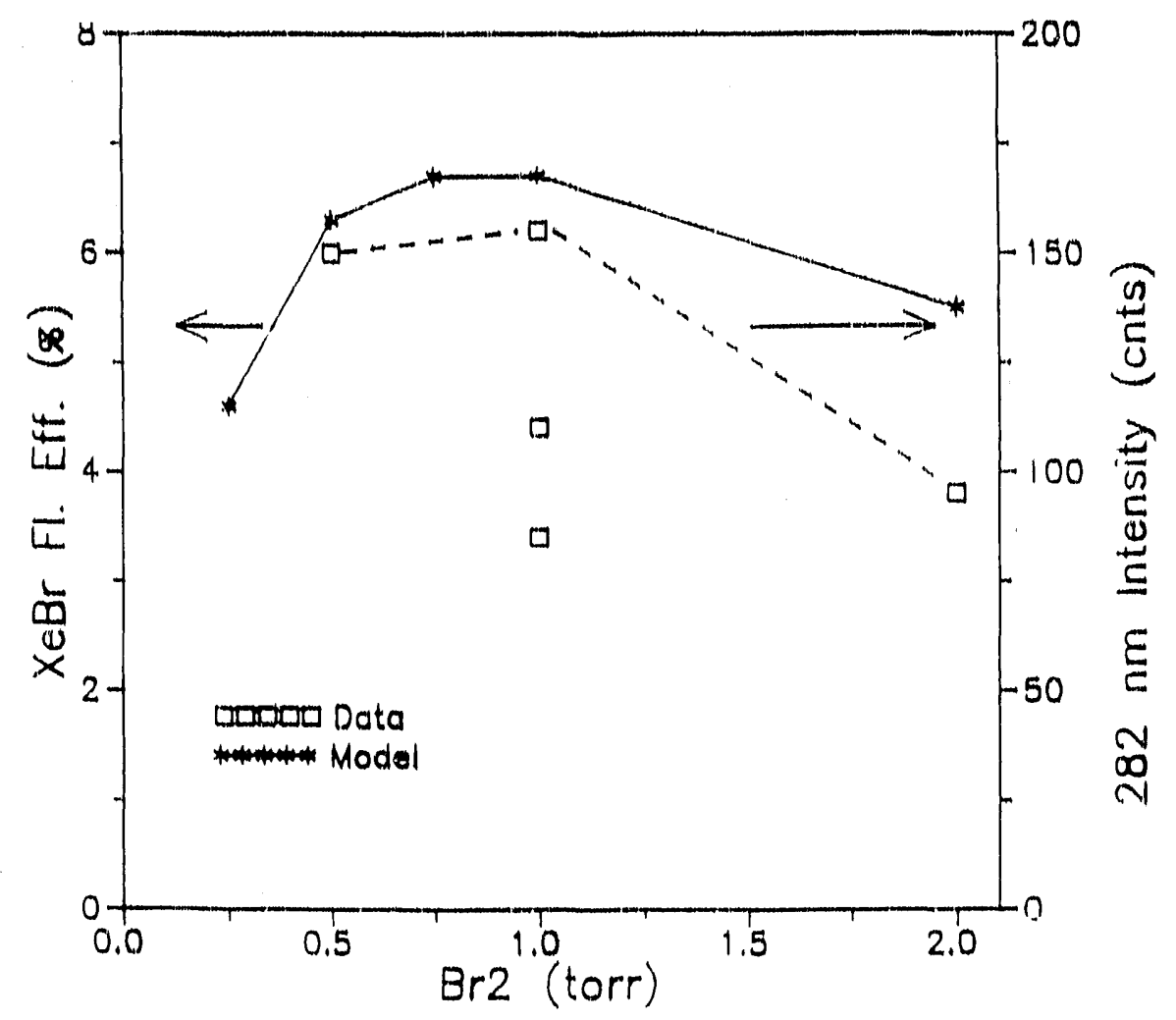

Figure 30. $\left\ulcorner\right.$ imparison of modeling and experimental results for $\mathrm{XeBr}^{*}$ fl. $4:$ : sence efficiency vs $\mathrm{Br}_{2}$ pressure.

nm. E-beam experiments reported in ref. 64 report the peak near $420 \mathrm{~nm}$. No explanation was found for this difference.)

In summary, some significant discrepancies were found between the modeling and TRIGA experimental results. The most important of these are that the model predicts higher $\mathrm{XeBr}$ fluorescence efficiencies than measured (ai much as an order of magnitude difference), and that it also predicts a significantly stronger preference for low Xe pressures than measured.

No firm explanation has been found for these problems, either in the theory, or in experiments. It was possible to force-fit the code to the data, but this required significant changes in three or four important, and fairly well-established rate constants. Such changes are difficult to justify. It is also possible that not all 
important gas reactions or species were included in the code. Such a reaction or species may be unique to $\mathrm{XeBr}$ (vs $\mathrm{XeCl}$ ), for which relatively little modeling has been done, or unique to the low pumping powers used in these experiments; or, it may relate to a condition unique to nuclear pumping, such as the extraordinarily low electron temperatures found in nuclear pumped plasmas. Whichever the case, none of these possibilities are considered likely, leaving no glaring weaknesses in the code. Perhaps most importantly, as explained above, the code seems to benchmark fairly well against other published materials.

Likewise, the difficulties, if any, in the experimental results are difficult to identify. The possibility of a quenching impurity in the system is very important. Several different experiments were run using three experimental cells, two different bromine donors (from three or four new bottles), two or three new Xe bottles, a new $\mathrm{Ar}$ bottle, and two new ${ }^{3} \mathrm{He}$ bottles. All gave fairly self-consistent and repeatable results over many different days of testing. This helps preclude the possibility of an unknown impurity from one of the material bottles.

Another possibility is a system impurity common in all experiments, such as a trace impurity in the gases. No direct evidence for this was ever found, in that all spectral lines were identified as part of the $\mathrm{XeBr}$ system. (Impurities that are taking energy out of the system would likely radiate some of this energy.) The OMA was only sensitive from 200 to $800 \mathrm{~nm}$, however, and there could have been impurity lines outside this window. An impurity may also have been acting as a quencher without radiating, of course. Some effort was made to reduce the impurities from the ${ }^{3} \mathrm{He}$ ( $32 \mathrm{ppm} \mathrm{N} 2,<20 \mathrm{ppm} \mathrm{O}_{2}, 28 \mathrm{ppm} \mathrm{Ar}, 7 \mathrm{ppm} \mathrm{Ne}$, and $<50 \mathrm{ppm} \mathrm{Ne}$ ). This was done by immersing the bottle of ${ }^{3} \mathrm{He}$ in liquid $\mathrm{N}_{2}$ to condense out the impurities with boiling points higher than $\mathrm{N}_{2}$ before releasing the ${ }^{3} \mathrm{He}$ into the test cell. No change in fluorescence output was observed. It should also be noted that experimental cells were evacuated to $10^{-3}$ to $10^{-4}$ torr prior to experiments to minimize residual impurities.

Another possibility for systematic experimental error is in the calibration of the detection system with the $D_{2}$ lamp. This calibration was done for two different 
OMA's with widely different sensitivities, both of which yielded similar results, though this still does not preclude the possibility of error. It was not possible to independently check the calibration without a separate calibrated light source. Consideration was given to the possibility that the fact that the calibration was done with a $50 \mathrm{~cm}$ distance between light source and OMA, versus a distance of $8 \mathrm{~m}$ in fluorescence experiments, may not have been correctable by a simple $1 / \mathrm{r}^{2}$ geometric factor (e.g., possible focussing in the spectrograph). Bench-top experiments were conducted by moving a light source different distances from the OMA and taking readings. They indicated the simple geometric factor (as shown in Appendix A) is accurate to $\pm 15 \%$. It should also be noted that any calibrationerror would help explain the low measured efficiencies, but would not explain the differing Xe pressure dependance.

An effort was made to verify the measured fluorescence efficiencies independent of any calibration procedure through looking at buildup of a photolysis product $\left(\mathbf{I}_{2}\right)$ in the lasant gas after laser shots. The effort was unsuccessful due to the lack of good literature data on the amount of photolysis required to produce a given concentration of $\mathrm{I}_{2}$. These experiments and background are detailed in Appendix C.

A final possibility is that the low experimental results could be due to inadequate passivation of the cell and gas handling materials against attack by the bromine donors. The reactivity of the bromine was well-recognized by the author, and care was taken to use resistant materials and to expose materials from minutes to hours to the bromine prior to experiments. The low pressures used (ca. 1 torr), and the long distances from the vacuum station to the cell (ca. 20 feet), however, allow for potential difficulty in determining the bromine pressure in the test cells if the gas were reacting with materials in the cell or in fill lines. Resulting low bromine pressures, along withe reaction species that may have acted as impurities, could have yielded the anomalously low and erratic results.

The implications of the failure to measure $248 \mathrm{~nm}$ emission in $\mathrm{KrF}$ experiments, as outlined in section 3.9, are not fully clear. It may indicate experimental problems, with, for example, uncontrolled reactions of the $\mathrm{NF}_{3}$ taking place, which might 
reflect on problems encountered with the $\mathrm{XeBr}$. Alternately, it may indicate a fundamental kinetic difficulty in nuclear pumping excimers (at low pump powers) not anticipated in modeling.

In summary, no firm explanation has been found for this discrepancy between experimental and modeling results, though several possibilities are candidates. Certainly, this is an area deserving further study. On a more positive note, however, this discrepancy suggests the possibility for better future results in this system. If later efforts are able to improve the experimental conditions and attain the factor of ten increase in output promised by the code, pumping of the atomic iodino laser, already shown feasible in this work, would appear even more attractive. 


\section{Chapter 5}

\section{LASER EXPERIMENTS}

This chapter will cover the design, construction, and testing of an atomic iodine laser utilizing the ${ }^{3} \mathrm{He}$-pumped fluorescence of $\mathrm{XeBr}$. The first part will detail calculations done with a ray tracing computer code to determine the efficiency with which fluorescence can be coupled from the fluorescing $\mathrm{XeBr}$ into the lasant. This will be followed by a brief analysis of nuclear radiation effects on the lasant. Design of the laser cell and experimental set-up in the reactor will then be given, followed by experimental laser results. Some description will also be given of experiments done to consider direct pumping of the lasant by addition of ${ }^{3} \mathrm{He}$ to the $\mathrm{C}_{3} \mathrm{~F}_{7} \mathrm{I}$. Finally, comments regarding scale-up of these results to higher powers will be offered.

\subsection{Coupling Emciency Calculations}

In order to design the laser cell, and to have a quantitative measure of the performance of the system, it was necessary to determine the efficiency with which light generated in the $\mathrm{XeBr}$ fluorescing gas could be coupled into the lasant volume. One fundamental advantage of a nuclear flashlamp pumped laser is that, theoretically, a large flashlamp volume can be excited, and then the light from the volume concentrated into a small lasant volume to increase lasant pumping power. The corresponding difficultly is in coupling light from a large volume, isotropic source into a small volume with good efficiency. (In the case of the laser used here the flashlamp volume was $2550 \mathrm{~cm}^{3}$, and the lasant volume $153 \mathrm{~cm}^{3}$.) The term "coupling efficiency" is used for this parameter, defined as number of photons absorbed in the lasant, divided by the number born in the fluorescer.

In past conceptual studies of nuclear flashlamp pumped lasers some attention has been paid to this problem $[8,65,66]$. Reference 66 gives results from careful calculations done for several geumetries. 
Coupling efficiency, however, is a strong function of cell geometry, and it was determined that published results were insufficient to allow necessary design flexibility for these experiments. For that reason it was decided to write a computer code to determine this parameter for this application. The code was based on a ray tracing technique [67] used to create computer generated images which contain reflected lighting. It is a ray tracing technique because light rays are born at a point in space with given direction and intensity, and are followed as they bounce off surfaces in the geometry. (In actuality, for painting pictures, light rays are followed backwards, from the observer's eye back to the point of light origin.)

The basic approach of the algorithm used in this work is to model surfaces of objects in space with mathematical functions, and the light ray as a line in space. The mathematical functions representing the surfaces and the equation representing the ray are solved simultaneously; the roots represent points in space shared by the two, and, hence, intersection points for the light ray and the objects. To trace the light paths, then, a light ray is originated in space, and a possibie intersection of this ray' with all objects is checked. If an intersection is found, a reflection angle is determined, and a new light ray originates from that point.

A simple geometry for a laser, and that used in these experiments, is two concentric cylinders. The inner cylinder contains the lasant gas, and the annular region contains the fluorescer. The wall between the two is glass, and the inner surface of the outer cylinder is reflective. Photons are born in the fluorescing volume and bounce around inside the annular cavity; some of them intersect the inner cylinder and are fully, or partially, absorbed by the lasant. If partially absorbed, the ray continues on with decreased intensity. The ray also loses intensity at each bounce off the outer cylinder wall, which has a finite reflectivity (approximately $82 \%$ for aluminum at $282 \mathrm{~nm}$ ).

An additional, though small loss is incurred as the photon passes through the glass wall. This is because the glass darkens some during the pulse due to the high radiation field. This absorption was included in the calculations, with an absorption coefficient based on previous work at the U of I [68,41], but was found to be negligible. Likewise, a small absorption coefficient was included for the fluorescing 
medium itself, as some medium species, especially $\mathrm{Br}_{2}$ and $\mathrm{Xe}_{2}{ }^{+}[29,31]$ have appreciable absorption cross-sections at $282 \mathrm{~nm}$. As with the glass, however, this proved negligible.

Photons were born in the code at random locations in the fluorescing volume, and with random initial trajectories. The fact that less photons are born near the center of the cell than near the edges, due to the attenuation of the neutrons in the high pressure ${ }^{3} \mathrm{He}$, was accounted for by including a radial dependance of the intensity of the photons at birth. As the photons were bounced around inside the cavity, a tally was kept of the energy lost, either as reflective losses, absorption in the glass, absorption in the fluorescer, or absorption in the lasant.

The code was two dimensional, restraining photons to a cross-sectional plane of the laser. A random angle in the third dimension was included for each photon, however, to account for the longer pathlengths on each traverse across the cell which a photon would see in three dimensions as opposed to two. This angle is unchanging as the photon bounces around for a simple geometry, so a full three dimensional representation was not necessary. This allowed, for example, the surfaces of the inner and outer cylinders of the laser geometry given above to be modeled with equations as circles of given radii.

The code was written in FORTRAN, and set up to run on a PC. Graphics routines were also included to allow the geometry and bouncing photons to be shown on the screen. A printout of the code is included in Appendix D.

Flexibility in the code allowed choice of lasant pressure and cell geometry. As the experiments were always meant to be "proof-of-principle", it was not felt necessary to maximize laser output, so a few simple geometries were analyzed, with results shown in Figure 31. These zeometries were considered "buildable" for the purposes of this research (limited by the size of the reactor throughport, cost of ${ }^{3} \mathrm{He}$, and cost of materials).

The simple design of two concentric cylinders is shown in Figure 31, along with the

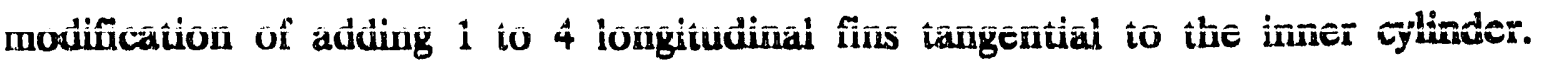




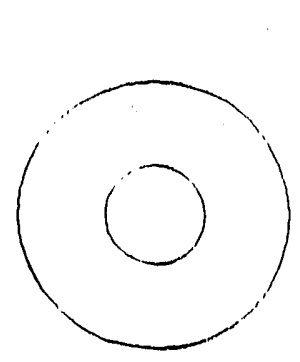

$28 \%$

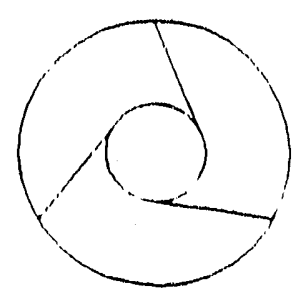

$43 \%$

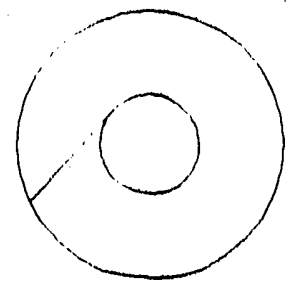

$41 \%$

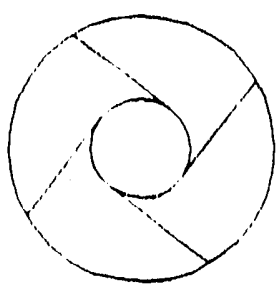

$43 \%$

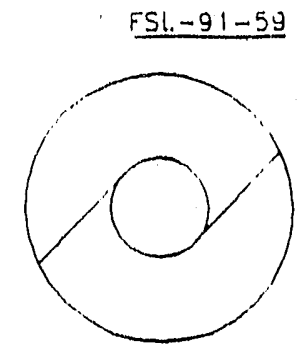

$44 \%$

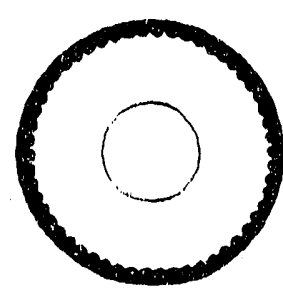

$50 \%$

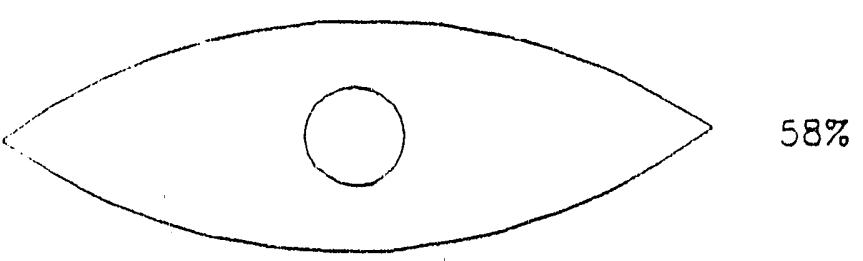

Figure 31. Calculated coupling efficiencies for various geometries. Laser tube radii $=1 \mathrm{~cm}$. Round fluorescer tube radii $=2.5 \mathrm{~cm}$. Parabolic-shaped fluorescer tube cross-section: height $=5 \mathrm{~cm}$; length $=8 \mathrm{~cm}$.

These fins served the purpose of deflecting photons which, in the simple concentric cylinder geometry, would bounce around inside the annulus, never intersecting the inner cell. An improvement in coupling efficiency is seen from this modification. Another modification similar to this design is to have a reflective annulus wall, as above, but have a rough surface so photons are reflected off at random angles. This, again, keeps photons from endlessly looping around the center cell without intersecting it. A final modification changes the fluorescing cell shape to approximately concave. This also allows more photons to be directed toward the center of the geometry, increasing coupling efficiency. Similar dimensions (for 
example, cell radii) were used for designs shown in the figure to allow comparison. Lasant pressure used in these calculations was 100 torr $\mathrm{C}_{3} \mathrm{~F}_{7} \mathrm{I}$.

Through calculations sust is these it was decided to construct the laser cell of two concentric cylinders, with a smooth, reflective annulus surface. (A rough inner surface could have been fabricated, but the coupling efficiency would hove been more difficult to predict with confidence.) A coupling efficiency of $15 \%$ was calculated for this geometry with 15 torr of lasant gas, the approximate pressure used in laser experiments.

\subsection{Nuclear Radiation Effects on Lasant}

In considering the possibility of pumping an iodine laser in the radiation field from a nuclear reactor, some consideration was given to the question of whether the radiation would damage the lasant. Such damage, called radiolytic decomposition, comes about as gammas and high energy neutrons from the reactor break molecular bonds in the compound. An especially important product in decomposition of alkyliodides comes as atomic iodine atoms recombine with themselves to form $\mathbf{I}_{2}$. Molecular iodine is an especially bad quencher of the upper laser state for the atomic iodine laser, and cannot be tolerated in concentrations of more than approximately $1 \%$. The concern, then, in the radiolytic decomposition of the lasant would be formation of $I_{2}$.

To evaluate this potential, the $\mathrm{I}_{2}$ production rate in $\mathrm{CF}_{3} \mathrm{I}$ under Co-60 irradiation, as reported by McAlpine and Sutcliffe [69], was applied to the total dose to the lasant provided by the TRIGA in a pulse $(0.1 \mathrm{MRad})$. The $\mathbb{I}_{2}$ production so calculated is a $0.03 \%$ conversion of the lasant to $I_{2}$ from 50 reactor pulses. It is likely that $\mathrm{I}_{2}$ formation from flashlamp-induced phutolysis of the lasant would represent a larger problem, though there is little data on photo-induced $\mathbf{I}_{2}$ formation rates (see Appendix C). The conclusion, then, is that radiolytic decomposition should not be a problem in nuclear pumped laser applications, and no experimental evidence to the contrary was found in this work. (For example, the laser reached threshold at approximately the pump power reported in the literature, 
and lasing was achievable more than once on the same fill, neither which would not have been the case had there been extensive radiolytic decomposition.).

\subsection{Laser Cell Design and Experimental Set-up}

This section will describe the laser cell constructed for these experiments, followed by the experimental set-up used in the TRIGA reactor. Experimental results will be given in the following section.

5.3.1 Laser Cell. A schematic of the cell constructed for laser experiments is chown in Figure 32. The laser consisted of two concentric cylinders, the inner to contain the lasant gas, and outer to contain the fluorescing $\mathrm{XeBr} /{ }^{3} \mathrm{He}$ mix. The inner cylinder was $20 \mathrm{~mm}$ O.D. Suprasil fused silica tubing with $1 \mathrm{~mm}$ wall. Suprasil was selected because experiments [41] had shown the radiation-induced darkening of this material to be small. This material also has good transmission in the UV. The Brewster windows, affixed to the tube with Torr-seal, were made of Infrasil, a low water grade of fused silica. Normal fused silica has a small water absorption band near the laser wavelength of 1.3 micron which, it was feared, would grow upon irradiation.

The outer cylinder was $31 / 16$ inch I.D., $1 / 4$ inch wall aluminum. The inside of the cylinder was polished on a lathe with fine alumina powder in deionized water to a reasonably good mirrored finish. ("Reasonably good" means a good reflected image could be seen from the surface, though not with perfect clarity.) This polishing served the purposes of allowing a prediction of the coupling efficiency through the use of the ray tracing calculations outlined above, as well as removing the aluminum oxide coating to increase reflectivity. End plates of $5 / 8$ inch aluminum were bolted on the cylinder with buna-n o-rings. The inner glass cylinder was also sealed to these end plates with the use of o-rings. Fittings were attached to the cell for gas fill and vacuum lines. A small fused silica window, $3 / 8$ inch diameter, was installed in one end plate to allow viewing of the fluorescence chamber during a pulse. 


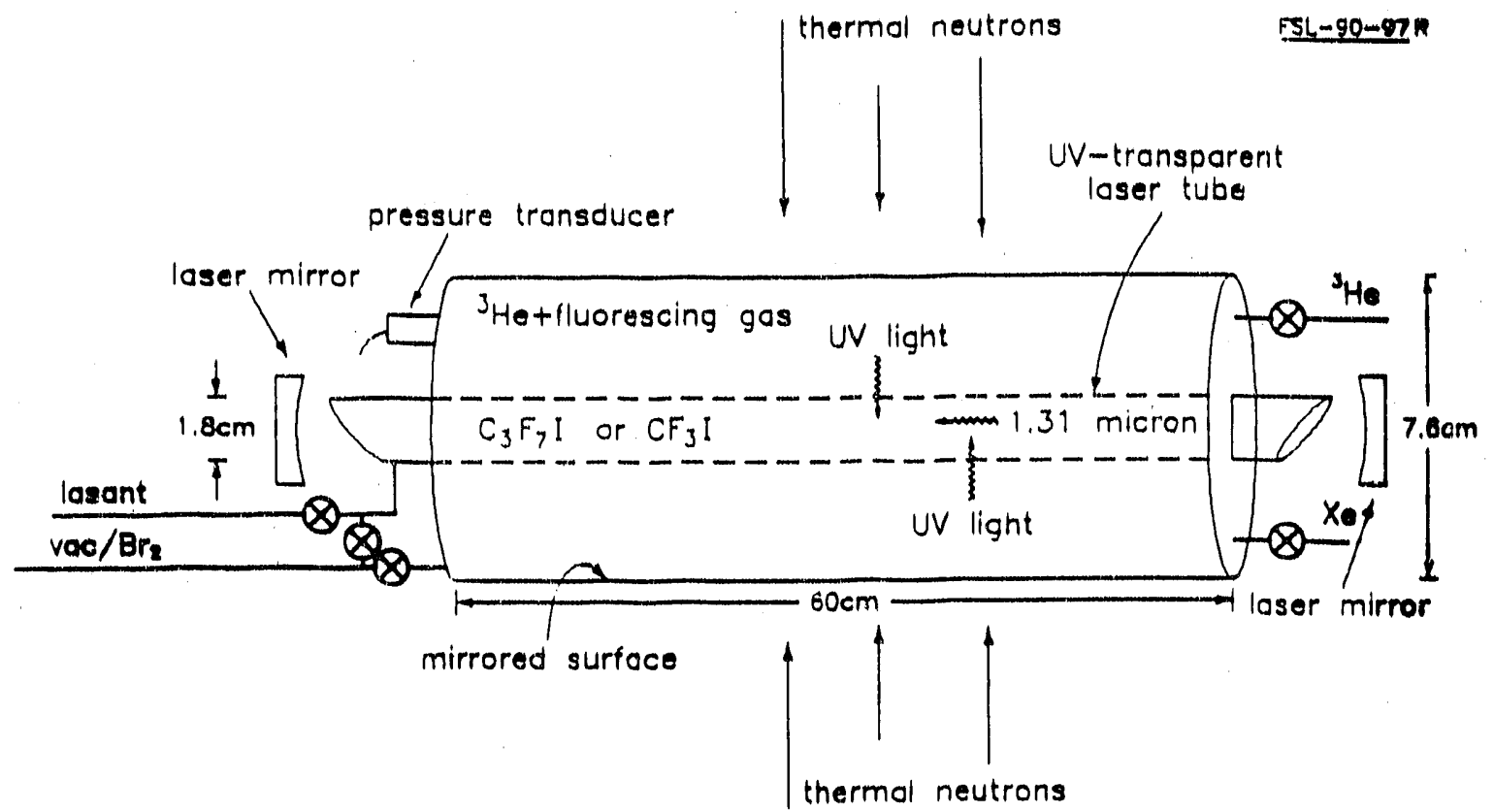

Figure 32. Schematic of laser cell (not to scale).

The cell was constructed to allow fluorescence gas fills of up to 3 atm. (which pressure increases to about 9 atm. during a pulse due to gas heating) with pressures in the laser tube of zero to several hundred torr.

Valves were attached on the laser carriage to allow control of vacuum and fill gases into both chambers. All valves were pneumatically operated, except the vacuum valve on the cell. No pneumatic valve was found with suitable conductance and service from vacuum to $10 \mathrm{~atm}$. To meet this need, a ball valve with $1 / 2$ inch I.D. and service over the needed pressure range was modified to allow external actuation. This was done by adding a worm gear fixture to the valve stem, and then by turning the gear with a long steel rod which ran out of the throughport. All valves were placed on the carriage with the laser cell, as close to the cell as possible, so as to minimize pump-down time during evacuations. A pressure transducer, such was used in fluorescence measurements, was also attached to the cell. 
Laser mirrors had reflectances of 99.7 and $98 \%$ at 1.31 micron, and were one inch in diameter. The output mirror was a fused silica substrate to minimize radiation darkening. The rear mirror had a Pyrex substrate. Both mirrors were affixed to the carriage in adjustable mirror mounts. Where possible, all non-aluminum metals were wrapped with rubber sheeting laced with ${ }^{10} \mathrm{~B}$ to minimize activation.

5.3.2 Experimental Set-Up. All laser experiments were done in the throughport of the University of Illinois TRIGA reactor. As in fluorescence experiments, this facility allowed vacuum/gas fill lines to be attached to the cell in-situ, and casy optical access for diagnostic equipment.

A schematic of the set-up is shown in Figure 33. The cell was viewed for two optical signals simultaneously, the laser line coming from the laser tube, and the fluorescence light coming through the small viewport in the flashlamp wall. Two sets of aluminum-coated mirrors were used to separate the two signals. The laser line was focussed onto a $2 \mathrm{~mm}$ diameter InAs photodiode, blocked with a bandpass

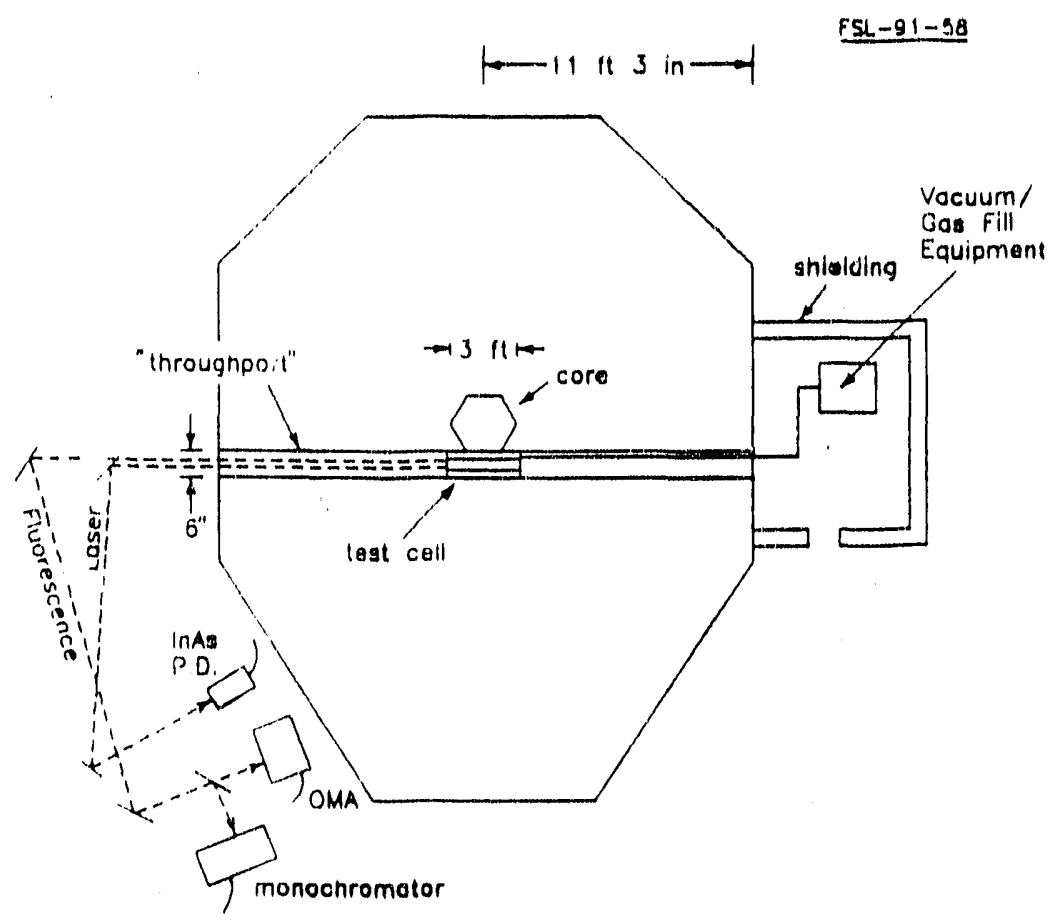

Figure 33. Set-up for laser experiments in the TRIGA (not to scale). 
filter which passed light only a few $\mathrm{nm}$ around 1.31 micron. The fluorescence signal was viewed with an OMA, as in fluorescence studies, and with a monochromator/PMT to look at the temporal dependance.

The attached gas handling lines allowed changing of both fluorescence and lasant gas fills. It was found, however, that the fluorescer output was constant, and did not degrade with repeated pulses. (This was fortunate, because approximately $\$ 600$ in ${ }^{3}$ He was required for a fill.) The lasant was replaced frequently, both because laser output was found to degrade under repeated pulses on the same fill (presumably due to $I_{2}$ buildup), and to study laser output with varied lasant pressure.

Materials used as lasants were $\mathrm{i}-\mathrm{C}_{3} \mathrm{~F}_{7} \mathrm{I}$ and $\mathrm{CF}_{3} \mathrm{I}$, both common in atomic iodine lasers. Two other common candidates are $\mathrm{n}_{-} \mathrm{C}_{3} \mathrm{~F}_{7} \mathrm{I}$, which bohaves almost identically to the iso- form; and $\mathrm{t}-\mathrm{C}_{4} \mathrm{~F}_{9}$ I. This latter compound has been shown [70] exceptional in its ability to be used for repeated laser shots. Its photodissociation cross section is not significantly different than the other alkyliodides, however, and because it is a somewhat more difficult and costly material to work with, its use was not attempted.

Buildup of $I_{2}$ from photolytic and thermal decomposition in purchased bottles of $\mathrm{C}_{3} \mathrm{~F}_{7} \mathrm{I}$ was found to be a problem. The $\mathrm{I}_{2}$ is apparent upon visual inspection because it gives a purpie tinge to the otherwise clear, water-white material. To remove the iodine, the $\mathrm{C}_{3} \mathrm{~F}_{7} \mathrm{I}$ was mixed with fine copper powder, which reacts with $I_{2}$ to form an insoluble compound. The mix was then drained through filter paper to remove the copper. This procedure was sometimes repeated several times until the liquid showed no tinge. $\mathrm{CF}_{3} \mathrm{I}$, being a gas a room temperature, was not treated prior to use.

Also, at all times, exposure of the $\mathrm{C}_{3} \mathrm{~F} 7 \mathrm{I}$ to fluorescent room lights was kept to a minimum, as the UV component in these lights will photo-decompose the lasant over a period of minutes to hours. Illumination during handling was done, instead, with an incandescent light (flashlight). 


\subsection{Laser Results}

This section will detail results of laser experiments. Primary areas of interest include evidences that lasing was actually observed, lasant pressure dependance, lasing pump power threshold, and repeatability. A discussion will also be given of results of an experiment looking at direct pumping of the lasant (through addition of ${ }^{3}$ He to the lasant).

5.4.1 Laser Signal. A trace of the laser output from the photodiode is shown in Figure 34, with the neutron signal superimposed. It is seen that the laser signal jumps up suddenly as the pump power reaches threshold (as opposed to the smooth increase in neutron signal), a characteristic of laser behavior. This is due to the fact the sub-threshold spontaneous emission is spatially isotropic, with little light hitting the detector at its distance of $8 \mathrm{~m}$. At threshold, however, stimulated emission collimates the cavity light and directs it into the detector. Accordingly, the amount

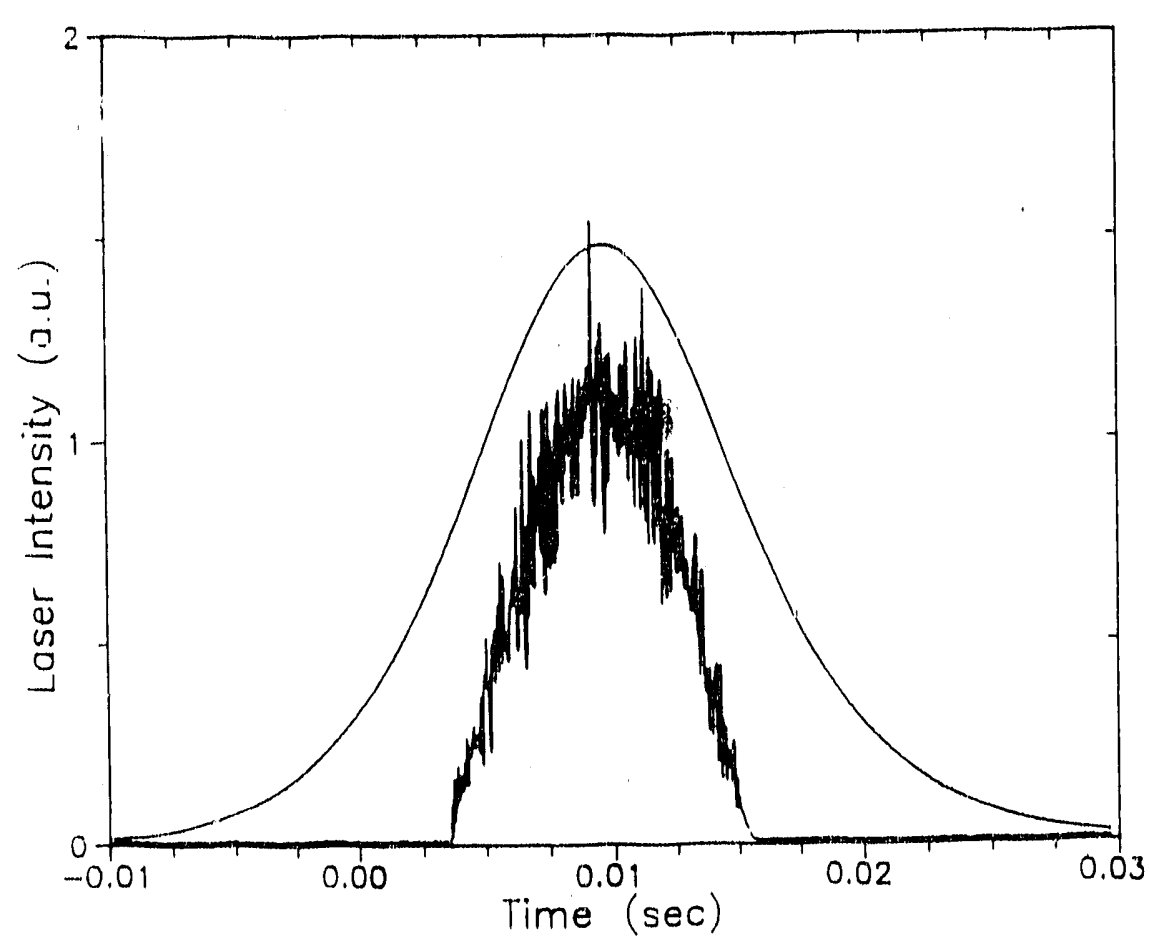

Figure 34. Trace of laser output from 15 torr $\mathrm{C}_{3} \mathrm{~F}_{7} \mathrm{I}$ with reactor power superimposed. 
of light registered by the detector can jump several orders of magnitude when the pumping crosses threshold. The lasing follows the shape of the neutron pules.until the pump power drops below threshold on the back side of the pulse, and the laser switches off.

The "noise" in the laser signal is actually fast oscillations in the laser output. These oscillations are termed "relaxation oscillations", and are common in lasers. Reference 44 reports them for the atomic iodine laser pumped at low pump rates. They occur as the upper and lower laser states compete for atoms. These states have different lifetimes, depending on the atomic species and the gas kinatics. These oscillations occur on a fast time scale (microsecond), faster than the resolution of the digital oscilloscope used to record this data. A description of this phenomenon can be found in reference 71. For purposes of these experiments, these oscillations are unimportant, except as an evidence of lasing.

A few other evidences of lasing should also be mentioned. As indicated above, the photodiode used to register the laser signal was covered with a few nm wide, 1.31 micron bandpass filter. This minimized the possibility of other, non-laser light entering the detector to confuse measurements. Radiation effects on. the photodiode were too small to be measured, as indicated in experiments with an empty laser cell. Finally, the light registered by the detector could not have been spontaneous emission at 1.31 micron by the lasant. The measured signal (approximately $20 \mathrm{~mW}$ at peak) would have required a spontaneous emission power from the lasant in the cell of $8 \mathrm{~kW}$, far larger than possible in this system. (The actual peak spontaneous emission, not measurable in these experiments, would have been $<50 \mathrm{~W}$.)

As mentioned, the peak laser power was determined approximately from the InAs photodiode response as $20 \mathrm{~mW}$ for the shot shown in Figure 34. When integrated over the $10 \mathrm{msec}$ pulse duration, the laser energy was approximately 100 microjoules.

The above data, and all laser data, were taken with $\Gamma_{3} \mathrm{~F}_{7} \mathrm{I}$. An attempt was made to use $\mathrm{CF}_{3} \mathrm{I}$, but lasing was not achieved. This was due presumably to the somewhat 
lower photodissociation cross section of this material at $282 \mathrm{~nm}$, or may have been due to $I_{2}$ contamination in the lasant.

5.4.2 Lasing Threshold. It is seen from Figure 34 that the laser was being pumped very close to threshold, that threshold being $1 / 2$ peak reactor power in the shot shown. Given this, it was very fortunate that the laser worked. It actually required four days of attempts before lasing was achioved. A somewhat better vacuum in the laser tube was accomplished for the fourth day's experiments (reduced from 5 to 0.5 mtorr), due to some valving modiffications. This small reduction in background impurities was sufficient to allow laser operation.

Given the knowledge of the fluorescence intensity of the $\mathrm{XeBr}$ and coupling efficiency inside the laser cell, it was possible to predict the flashlamp pumping power in the lasant at threshold, and compare this to literature values for the same parameter. Using a fluorescence efficiency of $0.8 \%$ with pump power of $40 \mathrm{~W} / \mathrm{cm}^{3}$ (see Table 2) with $15 \%$ coupling efficiency, a pump power in the lasant of approximately $0.4 \mathrm{~W} / \mathrm{cm}^{3}$ at threshold is calculated. This is reasonably closa to the values of 0.06 and $0.07 \mathrm{~W} / \mathrm{cm}^{3}$ reported in the literature [43,44], given the difficulties of setting up a laser in the reactor, and the inexperience of the author. As an aside, this agreement is also supporting evidence that measurements of the low $\mathrm{XeBr}$ fluorescence efficiencies were accurate (i.e. that detector calibrations were not grossly inaccurate).

5.4.3 Lasant Pressure Dependance. Measurements were done to determine laser performance with changing lasant pressure. Results are shown in Figure 35. A wide scatter in the data was found, with poor repeatability. This is attributed to the fact that the laser was being pumped so close to threshold, and small variations in the system (e.g. impurities left from inadequate pumping on the cell between pulses) could effect performance significantly. Sufficient pulses were taken, however, to indicate lasing was only possible between approximately 5 and 25 torr, which agrees with other published data on the atomic iodine laser pumped at low powers [14,72]. (At lower pressures there are insufficient lasant molecules to absorb the flashlamp light. At higher pressures, the lasant molecules quench the excited laser state.) In 


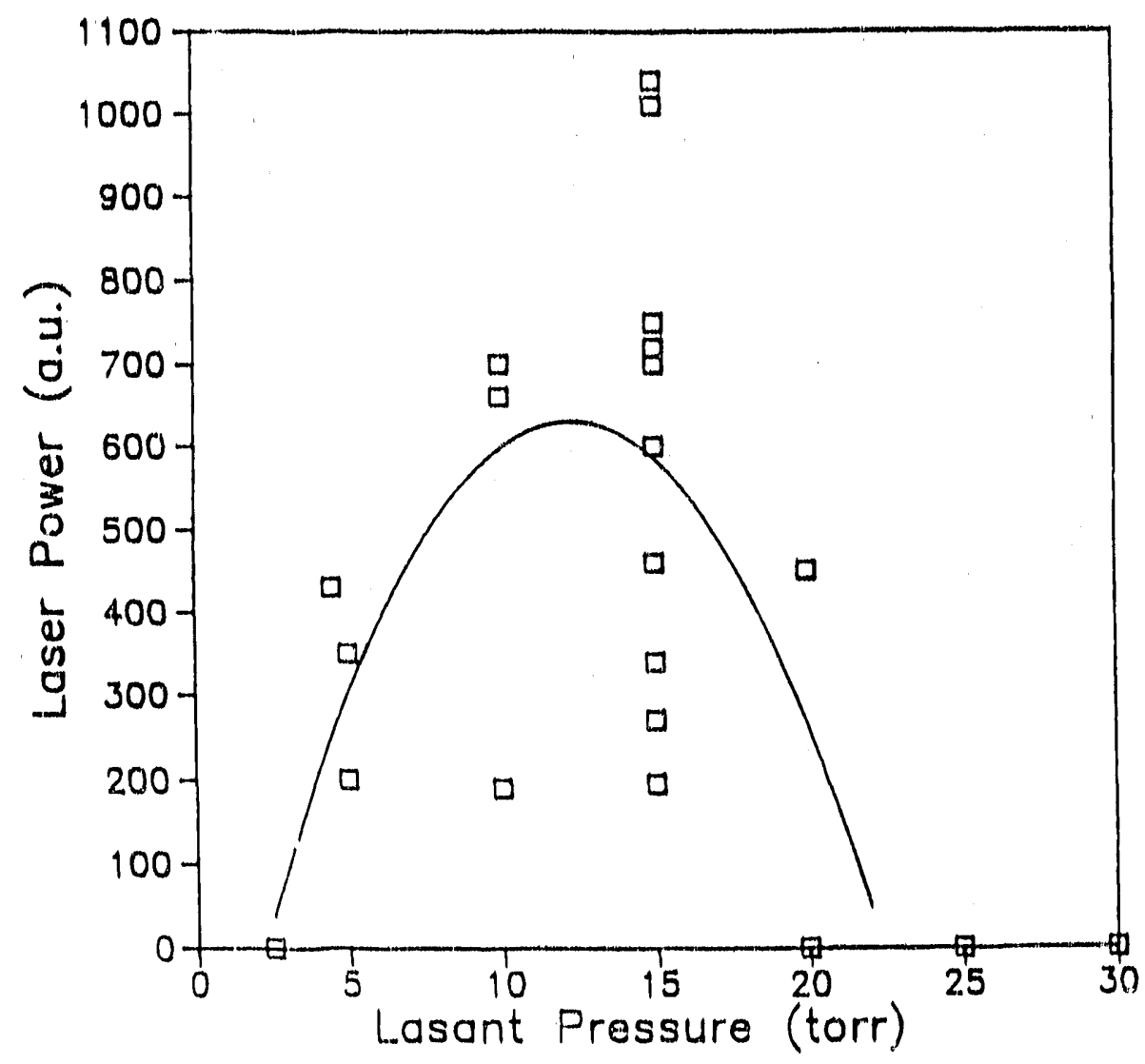

Figure 35. Lasant pressure dependence on laser output. The solid curve is included only as a visual aid, indicating that lasing was achievable between approximately 5 and 25 torr $\mathrm{i}-\mathrm{C}_{3} \mathrm{~F}_{7} \mathrm{l}$.

Figure 35 a curve has been drawn through the data only to help indicate this range, and is not meant to represent the actual dependance.

There did not seem to be any correlations between the sequence of pulses on any given day of testing and the randomness in the data, except the first pulse of the day gave good results. This may suggest the long purnp-down times previous to the first pulse (overnight) removed residual gases, especially $I_{2}$ adsorbed on cell walls.

5.4.4 Multiple Pulses. In most experiments the lasant was replaced after each reactor pulse to maximize output. In one set of runs, however, the same fill was lefit in for several pulses. In this case laser power decreased with each pulse, until no 
lasing was attained after five pulses. It was assumed sufficient $I_{2}$ or some other impurity had built up to quench lasing.

\subsection{Direct Lasant Pumping}

A brief experiment was also conducted looking at direct pumping of the laser through addition of ${ }^{3} \mathrm{He}$ to lasant. This was done to investigate the possibility of changing the atomic iodine formation mechanism from one of photodissociation with a flashlamp to one of collisional dissociation with the $n-{ }^{3} \mathrm{He}$ reaction proctucts.

From a kinetics standpoint there should be no reason this approach (the addition of ${ }^{3} \mathrm{He}$ to the lasant) would be prohibitive, as high pressures of $\mathrm{He}$ are commonly used in the atomic iodine laser to lower the stimulated emission cross section for large amplifiers [44,73]. Also, experiments by Ramirez, et al. [74] had shown the potential feasibility of using e-beams to direct pump this laser, demonstrating population inversions. A major obstacle, however, was that the necessary pumping powers reported by Ramirez, et al. were on the order of $400 \mathrm{~kW} / \mathrm{cm}^{3}$, much larger than the $60 \mathrm{~W} / \mathrm{cm}^{3}$ attained in these experiments. Nonetheless, the experiment was conducted because, after the laser cell had been built for flashlamp experiments, it was a simple matter to divert some ${ }^{3} \mathrm{He}$ into the laser chamber for these runs.

Lasing results were negative, as expected based on pumping powers. Spectra of the lasant under this stimulation showed broad, weak emissions at 322, 402, and $465 \mathrm{~nm}$. No attempt was made to identify these transitions.

\subsection{Laser Scale-Up}

Based on these experiments, some comments can be made regarding scale-up to a large nuclear flashlamp pumped atomic iodine laser. An important conclusion is that these proof-of-principle results showed that the high radiation field of nuclear pumping poses no special difficulties for this laser. That is, there was no evidence that radiation effects on the lasant or in the optics were significant, or that they would be a problem, even in a much higher flux environment. 
The parameter of principle interest in these experiments, however, was the fluorescence efficiency of an excimer under nuclear pumping, and measurernents of $<1 \%$ for this parameter were disappointing (although modeling efforts seemed to suggest the efficiency should have been higher). If future experiments are able to increase this efficiency, the potential for a high power system becomes more promising. For example, with a flashlamp efficiency of, say, 10\%, a coupling efficiency of $30 \%$, and a lasant quantum efficiency of $20 \%$, an overall system efficiency of ca. $0.6 \%$ is anticipated. This compares well with electrically pumped iodine laser efficiencies of $0.08-0.3 \%$ [4].

The fluorescence power which could be extracted from a nuclear flashlamp of certain size, is, of course, dependant on many factors, including neutron flux, ${ }^{3} \mathrm{He}$ pressure, and fluorescence efficiency. For purposes of illustration, however, if we assume a flashlamp of dimensions $1 \mathrm{~m}$ by $1 \mathrm{~m}$ by $5 \mathrm{~cm}$, containing $3 \mathrm{~atm}$. ${ }^{3} \mathrm{He}$ in a $10^{17} \mathrm{n} / \mathrm{cm}^{2} \mathrm{sec}$ neutron flux, and a fluorescence efficiency of $10 \%$, we can calculate a flashlamp power out of this lamp of $11 \mathrm{MW} / \mathrm{m}^{2}$, or $220 \mathrm{MW} / \mathrm{m}^{3}$ of fluorescer. The energy emitted in the UV in a 150 microsec fast burst reactor pulse would be approximately $1.6 \mathrm{~kJ}$. By way of comparison, reference 4 reports information on electrical Xe flashlamps used in iodine laser pumping. An output of $0.4 \mathrm{~kJ}$ of UV light in a 20 microsec pulse is reported from a $90 \mathrm{~cm}$ long by $3 \mathrm{~cm}$ diameter cell. Given that a large number of these could be placed in the volume occupied by the nuclear pumped flashlamp described above, it can be concluded that, in terms of fluorescence power output, electrical flashlamps show advantage over nuclear pumping.

Other benefits of a nuclear flashlamp pumping configuration, such as may be important in space-based systems, may also be important, however. As a specific example of scale-up, it is instructive to compare, to first order, how a nuclear flashlamp for pumping of a very large laser amplifier (ca. $1000 \mathrm{~J}$ ) might compare to a capacitcr-driven xenon flashlamp bank, as is usually used. A parameter of interest for space-based application would be flashlamp system size and weight.

If we consider a nuclear source of $10^{18} \mathrm{n} /$ pulse, such as from a fast burst reactor, then, given a $100 \%$ coupling efficiency of neutrons into the fluorescer, and of the 
fluorescence into the lasant, and a $10 \%$ conversion efficiency of ${ }^{3} \mathrm{He}$ reaction energy into UV light, we have a flashlamp providing around $10^{4} \mathrm{~J}$, approximately sufficient to pump a $1000 \mathrm{~J}$ amplifier. To generate this energy from xenon flashlamps; given an $8 \%$ efficiency of converting electrical energy into UV light [4], we need a $10^{5} \mathrm{~J}$ capacitor bank. Such a bank, based on vendor data, would have a velume of approximately $60 \mathrm{ft}^{3}$. By contrast, a fast burst reactor is approximately $2 \mathrm{ft}^{3}$ in volume. In addition, the electricity generating equipment to charge the capacitors (presumably solar cells for space-based concerns) would be of extensive size. Hence, the potential for significant advantage in volume (and weight) is indicated in the nuclear flashlamp over the xenon flashlamps.

Other factors, of course, would also need to be considered. Neutrons cannot be carried in wires, as electricity, so the useable fraction of the $10^{18}$ neutrons in the above example may be significantly less than one. Also, the nuclear flashlamp duration of approximately 150 microsec with a fast burst reactor would be somewhat longer than recommended [4] for an iodine laser amplifier ( $<100$ microsec). Nonetheless, this simple example does illustrate the potential for such technology in certain applications. 


\section{Chapter 6}

\section{CONCLUSIONS AND RECOMMENDATIONS}

\subsection{Summary and Conclusions}

These results represent the first demonstration of the atomic iodine laser stimulated with nuclear-induced fluorescence. This is also the first demonstration of a nuclear flashlamp pumped laser of any kind. This project was broken into twe parts, studying nuclear pumped fluorescence of $\mathrm{XeBr}$, and then using the resulting fluorescence to excite a laser. A summary of the fluorescence experiments, along with relevant conclusions, will first be given, followed by a discussion of the laser results.

6.1.1 XeBr Fluorescence. These fluorescence studies were the most comprehensive to date of $\mathrm{XeBr}$ under nuclear excitation. The only previous experimental examination of nuclear-excited $\mathrm{XeBr}$ [11] reported a spectrum and fluorescence efficiency for only one, non-optimum excimer mixture, yielding little $\mathrm{XeBr}$ fluorescence (mostly $\mathrm{Br}_{2}{ }^{*}$ ).

Fiuorescence spectra were taken of nuclear-excited $\mathrm{XeBr}$, both with ${ }^{10} \mathrm{~B}$ and ${ }^{3} \mathrm{He}$ pumping. These were the first to show that $\mathrm{XeBr}$ under nuclear excitation emits light similar to that seen in electrical excitation, with strong emission at $282 \mathrm{~nm}$, and weaker emissions at 320 and $415 \mathrm{~nm}$. This emission at $282 \mathrm{~nm}$ proved the spectral suitability of using nuclear-induced $\mathrm{XeBr}$ emission to pump the iodine laser.

All results given in the present work were new information on the excimer emission under nuclear pumping as a function of the pressure of constituent gases, with two different bromine donors $\left(\mathrm{Br}_{2}\right.$ and $\left.\mathrm{CHBr}_{3}\right)$. Pressure ranges covered in these parametric experiments were 0 to 5 torr of the bromine donor; 0 to 500 torr $\mathrm{Xe} ; 175$ to 775 torr Ar (as a buffer gas in ${ }^{10} \mathrm{~B}$ pumping); and 1.5 to $3.5 \mathrm{~atm}{ }^{3} \mathrm{He}$. Pressure dependance was found to be similar to that found in electrical pumping, though there was not sufficient information in the literature to make a detailed comparison. 
These results indicated a weak dependence on the gas constituent pressures over the ranges considered, based on $\mathrm{XeBr}$ " fluorescence. A rough optimum mixture of 0.5 torr $\mathrm{CHBr}_{3}$ and 200 torr $\mathrm{Xe}$ (in eithor $\mathrm{Ar}$ or ${ }^{3} \mathrm{He}$ ) was determined. $\mathrm{CHBr}$ was found to be a slightly better bromine donor than $\mathrm{Br}$, in terms of $\mathrm{XeBr}$ emission.

The fluorescence measurements were also used to determine the absolute light emission from the excimer during a pulse (in $\mathrm{J} / \mathrm{cm}^{3} \mathrm{~nm}$ ) This was important for determining whether the fluorescence was sufficient to drive an iodine laser, and for fluorescence efficiency calculations. This was done by measuring the fluoreacence output from a test cell with an intensity-calibrated optical multichannel aalyzer. Two fluorescence cells were utilized, one coated on the inside with $10_{\mathrm{B}}$, and the other, bare, used in ${ }^{3} \mathrm{He}$ pumping. Results showed the fluorescence output around $282 \mathrm{~nm}$ was found to be, for example, $0.0062 \mathrm{~J} / \mathrm{cm}^{3}$, averaged over the cell volume, under pumping with $2.4 \mathrm{~atm} .{ }^{3} \mathrm{He}$ in a 1-inch diameter tube. The exposure conditions were a $\$ 3.00$ pulse from the TRIGA reactor (used in all measurements reported here), of duration $12.5 \mathrm{msec}$ FWHM, with a peak flux of $3.1 \mathrm{e}^{15} \mathrm{n} / \mathrm{cm}^{2} \mathrm{sec}$. These results showed that sufficient fluorescence could be produced to pump a laser. The accuracy of this technique was estimated to be approximately \%30\%. To the knowledge of the author, these are the most in-depth studies of absolute fluorescence emission for any gas under nuclear pumping to date, and the first done in any detail for $\mathrm{XeBr}$.

In order to determine fluorescence efficiencies, an energy deposition technique utilizirg a measurement of the pressure rise in the fluorescence cell during a pulse was implemented. These measurements were done with a fast-response pressure transiducer attached to the cell. While this technique has been used in e-beam and fast burst reactor pumping, this was the first application of the technique to TRIGA reactor pulsing. The approach was found very well-suited to the moderately-long pulses generated by the TRIGA. Energy depositions during a \$3.00 TRIGA pulse were $0.14 \mathrm{~J} / \mathrm{cm}^{3}$ under ${ }^{10} \mathrm{~B}$ pumping of $1 \mathrm{~atm}$. gas in a 1-inch diameter cell; and $0.98 \mathrm{~J} / \mathrm{cm}^{3}$ in $3.5 \mathrm{~atm} .{ }^{3} \mathrm{He}$ in the same size cell. These results were very similar to that predicted from theoretical calculations. In addition to being necessary for fluorescence efficiency determinations, these measurements also helped develop 
this technique for TRIGA application, which will hopefully prove useful in future experiments at the facility.

Measurements were also taken on the temporal dependance of the $282 \mathrm{~nm} \mathrm{XeBr}$ emission during a pulse. They showed the fluorescence to be synchronous with the pulse, indicating no bromine donor depletion (something which can be a problem in excimer systems). The measurements also showed the ratio of fluorescence intensity to pumping power to be higher at the peak of the pulse than on the wings by a factor of approximately $50 \%$. This observation indicates that the fluorescence efficiency may increase with increasing pumping power, which would be importunt for scale-up considerations. (This dependance was not in agreement with modeling results discussed below.)

The combination of fluorescence intensity and energy deposition measurements allowed a determination of the fluorescence efficiency of the excimer under nuclear pumping (light out at $282 \mathrm{~nm}$ divided by energy deposited in the gas). The results showed an efficiency of approximately $1 \pm 0.5 \%$ under both ${ }^{10} \mathrm{~B}$ and ${ }^{3} \mathrm{He}$ pumping with a \$3.00 TRIGA pulse. This efficiency was significantly lower than expected. Several potential causes of this discrepancy were considered, but none were conclusive. These included the possibility of inadequate passivation of experimental cells against attack by bromine donors, inaccurate detector efficiency calibration, impurities in gases, or other experimental problems. Likewise, there may have been some deficiencies in the kinetic modeling detailed below, including an inaccurate modeling of the electron or thermal temperatures in the nuclear-induced plasmas, or an incomplete handling of some reaction or species.

A kinetic modeling effort was conducted to analyze the XeBr system under nuclcar pumping. This work yielded substantial additions to results of the only other previous modeling work on $\mathrm{XeBr}$ [7]. These additions included deriving a timedependant solution for the modeled species (vs steady-state), allowing for better understanding of the system dynamics. Especially important was the ability to understand bromine donor depletion during a pulse. 
The model was also modified to study three different pulsing time regimes, a TRIGA pulse, a fast burst pulse, and an e-beam pulse. The peak pumping powers in the regimes ranged over three orders of magnitude. Two important conctusions were drav from those studies, 1) that the peak fluorescence efficiency of $\mathrm{XeBr}$ is approximately $10 \%$, and is insensitive to pumping powers over this range (40 to $40,000 \mathrm{~W} / \mathrm{cm}^{3}$ ), and, 2) that similar dependencies on Xe pressure are found in the three regimes. To the knowledge of the author, this is the first modeling effort of any excimer to consider such low pumping powers, and to show that the fluorescence efficiency is insensitive to pumping power over such a wide range. (Kinetic models of excimers almost exclusively consider the $\mathrm{MW} / \mathrm{cm}^{3}$ ranie of pumping powers to study intense e-beam pulses. Few discuss the effect of pumping power on fluorescence efficiency.) This prediction that fluorescence efficiency should not be a function of pumping power has important ramifications for scale-up of these or similar experiments from the low power research environment of the TRIGA to a high power nuclear pumped laser system.

6.1.2 Laser Experiments. In order to assis in designing a cell for laser experiments, a ray tracing computer code was developed to help predict, for a given laser geometry, the fraction of light generated in a flashlamp volume which could be coupled into the lasant volume. Other workers had previously looked at this problem in some detail. Results from one geometry, however, are not easily applicable to another geometry (e.g. varying tube radii), so this code was written for this specific application. It added to published results by considering two new modifications to ceil design (the addition of fins to a concentric cylindrical geometry, and a roughened mirror surface). Both these modifications substantially improved fluorescence coupling. Results of calculations also allowed prediction of a $15 \%$ coupling efficiency for the laser cell design used in experiments.

Based on these calculations and experimental considerations, a laser cell was constructed, and laser experiments performed in the TRIGA reactor. These experiments were successful, with lasing achieved at 1.31 micron at a peak output power of approximately $20 \mathrm{~mW}$. Pumping powers at threshold were measured, and found to be approximately $0.4 \mathrm{~W} / \mathrm{cm}^{3}$, in reasonable agreemunt with published values of $0.06 \mathrm{~W} / \mathrm{cm}^{3}$ from non-nuclear pumped experiments. Measurements were 
also taken on the laser output dependance on lasant pressure, showing that lasing was possible between approximately 5 and 25 torr $\mathrm{i}-\mathrm{C}_{3} \mathrm{~F} 7 \mathrm{I}$. This dependency was in agreement with literature values. Attempts to achieve lasing in $\mathrm{CF}_{3} \mathrm{I}$ were unsuccessful, presumably due to $I_{2}$ impurities in the gas.

The most important conclusion from these results was that the laser performed as anticipated, indicating that conditions incident to nuclear flashlamp pumping had been correctly understood, allowing this proof-of-principle demonstration. Of particular note was the lack of effect of the high-intensity radiation field during a pulse on the laser optics and lasant. Previously reported studies had suggested this should not be a problem. These experiments found no evidence to the comtrary though a determination of the exact magnitude of these effects was not possible. Given this demonstration of understanding of the iodine laser under nuclear pumping conditions, considerations for use of the laser in higher power system can be approached with more confidence.

\subsection{Suggestions for Future Work}

There are several areas of research which deserve further investigation following this work. Specifically, more work is necessary to fully elucidate the operation of the $\mathrm{XeBr}$ under nuclear pumping, to help determine if the measured low florescence efficiencies can be improved upon. Special care should be taken to determine the effects of various system materials on cell passivation, and the presence and effects, if any, of impurities, either from bromine reactions or as present in constituent gases. Experiments could be carried out at a fast burst reactor facility to study the effects of higher power deposition. Similarly, a more detailed kinetics study, especially considering electron energy distribution in the plasma, may contribute to understanding of the system. Such investigations would be necessary to fully evaluate the potential of the system to large scale-up.

Other candidates for the flashlamp gas besides $\mathrm{XeBr}$ also deserve investigation. Of these, $\mathrm{KrF}$ is the most likely candidate. As indicated above, limited attempts in this work to measure emission from this excimer were unsuccessful; further efforts could, presumably, better study the suitability of this gas for this application. Such 
experiments would need to determine whether the above-mentioned failures were due to improper experimental conditions, or to a fundamental problem in the gas kinetics.

As scale-up of the laser is considered, accurate determinations of lasant degradation in the reactor radiation environment should be considered, as well as effects of the radiation on optics at the wavelengths of interest (in this case, $282 \mathrm{~nm}$ and 1.3 micron). Experiments to measure coupling efficiencies could also be considered.

On a more general level, further experimental studies of other nuclear flashiamp pumped systems and applications are warranted. Flashlamps for other photolytically pumped laser systems could be considered, as well as use of incoherent flashlamp radiation for other non-laser applications (e.g. photovoltaic electrical generation, chemicals processing, etc.) 


\section{APPENDIX A: OMA CALIBRATION}

As discussed in ssation 3.3, determination of absolute fluorescence efficiency of the $\mathrm{XeBr}$ was made by using an OMA system of calibrated sensitivity. Examples of this calibration procedure are discussed in this appendix. This will be done by first reviewing the calibration calculations, and then applying this calibration to a fluorescence measurement from the ${ }^{3} \mathrm{He}$ test cell.

Calibration was done by placing the $\mathrm{D}_{2}$ lamp of known spectral intensity $50 \mathrm{~cm}$ directly in front of the OMA. A scan was then taken for $90 \mathrm{msec}$, and the number of counts in each channel determined. With the aid of the computing ability of the OMA 1460/1456, this was done every half $\mathrm{nm}$ between the wavelengths of $250 \mathrm{~nm}$ and $400 \mathrm{~nm}$ to retrieve the corrected fluorescence spectrum shown in Figure 22. (Extrapolation was used to adjust the spectrum at wavelengths outside this band.)

For the example given in this appendix, and for most measurements reported in this report, however, calculations were done only around the $\mathrm{XeBr}$ peak at $282 \mathrm{~nm}$. The calibration procedure provided an OMA sensitivity at. $282 \mathrm{~nm}$ in $\mathrm{J} /\left(\mathrm{cm}^{2}\right.$-OMA count) which could then be applied to the total number of OMA counts registered under the $\mathrm{XeBr}$ peak in experimental measurements. A knowledge of distance between the OMA and the fiuorescence cell and the volume of the cell allowed conversion of the energy fluence $\left(J / \mathrm{cm}^{2}\right)$ to energy emitted in the cell gas $\left(J / \mathrm{cm}^{3}\right)$.

Considering the calculations in detail, the calibration was done with the $\mathrm{D}_{2}$ lamp 50 cm from the OMA, providing a light intensity at the OMA face of $2.1 \mathrm{e}-8 \mathrm{~W} / \mathrm{cm}^{2} \mathrm{~nm}$ for wavelengths near $282 \mathrm{~nm}$ (based on vendor calibration). Four neutral density filters were used in front of the OMA to reduce this intensity to acceptable levels for the OMA, these filters having optical densities at $282 \mathrm{~nm}$ of $0.924,0.393,0.258$, and 0.168 (total: 1.743 ). The number of counts detected in one channel at $282 \mathrm{~nm}$ was 2700 during the $90 \mathrm{msec}$ scan. The channel width was 1.872 channels/nm. The sensitivity is, then, calculated as: 


$$
\begin{aligned}
& \left(2.1 \mathrm{e}-8 \mathrm{~W} / \mathrm{cm}^{2} \mathrm{~nm}\right)(1.872 \text { channels } / \mathrm{nm})^{-1}\left(10^{-1.743}\right)(0.090 \mathrm{sec}) \\
& =2700 \text { counts }
\end{aligned}
$$

or

$$
1 \text { count }=6.8 \mathrm{e}-15 \mathrm{~J} / \mathrm{cm}^{2} \text {. }
$$

(OMA Sensitivity)

The fluorescence experiment to which this calibration will be applied in this example involved viewing ${ }^{3} \mathrm{He}$-induced fluorescence from a $114 \mathrm{~cm}^{3}$ cell at a distance of $8 \mathrm{~m}$ from the OMA. Two flat mirrors were used in the beam path to direct the light having reflectivities of approximately $82 \%$ at $282 \mathrm{~nm}$ (based on bench-top measurements). Two neutral density filters were used in front of the OMA having optical densities of 1.0 and 0.5 (total: 1.5), along with a piece of Pyrex glass having a transmission of $6 \%$ at $282 \mathrm{~nm}$. The total OMA counts registered during a pulse under the $282 \mathrm{~nm}$ peak (approximately $10 \mathrm{~nm}$ wide) was $\mathbf{2 2 0 0 0}$ counts. Given these numbers, the flinorescence energy from the cell is calculated as

$$
\begin{aligned}
& (22000 \text { counts })\left(6.8 \mathrm{e}-15 \mathrm{~J} / \mathrm{cm}^{2} \text { count }\right)\left(10^{1.5}\right)(.06)^{-1}(0.82)^{-2}\left(4 \mathrm{Pi}(800 \mathrm{~cm})^{2}\right)\left(114 \mathrm{~cm}^{3}\right)^{-1} \\
& =0.0082 \mathrm{~J} / \mathrm{cm}^{3} . \\
& \text { (Fluorescence Energy) }
\end{aligned}
$$

The average energy deposited in the cell gas during the pulse, as measured by the pressure transducer, was $0.7 \mathrm{~J} / \mathrm{cm}^{3}$. Hence, the fluorescence efficiency is

$$
\left(0.0082 \mathrm{~J} / \mathrm{cm}^{3}\right) /\left(0.7 \mathrm{~J} / \mathrm{cm}^{3}\right)=1 \%
$$

(Fluorescence Efficiency) 


\section{APPENDIX B: KINETICS CODE}

As discussed in chapter 4, a kinetics code was developed to consider the time dependant concentrations of species in a $\mathrm{XeBr}$ gas mixture under nuclear pumping conditions. Parts of that code written especially for this research will be listed in this appendix. The kinetic reactions used were extracted mainly from Wilson's modeling work reported in ref. 7, with some additions and changes. Species and reactions modeled by the code are listed in Table 3 in chapter 4 .

A numerical differential equation solver package, called LSODE, was used to solve the set of 17 non-linear differential equation representing time rate of change of species concentrations. It was only necessary to write a main program to control the several subroutines in the package, and a subroutine representing the differential equations. This main program and subroutine are listed below for a model of the TRIGA pulse. Similar routines were written to model a fast burst reactor pulse, and an e-beam pulse.

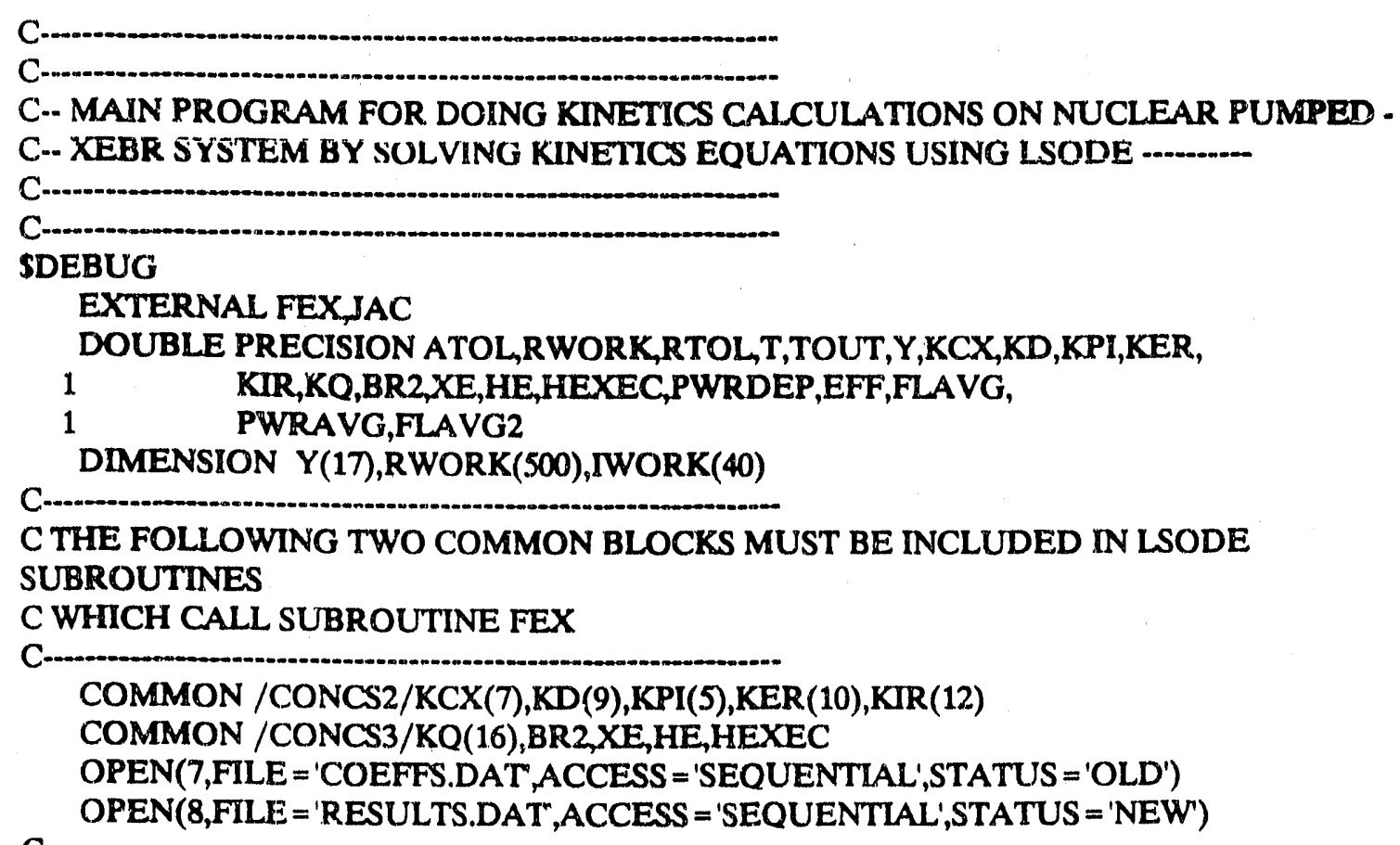


C READ IN RATE CONSTANTS STORED IN FILE 'COEFFS.DAT. RESULTS OF C CALCULATIONS WILL BE STORED IN FULE RESULTS.DAT.

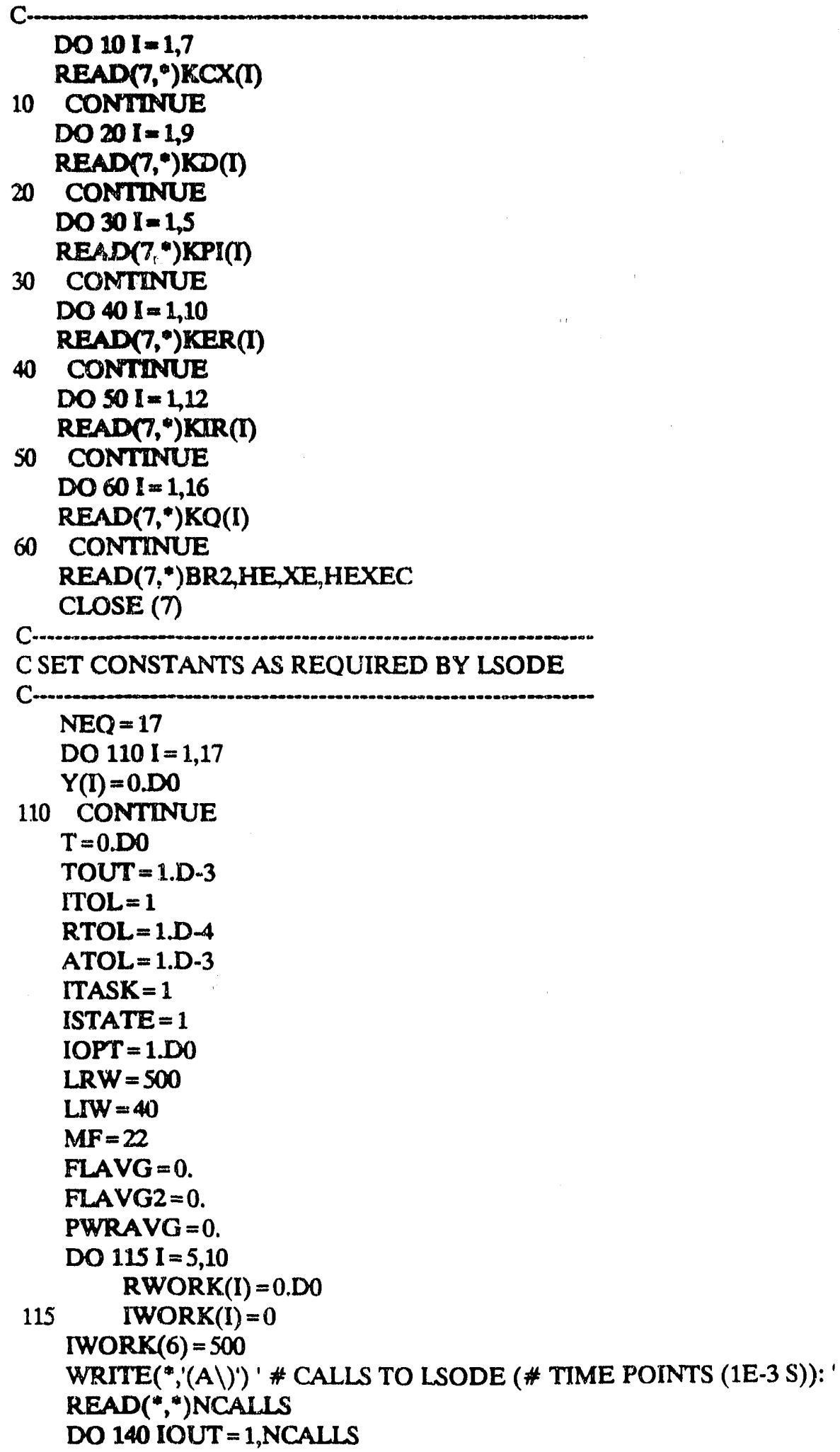




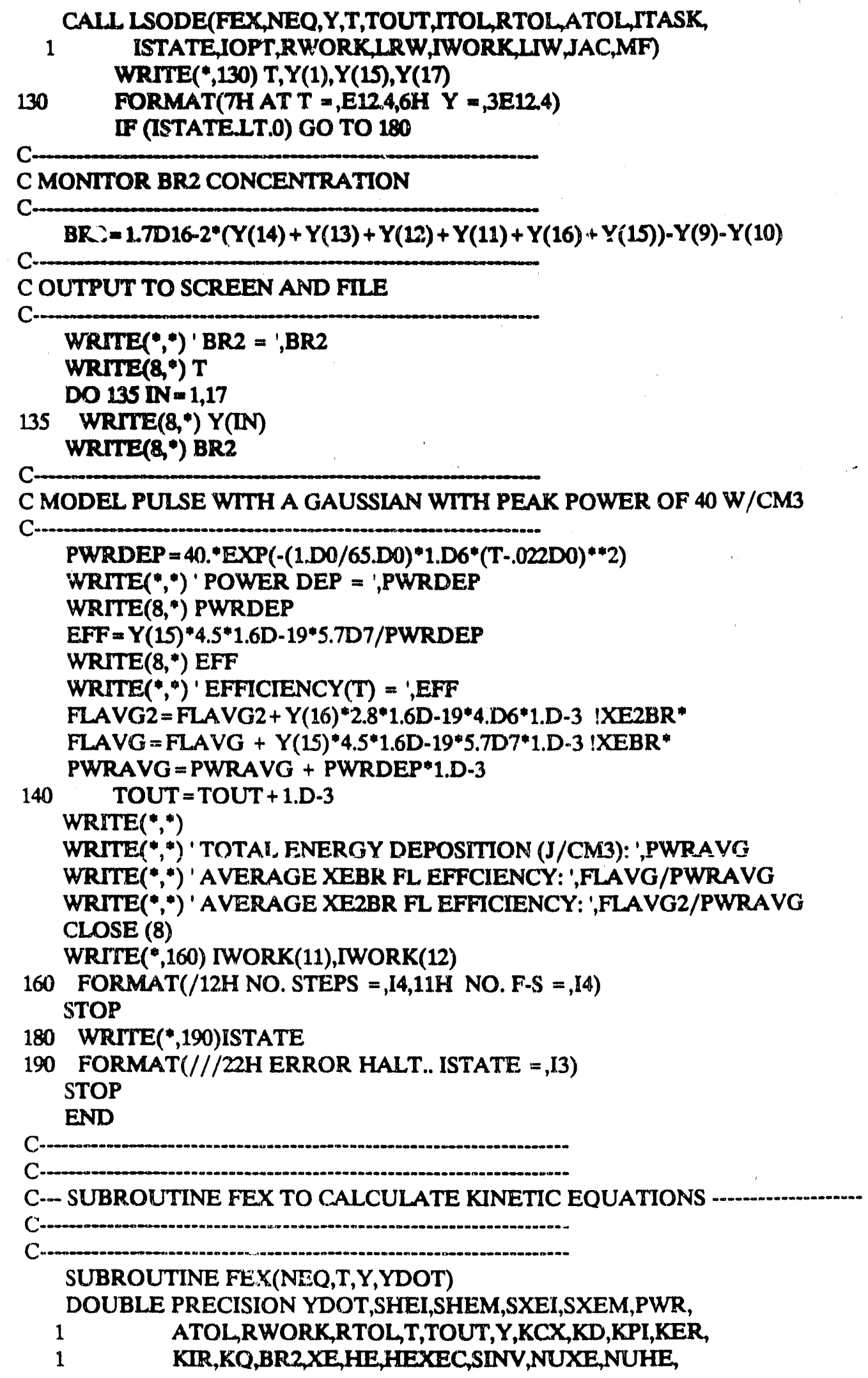




\section{SHEIO,SXEIO,SHEMO,SXEMO \\ DIMENSION Y(17), YDOT(17) \\ COMMON /CONCS2/KCX(7),KD(9),KPI(5), KER(10),KIR(12) \\ CDMMON /CONCS3/KQ(16),BR2,XE,HE,HEXXEC}

\section{$\mathrm{C}$ \\ C ION AND METASTABLE FORMATION RATIES ARE BASED ON PUMPING POWERS AS C SEEN IN A FAST BURST PULSE WITH PEAK, POWER DEPOSTION OF $1400 \mathrm{~W} / \mathrm{CM}$. C SO PUMPING POWER (PWR) IS CORRECTED BY THE RATIO OF TRIGA TO FAST C BURST PEAK PUMPING POWERS.}

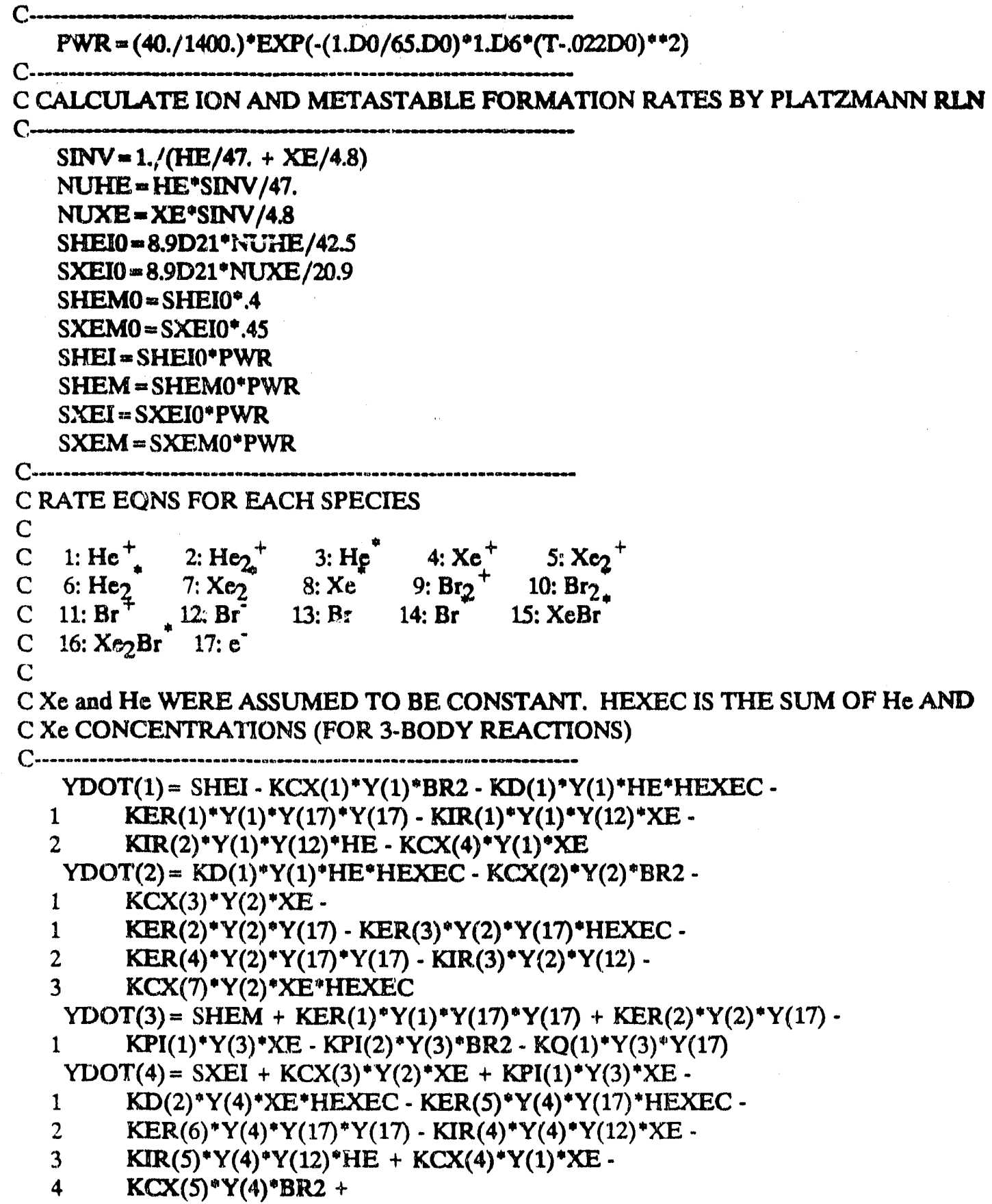




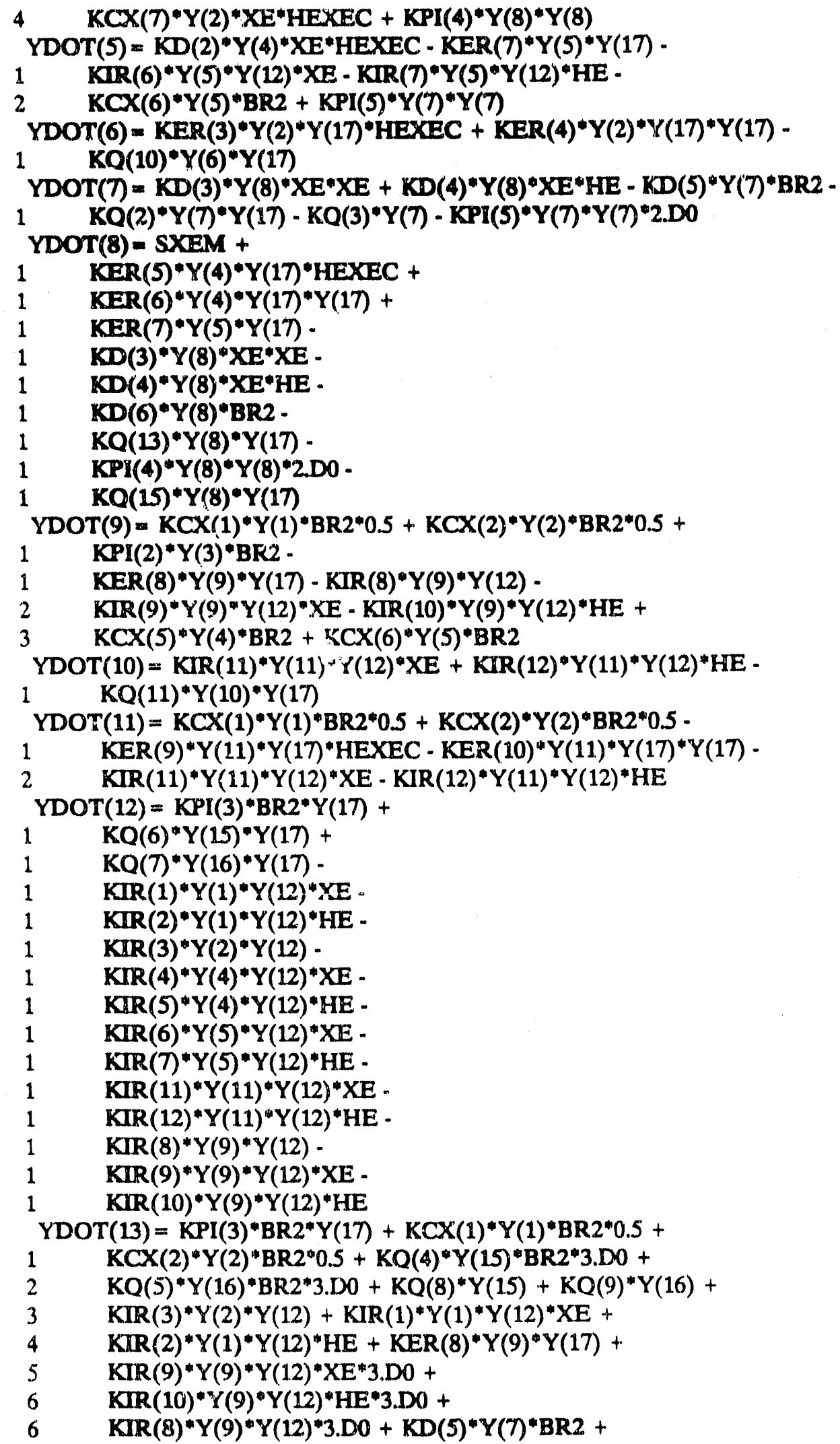




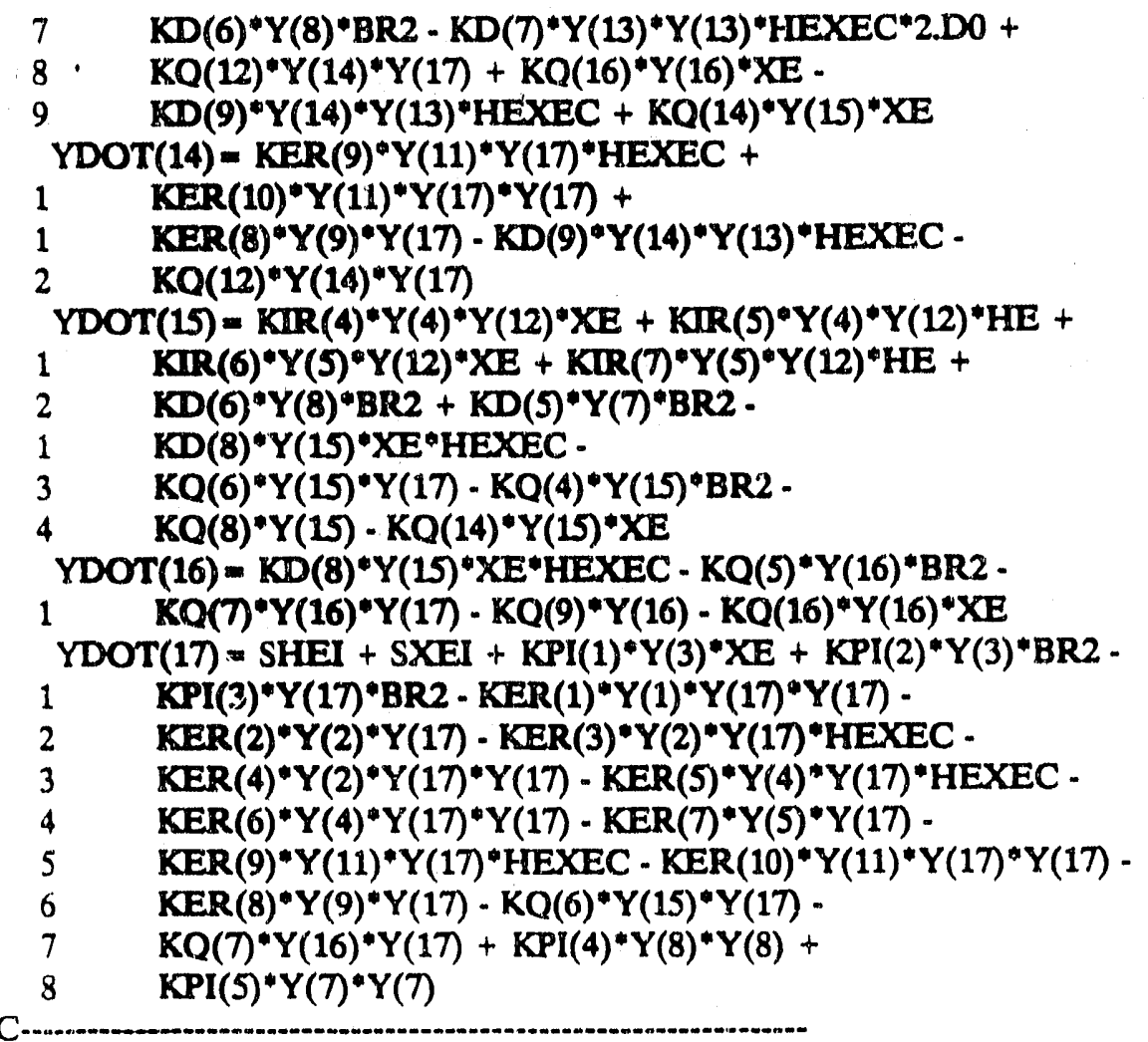

C CALCULATION CAN BE INTERRUPTED AT A SPECIFIC POINT IN TIME C TO LOOK AT THE VARIOUS CONTRIBUTIONS TO FORMATION AND LOSS C RATES FOR SEVERAL IMPORTANT SPECIES. TO DO THIS THE DESIRED C BREAK TIME (IN SECONDS) MUST BE SET IN THE NEXT LINE (PRESENTLY C. 22 SECONDS)

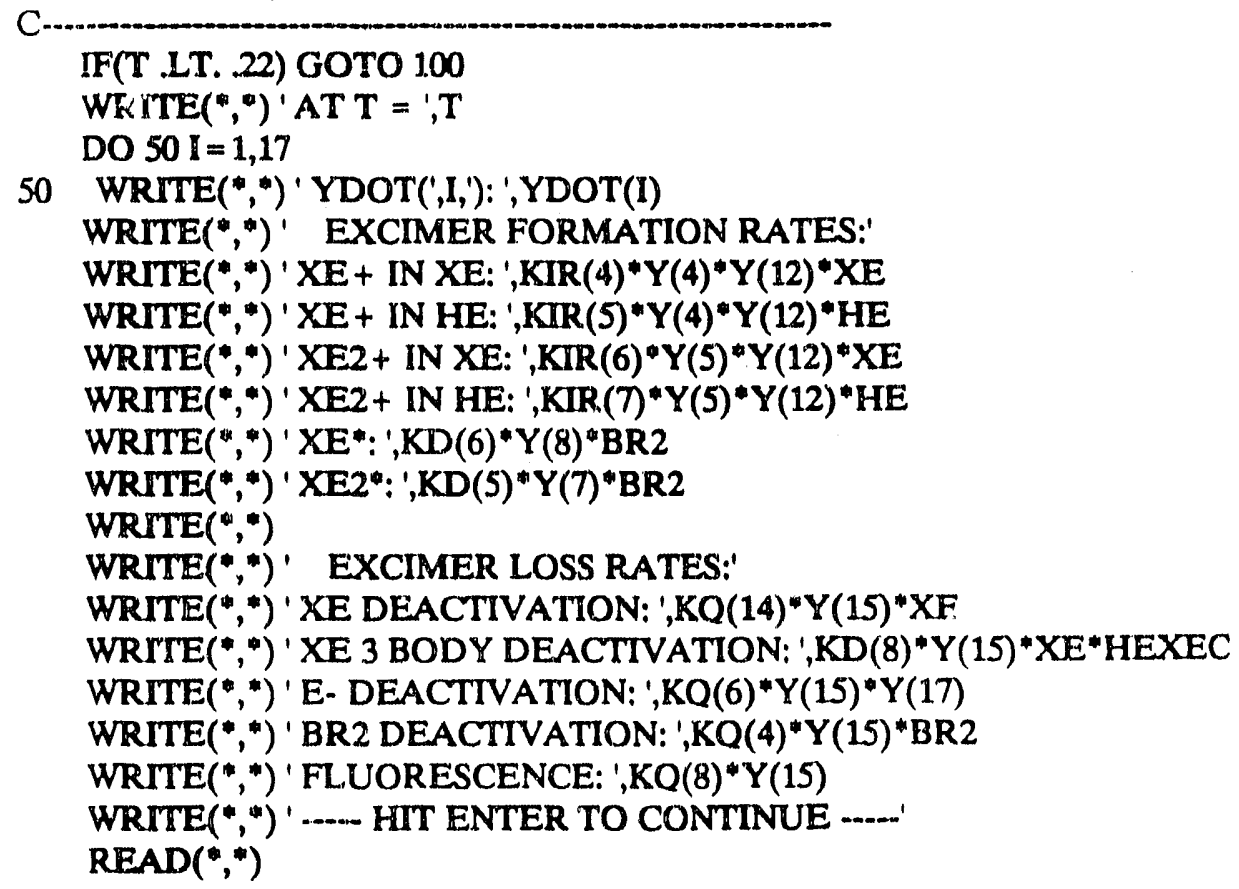




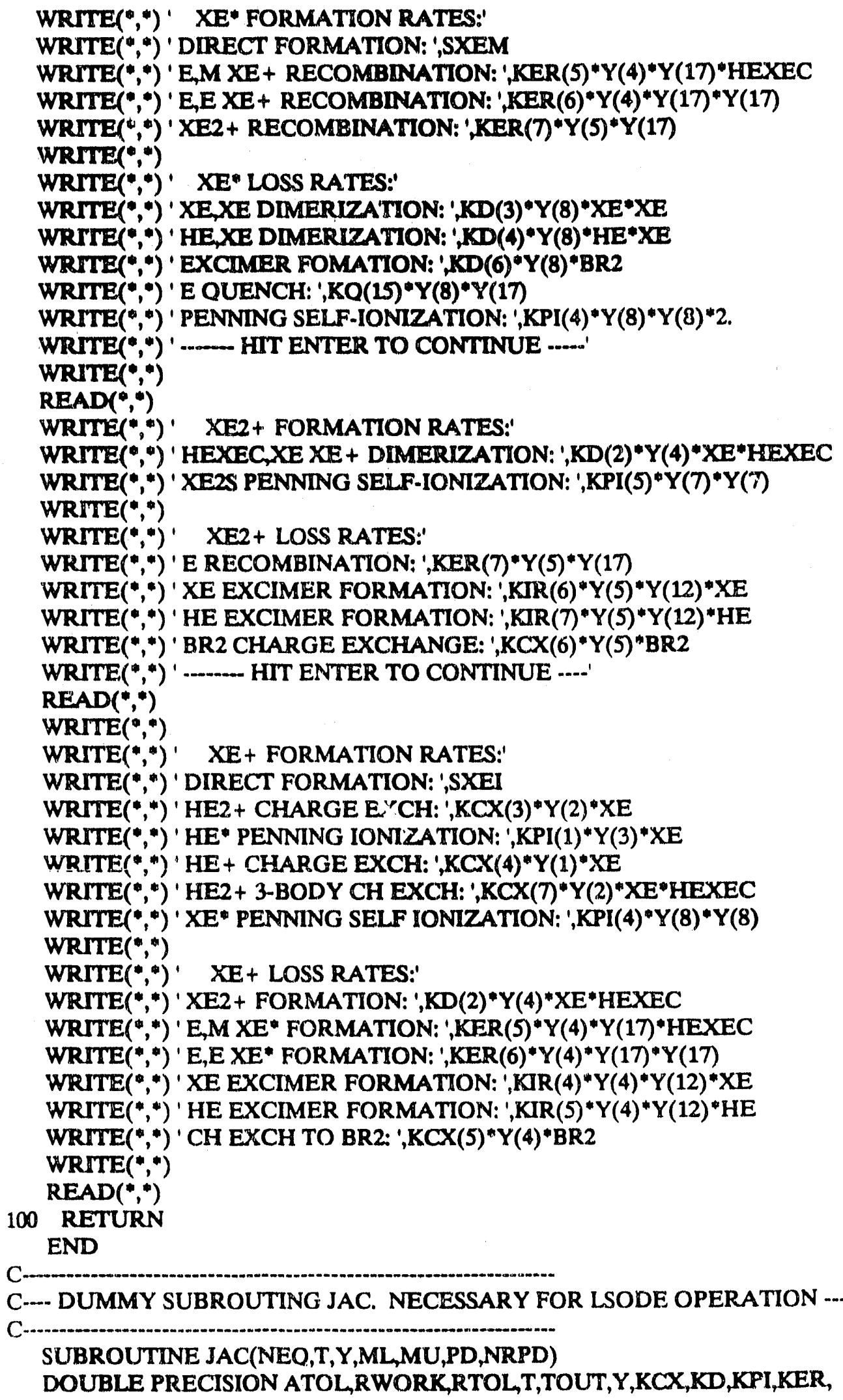


1

KIR,KQ,BR2,XE,HE,HEXEC

COMMON /CONCS2/KCX (7),KD(9),KPI(5),KER(10),KIR(12)

COMMON /CONCS3/KQ(16),BR2 XE,HE,HEXEC

RETURN

END 


\section{APPENDIX C: I/2 BUILDUP}

As noted in section 4.5, some consideration was given to an independent technique for determining fluorescence output, and, hence, fluorescence efficiency, for the $\mathrm{XeBr}$ flashlamp in the laser configuration. This technique is based on the fact that as the lasant gas $\left(\mathrm{C}_{3} \mathrm{~F}_{7} \mathrm{I}\right)$ is exposed to the UV light from the $\mathrm{XeBr}$ emission, one of the photolysis products is atomic iodine (the lasing species). This species can recombine with the organic radical to reform the parent molecule, or can recombine with itself to form $I_{2}$. A determination, then, of the $I_{2}$ buildup could theoretically be used to indicate the degree of photolysis in the lasant, and hence, the intensity and efficiency of the flashlamp.

$I_{2}$ is readily detectable because it has a high photoabsorption c1oss-section around $500 \mathrm{~nm}$ (extinction cuefficient of $550 \mathrm{l} / \mathrm{mol}-\mathrm{cm}$ [75]). The laser ceil used in these experiments had a length of $65 \mathrm{~cm}$, meaning that light from a lamp shone down the tube bore would show a $10 \%$ drop in intensity with partial pressure of 0.02 torr $I_{2}$ in the cell.

Experiments were done to look for this $I_{2}$ absorption by placing an incandescent light on the laser behind the rear mirror. The laser mirrors were transmissive in the visible, so this light was detectable outside the throughport. The light in a band around $500 \mathrm{~nm}$ was monitored by the OMA before and after several pulses. (A few other bands outside the $I_{2}$ absorption band were also monitored to correct for lamp output changes.) No transmission change was seen to within $10 \%$ after 5 pulses. Unfortunately, no better accuracy was obtainable because of transient radiation induced changes in the transmission of the rear mirror ( $1 / 2$ inch Pyrex substrate).

These measurements did give a upper bound on the amount of $I_{2}$ in the cell $(0.02$ torr). Originally, it was thought this could be compared against literature data on the formation rate of $I_{2}$ for given number of photolysis events to determine the amount of flashlamp light absorbed by the lasant. Combination of this number with the coupling efficiency in the laser would have yielded the amount of fluorescence generated in the flashlamp, and, hence, the fluorescence efficiency. 
Unfortunately, literature data proved inconclusive on the amount of $I_{2}$ formed per photolysis event. Because $I_{2}$ is a strong quencher for the laser, several experimental and theoretical studies have been done looking at $I_{2}$ buildup [76-79]. None of thess, however, are sufficiently applicable to these results for use due to the complicated behavior of diluents often used in the laser (not used in experiments in this work), and $I_{2}$ formation from pyrolysis with high-intensity pumping.

Without data on the $I_{2}$ formation rate it was impossible to infer the flashlamp intensity, so these experiments were inconclusive. Additional experiments, or utilization of a kinetics model of the iodine laser, would llow determination of this rate and use of this technique. There was not sufficient time in this project for either of these efforts. 


\section{APPENDIX D: RAY TRACING CODE}

As discussed in section 5.1, a ray tracing computer code was written to calc late the efficiency with which photons born in the flashlamp portion of the laser would be absorbed by the lasant for various geometries. A listing of the code is given bclow. It was written with Microsoft FORTRAN 5.0, using graphics subroutines enclosed with that software package.

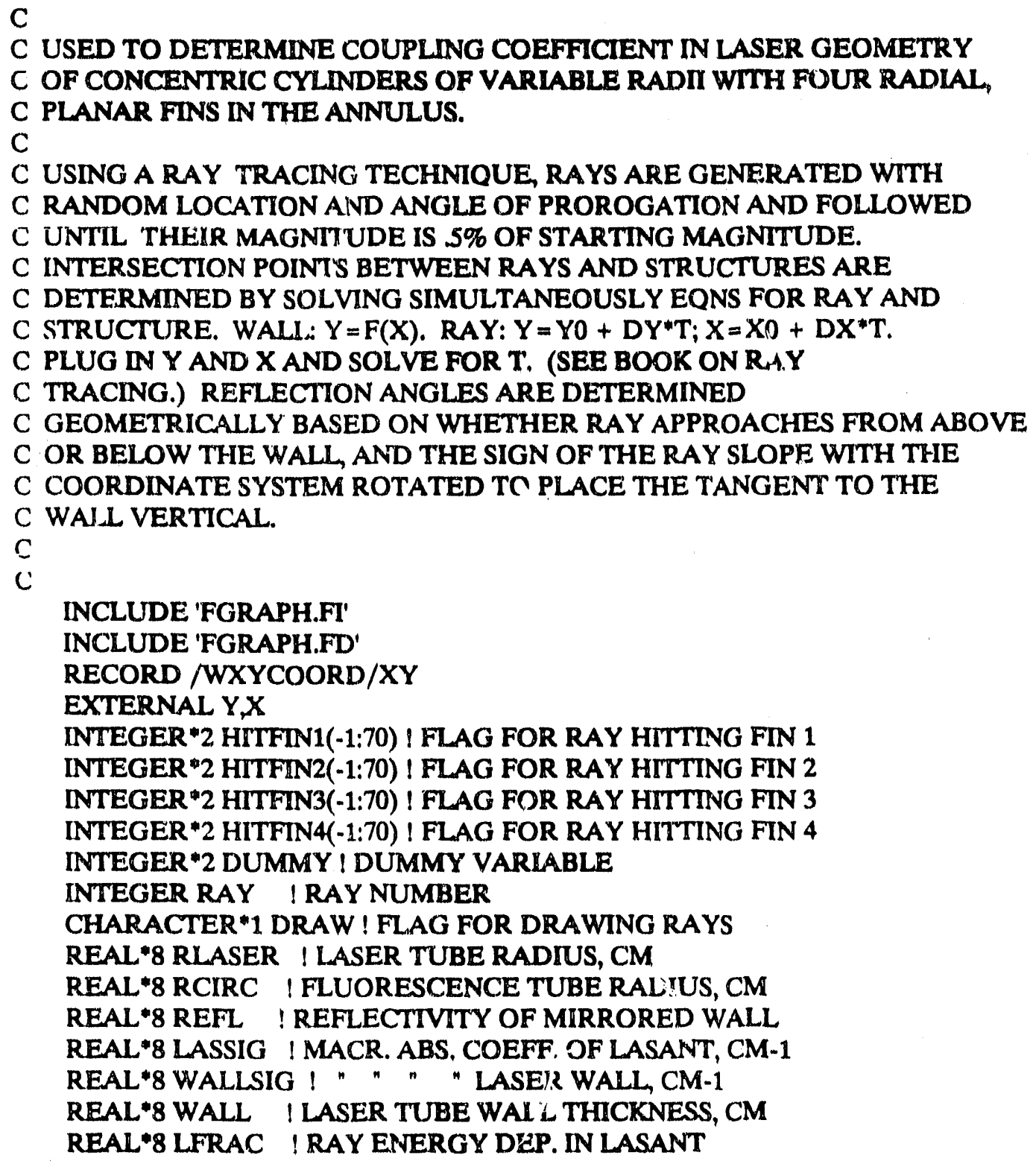




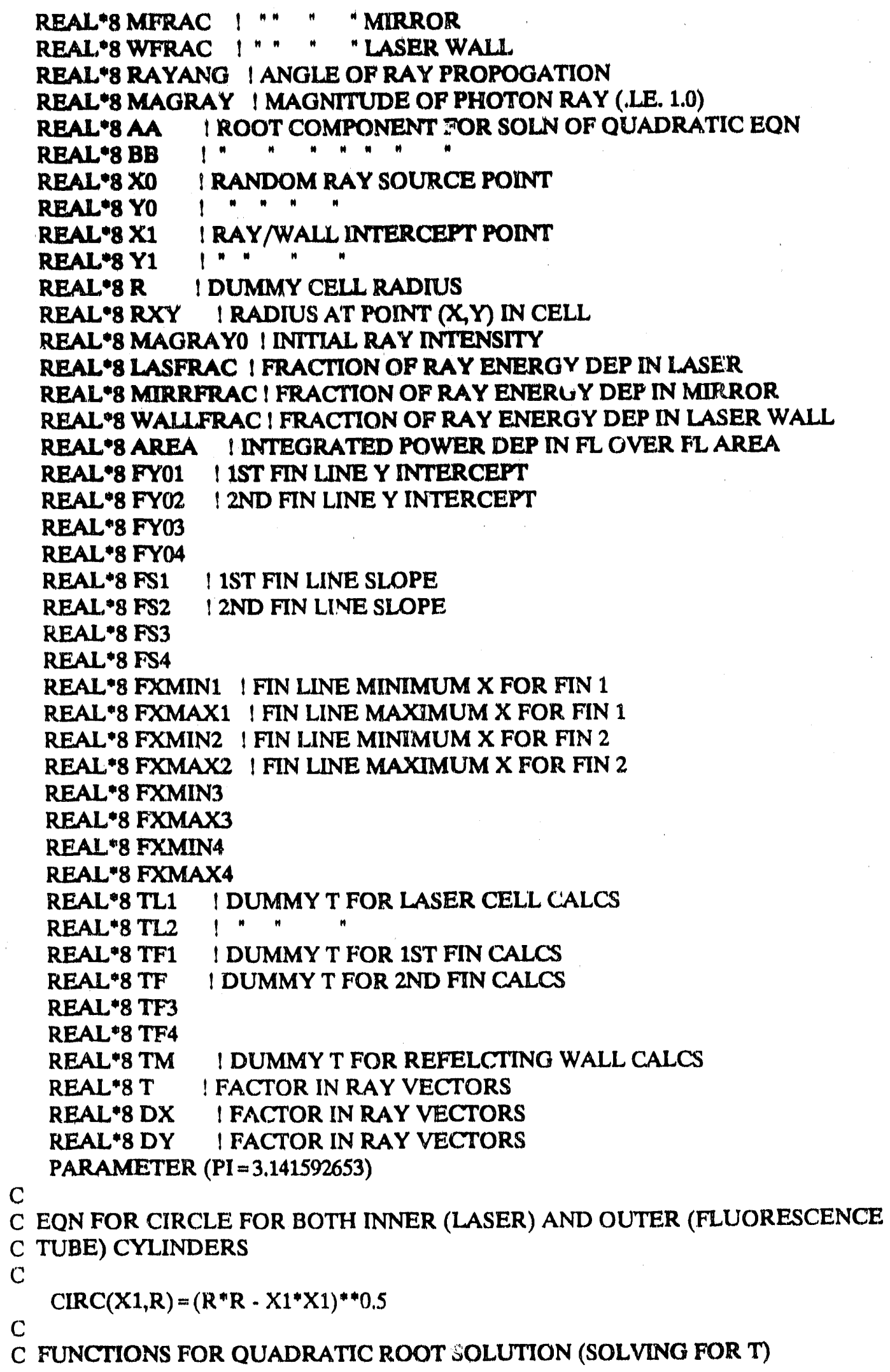


C

$A(D X, D Y)=D X * D X+D Y * D Y$

$B(X 0, D X, Y O, D Y)=2 * X D^{*} D X+2 * Y 0^{*} D Y$

C

$C(X 0, Y 0, \mathbb{R})=X 0^{*} X 0+Y O^{*} Y 0-R^{*} R$

C EQN FOR INTERCEPTS OF 1ST QUADRANT FIN WTTH T'" 'O CIRCLES

$\mathrm{C}$

FCONT1(FS1,FY01,R) $=\left(\left(\right.\right.$ FS1 ${ }^{\circ} F 1^{*}$ FY01 ${ }^{*} F Y 01-($ FS1"FS1 + 1.)

$+\quad$ "(FY01"FY01-R*R))**0.5 - FS1"FY01)/

$\mathrm{C}$

$+\quad(($ FS1'FS1 + 1.))

C EQN FOR INTERCEPTS OF ATH QUADRANT FIN WITH TWO CIRCLES

C

FCINT2(FS2,FYO2,R) $=\left(-10^{*}\left(\mathrm{FS}^{*} \mathrm{FS2}^{*} \mathrm{FY} 02{ }^{*} \mathrm{FY} 02-\left(\mathrm{FS} 2{ }^{*} \mathrm{FSZ}+1.\right)\right.\right.$

$+\quad$ "(FYO2"FYO2-R*R!)"*0,S - FS2*FYO2)/

C

$+\quad(($ FS2*FS2 + 1.) $)$

C INITLALIZE CONSTANTS

$\mathrm{C}$

IVRITE(“,40)' LASER TUBE RADIUS (cm): '

40 FORMAT $(/, A 31,1)$

READ("*)RLASER

WRITE(*,40)' FLUORESCENT TUBE RADIUS (cm): '

READ(",")RCIRC

WRITE $(*, 40)^{\prime}$ NUMBER OF RAYS:

READ(*,")NRRAY

WRITE(',44)' NLAXIMUM NUMBER OF BOUNCES PER RAY: '

44 FORMAT $(/:-136, \backslash)$

READ (*";LNUM

WTIE( ",40)' 1ST QUADRANT FIN LINE SLOPE: '

READ(*,")FS1

WRITE $(*, 44) '$ 1ST QUADRANT FIN LINE Y-INTERCEPT: '

READ(*,")FY01

WRITE(*,40)' 3RD QUADRANT FIN LINE SLOPE: '

READ(*,*)FS2

WRTTE $(*, 44)^{\prime}$ 3RD QUADRANT FIN LINE Y-INI ERCEPT: '

READ(*,")FY02

WRTT ? 40)' 4TH QUADRANT FIN LINE SLOPE: '

READ(",")FS3

WRITE $(\$, 44)^{\prime}$ 4TH QUADRANT FIN LINE Y-INTERCEPT: '

READ (*,")FY03

WRITE $(*, 40)$ ' 2ND QUADRANT FIN LINE SLOPE: '

READ(*,")FS4

WRITE(*,44)' 2ND QUADRANT FIN LINE Y-INTERCEPT: '

READ(*,*)FY04

WRITE $(*, 40)$ ' DRAW RAYS? (Y/N): '

45

READ(*,45)DRAW

FORMAT(A1)

REFL $=0.82$

LASSIG $=1.5$

WALLSIG $=0.08$ 


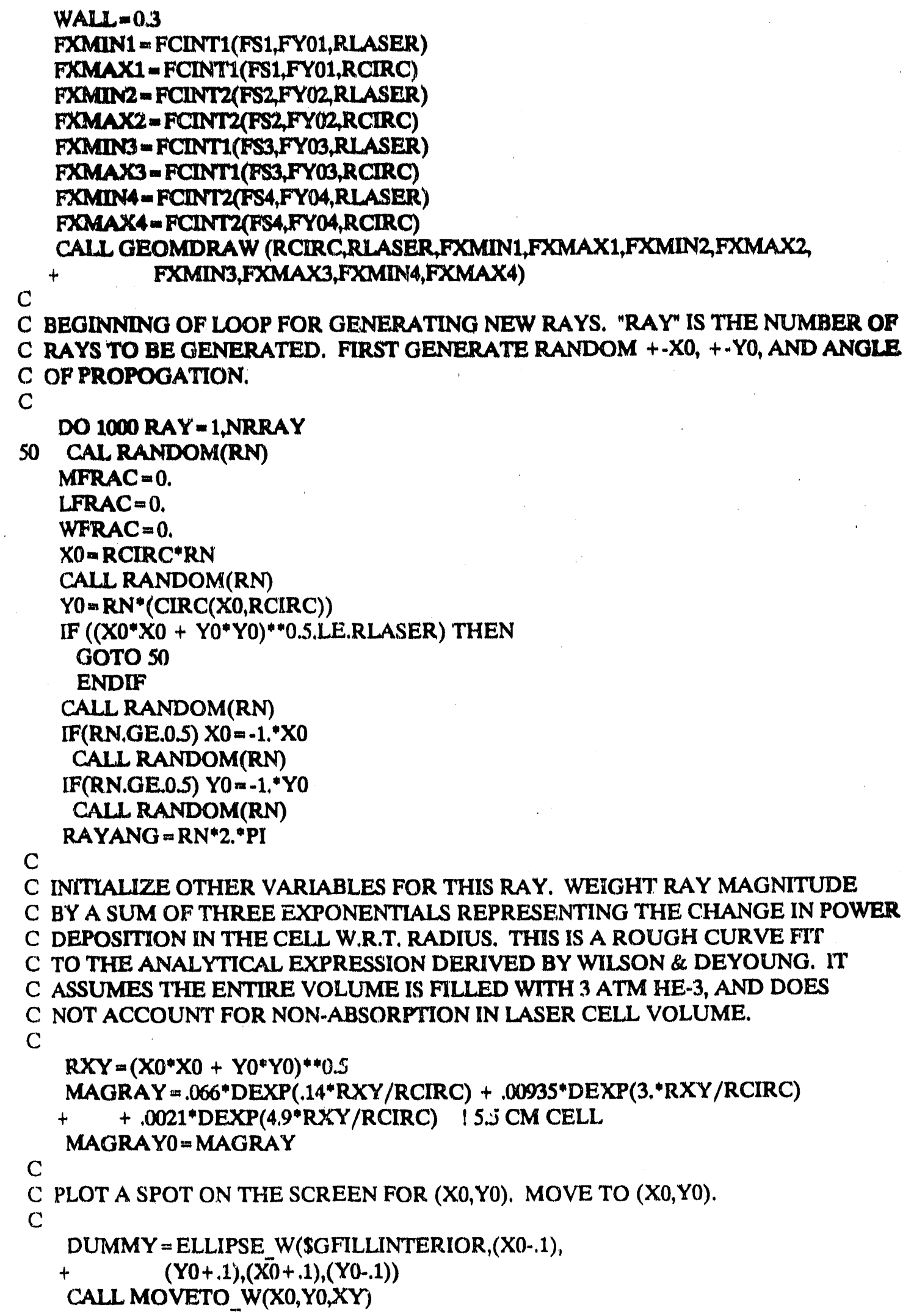




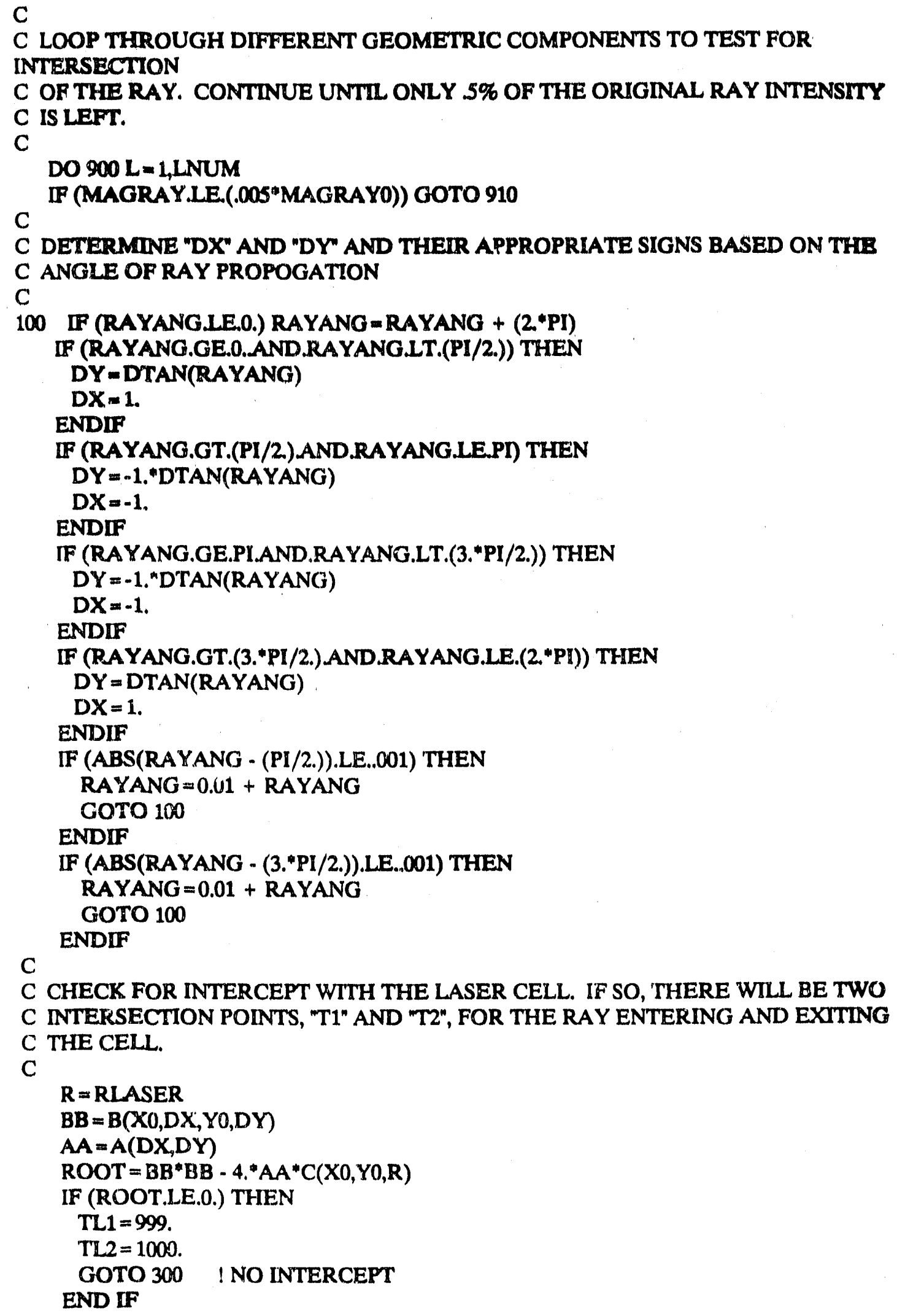




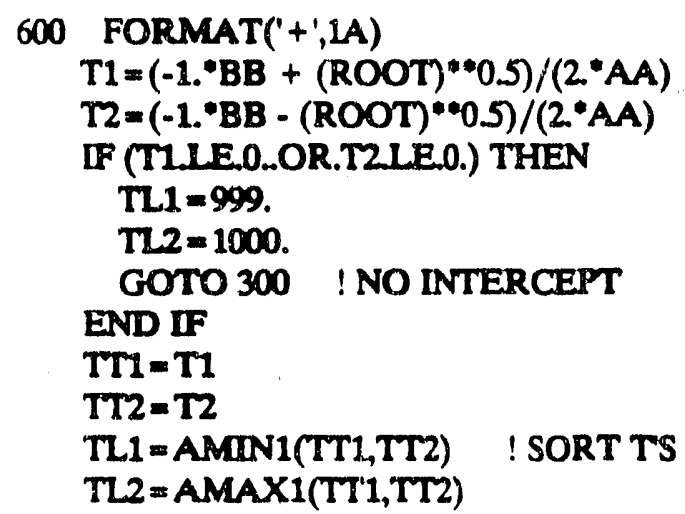




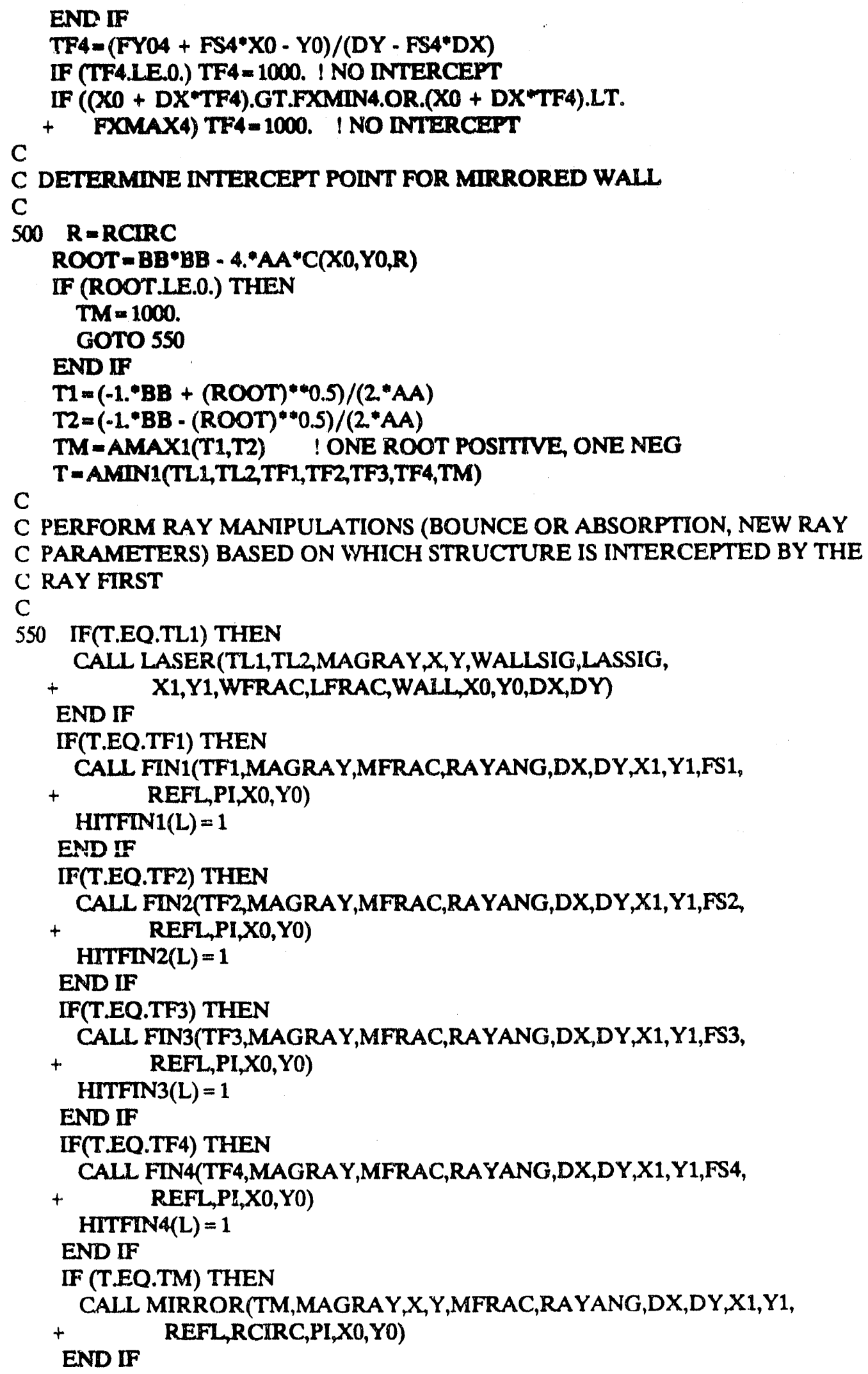




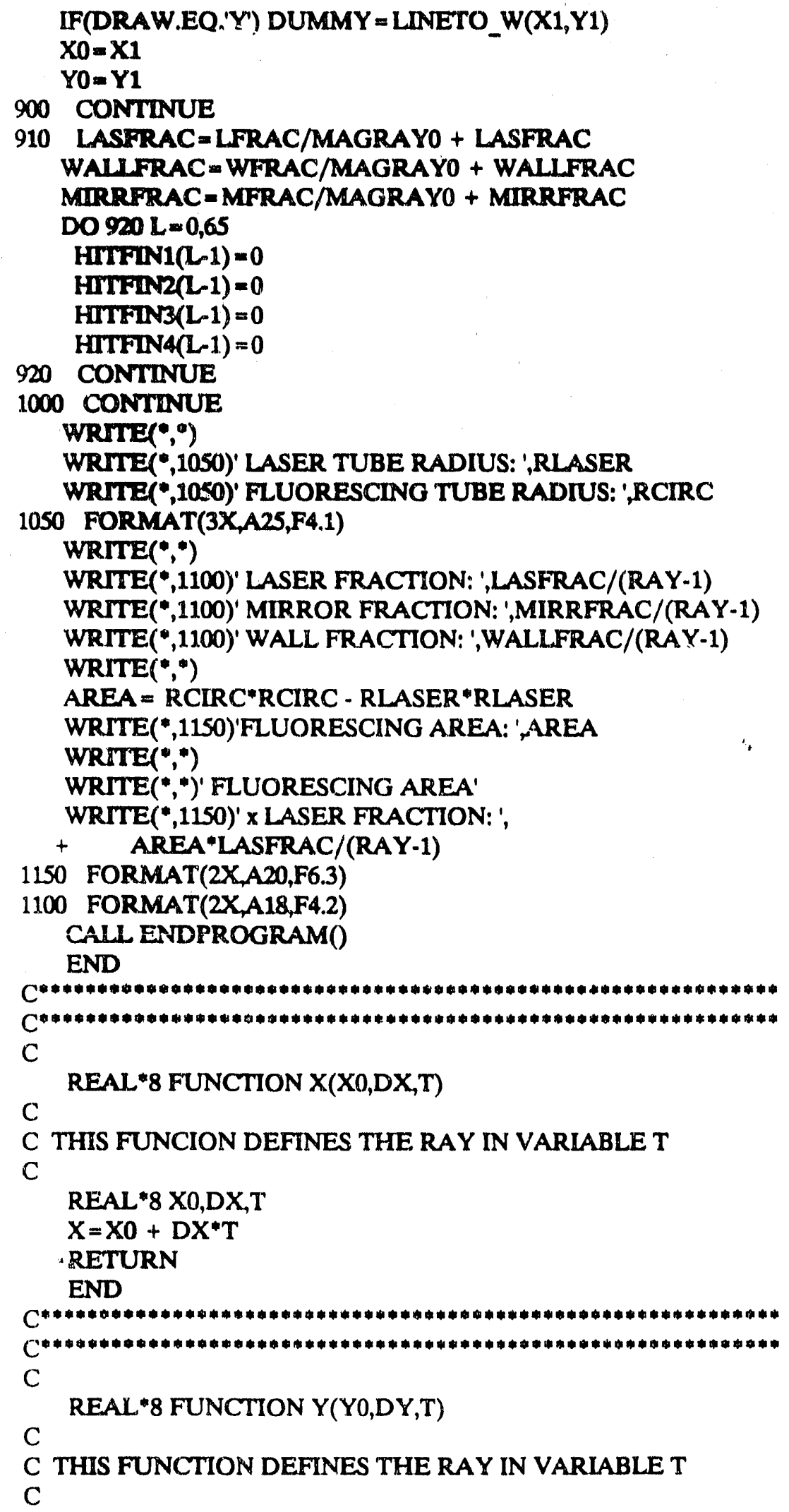




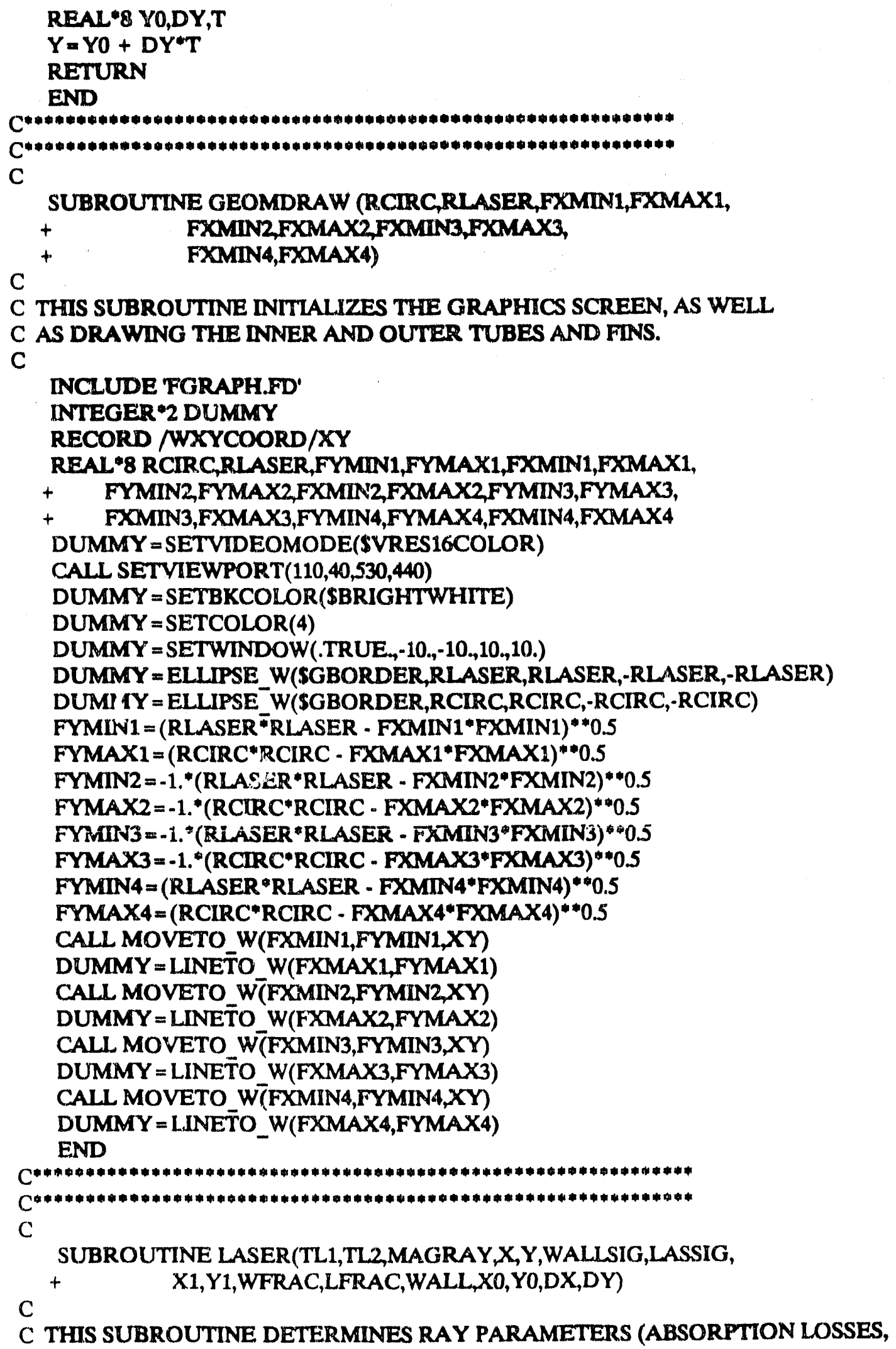


C NEW RAY ORIGIN POINT, I.E. EXIT OF CELL, NEW RAY MAGNITUDE) IF C THE RAY HUTS THE CELL.

C

REAL"8 WEXP,LEXP,TL1,TL2,MAGRAY,X,Y,WALLSIG,LASSIG,

$+\quad \mathrm{X1}, \mathrm{Y1}$,WFRAC,LFRAC,LASPATH,WALl,X0,Y0,DX,DY

LASPATH $=\left((X(X 0, D X, T L 1)-X(X 0, D X, T L 2))^{* * 2}+\right.$

$\left.+\quad(Y(Y 0, D Y, T L 1)-Y(Y 0, D Y, T L 2))^{* * 2}\right) * 0.5$

WEXP $=D E X P(-1$. "WALL*WALISIG)

LEXP $=$ DEXP(-1."LASSIG"LASPATH)

WFRAC $=$ MAGRAY ${ }^{\circ}$ (1. - WEXP) + WFRAC

MAGRAY = MAGRAY"WEXP I LOSS TO WALL

LFRAC = MAGRAY* $(1 .-$ LEXP) + LFRAC

MAGRAY = MAGRAY"LEXP ILOSS TO LASANT

WFRAC = MAGRAY* (1. - WEXP) + WFRAC

MAGRAY = MAGRAY"WEXP ILOSS TO WALL

$\mathrm{X} 1=\mathrm{XO}+\mathrm{DX} \mathrm{XTL}^{*}$

$Y 1=Y O+D Y^{*} T L 2$

RETURN

END

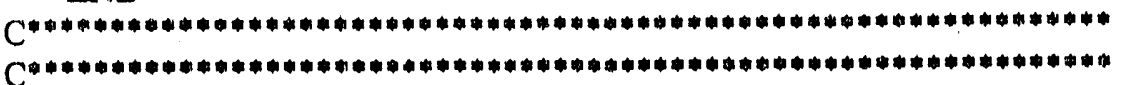

C

SUBROUTINE FIN1(TF1,MAGRAY,MFRAC,RAYANG,DX,DY,X1, $+\quad$ Y1,FS1,REFL,PI,X0,Y0)

$\mathrm{C}$

C THIS SUBROUTINE CALCULATES RAY PARAMETERS IF THE RAY HITS THE FIN

$\mathrm{C}$

REAL*8 TF1,MAGRAY,MFRAC,RAYANG,DX,DY,X1,Y1,TANG,

$+\quad X S, Y S, Y I N T, Y T A N G S, A L P H A, B E T A, T A N G P, R E F L, F S 1, X 0, Y 0$

$\mathrm{X} 1=\mathrm{X} 0+\mathrm{DX} \mathrm{X}^{\mathrm{T}} \mathrm{TF} 1$

$\mathrm{Y} 1=\mathrm{Y} 0+\mathrm{DY}$ TF1

$\mathrm{C}$

TANG $=$ FS1

C DETERMINE WHETHER RAY APPROACHES TANGENT FROM ABOVE OR BELOW TO

C INDICATE REFLECTION ANGLE. IT SHOUILD BE NOTED THE GEOMETRY IN THESE

C RELATIONS AND SIMILAR EQUATIONS IN SUBROUTINES BELOW IS BOILED DOWN,

C AND NOT OBVIOUS ON INSPECTION. THATS WHY WE GO TO THE TROUBLE TO

C SHOW THE BOUNCING RAY ON THE SCREEN, TO KNOW WE'RE DOING IT RIGHT!

$\mathrm{C}$

$\mathrm{XS}=\mathrm{X} 0+\mathrm{DX} * \mathrm{TF} 1 * .99$

$\mathrm{YS}=\mathrm{Y0}+\mathrm{DY}{ }^{*} \mathrm{TF} 1^{*} .99$

YINT $=$ Y1 $-($ TANG*X1)

YTANGS $=$ YINT + $\left(\right.$ TANG $\left.{ }^{*} X S\right)$

ALPHIA = DATAN(TANG)

BETA $=$ DATAN $(($ TANG $-($ DY $/$ DX $)) /($ TANG* $(D Y / D X)+1))$

TANGP $=((1 /$ TANG $)+($ DY $/ D X)) /(1-(D Y / D X) /$ TANG $)$

IF (YTANGS.LE.YS.AND.TANGP.LE.0.) RAYANG = ALPHA + BETA + PI

IF (YTANGS.LE.YS.AND.TANGP.GE.0.) RAYANG = ALPHA + BETA

IF (YTANGS.GE.YS.AND.TANGP.LE.0.) RAYANG = ALPHA + BETA

IF (YTANGS.GE.YS.AND.TANGP.GE.0.) RAYANG = ALPHA + BETA + PI

MFRAC $=$ MAGRAY* 1 . - REFL) + MFRAC 


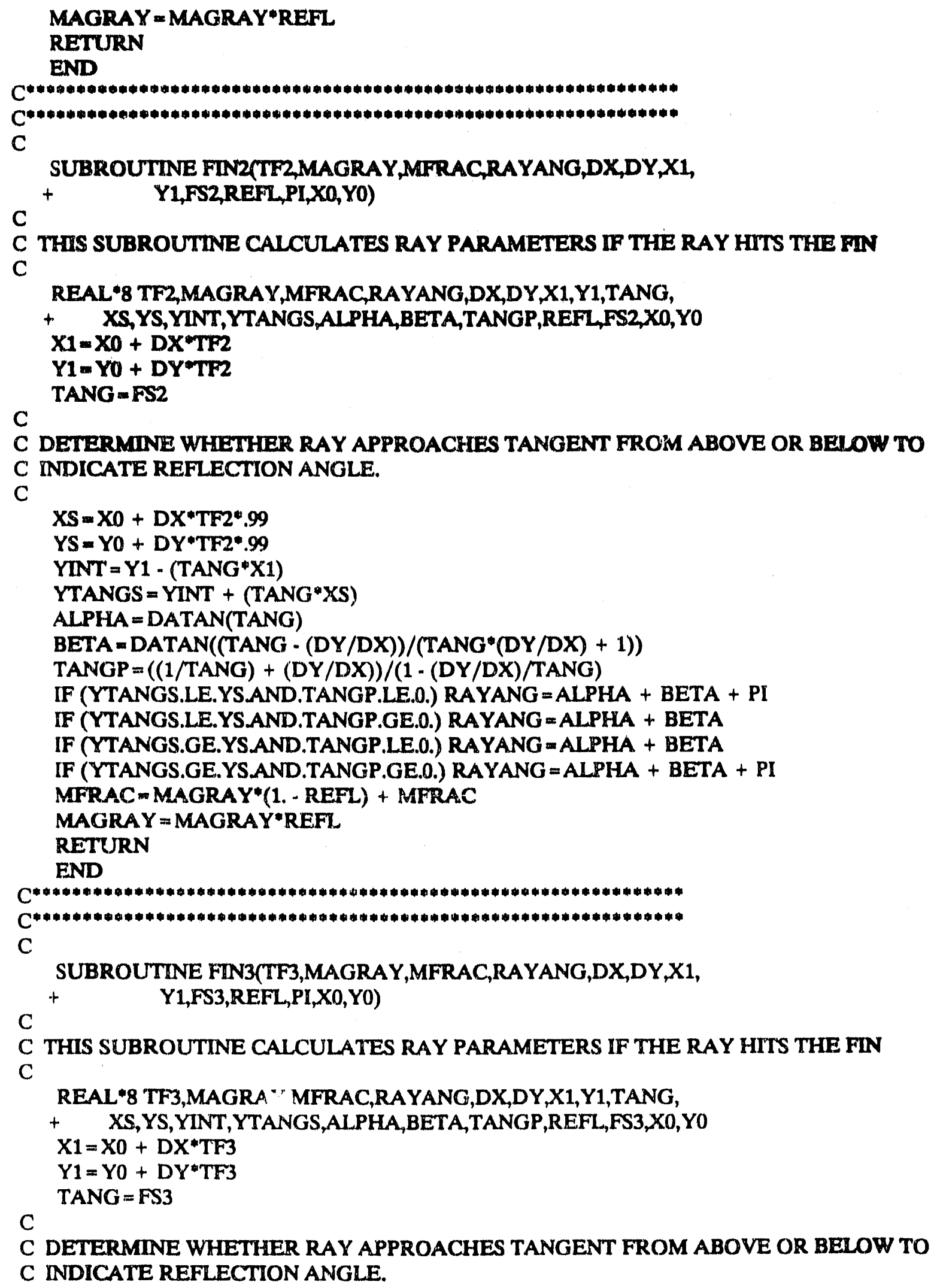




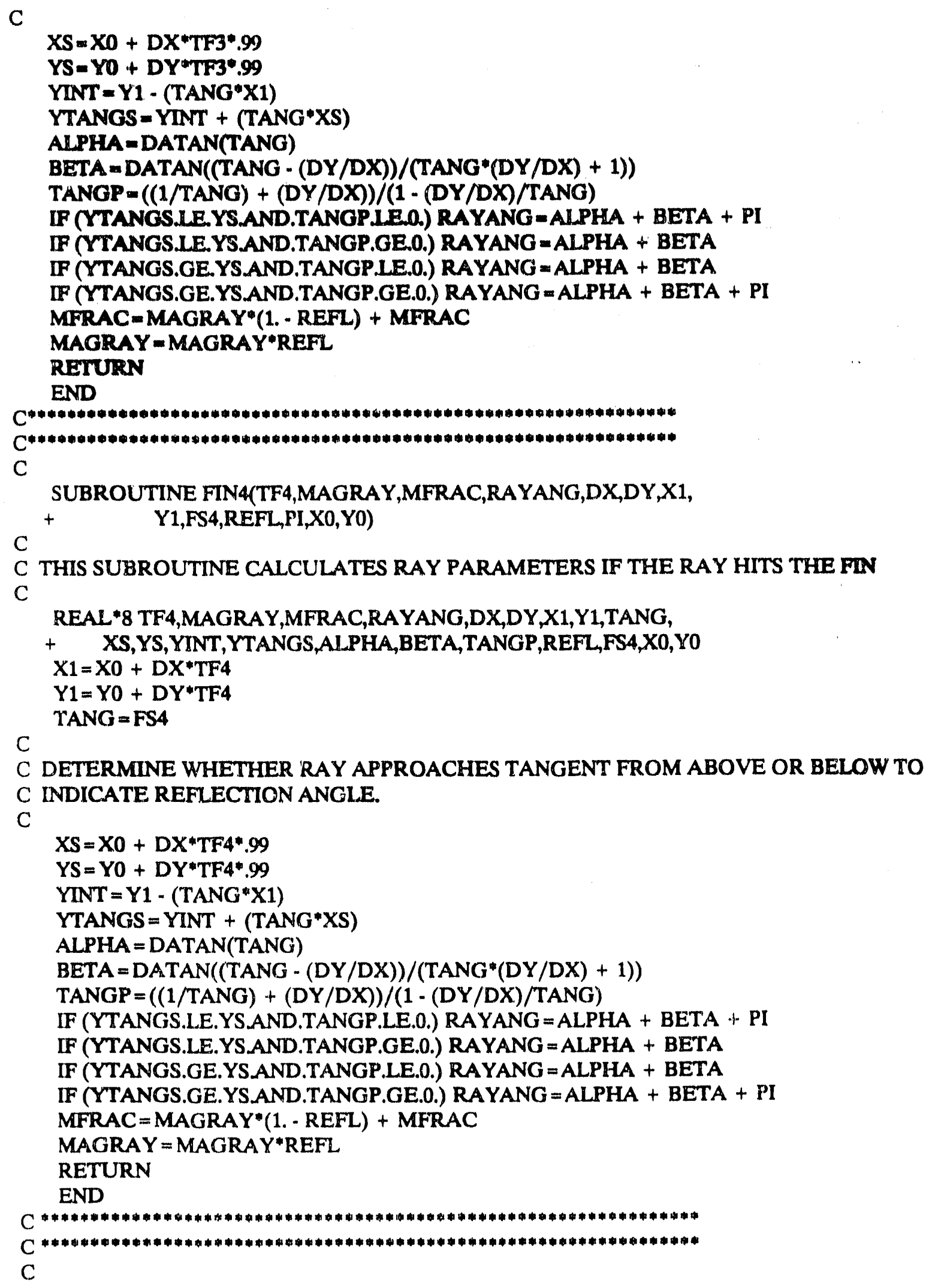

C DETERMINE WHETHER RAY APPROACHES TANGENT FROM ABOVE OR BELOW TO C INDICATE REFLECTION ANGLE. 


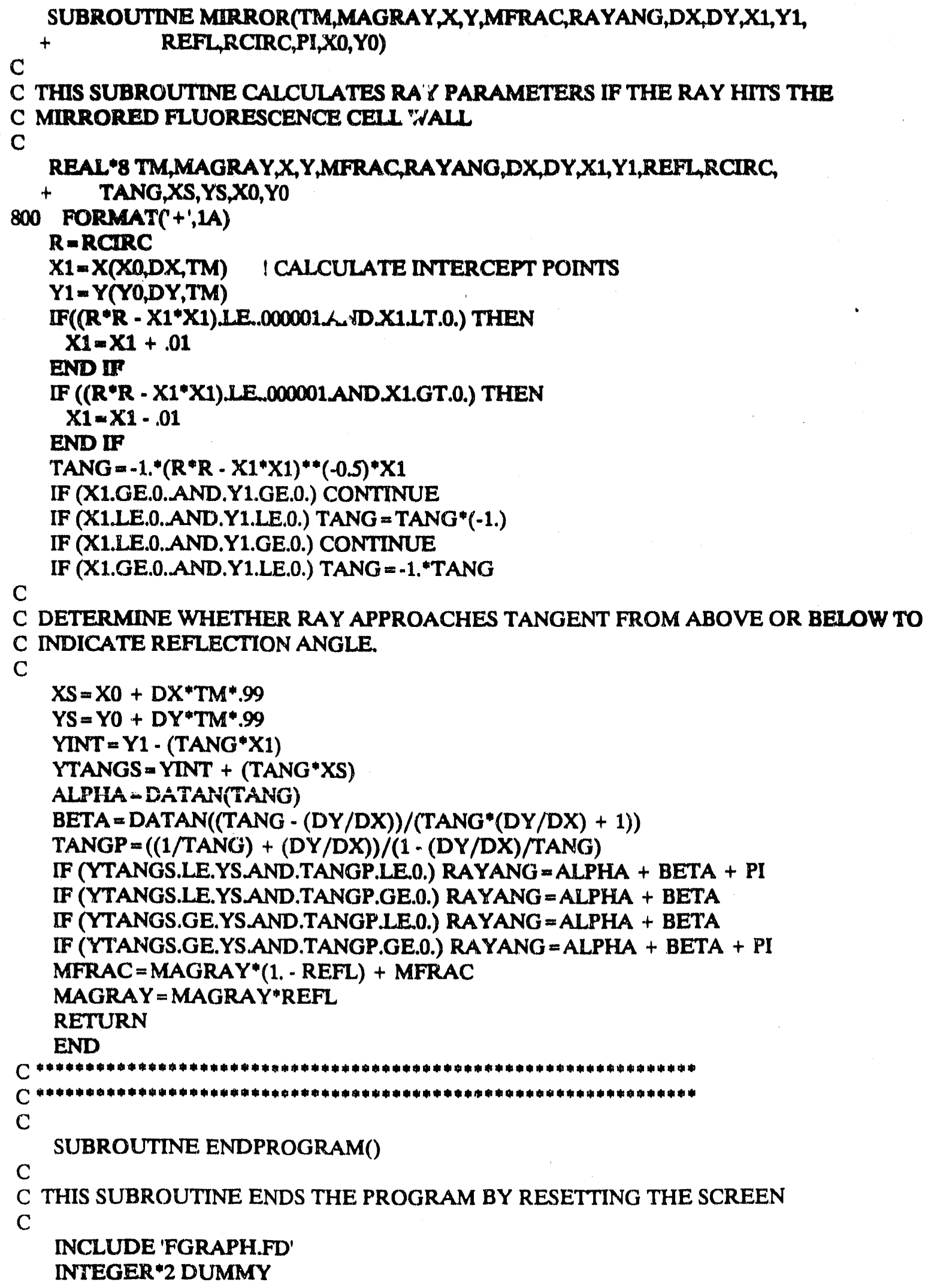


125

READ(*,")

DUMMY = SETVIDEOMODE(\$DEFAULTMIODE)

END 


\section{APPENDIX E: ERROR ANALYSIS}

As discussed in section 3.7.3, the estimated uncertainty in measured fluorescence efficiercies was $\pm 50 \%$. This relatively large value is derived from uncertainties in three factors which contribute to the determination of the fluorescence effidencys including the pressure transducer measurements, OMA calibrations, and alignment and viewing of the fluorescence cells by the OMA during experiments. Each of these will be discussed below.

The uncertainty associated with the energy deposition measurements, as determined from the pressure transducer, is principally due to the lack of ability to compane the results of those measurements against known references for energy deposition (i.e., calibrate the technique). Some comparison was made in the text of theoretical energy deposition calculations for similar, but not identical gas mixtures as used in both ${ }^{10} \mathrm{~B}$ and ${ }^{3} \mathrm{He}$ experiments. In both cases, the experimental results were in good agreement with theoretical predictions, but an exact comparison was not possible due to the difference in gas mixtures considered. The fact that the agreement was good is supporting evidence that the pressure transducer was approximately accurate in its determination of energy deposition. Only an estimate can be suggested for the uncertainty, here assumed to be $\pm 20 \%$.

Uncertainty in the OMA calibration included uncertainty in the stability of the $\mathrm{D}_{2}$ lamp used in calibrations, and the uncertainty associated with extrapolating a sensitivity determined with a light source at $50 \mathrm{~cm}$ to a light source at $8 \mathrm{~m}$ (e.g. possible focussing in the OMA spectrograph). As indicated in the text, the uncertainty of the lamp stability was $\pm 10 \%$, and the measured uncertainty in the distance extrapolation was $\pm 15 \%$. Based on these two numbers, an overall uncertainty of the OMA calibration of $\pm 15 \%$ is assumed.

Finally, there is uncertainty due to the difficulty of aligning the fluorescence cells in experiments such that the entire cell volumes could be viewed by the OMA's. Unfortunately, there is no straightforward way to estimate the uncertainty 
associated with this technique. An educated guess, based on the care takenidaring alignmemts, is $\pm 15 \%$.

Taken together, these uncertainties add to give a total uncertainty of $\pm 50 \%$ for fluorescence efficiency determinations. As indicated above, however this uncertainty cannot be considered well-detarmined.

It should be noted that the scatter in the experimental fluorescence data (presumably due to diagnostic equipment problems) is not includeds the:

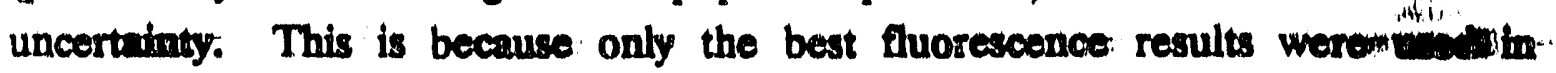
determining the reported efficiencies. It was assumed enough measurementwere taken that, even with the scatter, these best results represcnted the matmmin achievable in the system. 


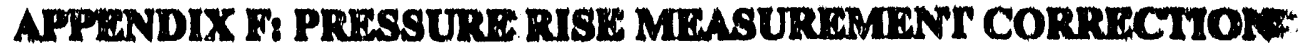

As discussed in section 3.4.1, the pressure rise as measured by the pressure: transducer in fluorescence experiments had to be corrected for the coolingof the cell gas before the pulse was complete. To subtract out this cooling theneren: input to the gas was modeled as a Gaussian-shaped source term, and an exponential-shaped cooling loss term. The Gaussian input was determined as a relatively good fit to a reactor pulse (within approximately 5\%). The losa vermavi. modeled as a single exponential, determined by curve-fitting the dectingith the pressure in the cell after the pulse. For the pulse shown in Figure 5, this deeng had: a time constant of $0.009 \mathrm{sec}$. The equation, then, was set up as follows:

$$
\frac{d E}{d t}=D_{0} e^{-(1 / B)\left(t-t_{w}\right)^{2}} \cdot \lambda E
$$

Using the integrating factor $\mathrm{e}^{-\lambda t}$ gives

$$
E(t)=e^{-\lambda t} D_{0} \int_{0}^{t} e^{-(1 / B)\left(r-t_{w}\right)^{2}+\lambda} d r
$$

For the $\$ 3.00$ pulse modeled, $B=65, t_{w}=12 \mathrm{msec}$, and $\lambda=(0.009 \mathrm{sec})^{-1}$. Only the coefficient $D_{0}$, representing the magnitude of the energy input term, is unknown.

The integral was integrated several times with guesses for $D_{0}$ until a good visual fit to the experimental data was found with $D_{0}=0.9$. The equation was then reintegrated using this value, but with $\lambda=0$ (no cooling), and a corrected pressure rise of 12.6 psi was calculated. 


\section{REMERTUNCES}

1) Kasper, J.V.V., Pimentel, G.C., "Atomic Iodine Photodissociation Laser", Appl.Phys.Lett. 5, 231 (1964).

2) Kasper, J.V.V., Parker, J.H., Pimentel, G.C. "Iodine-Atom Laser Emission in Alkyl Iodide Photolysis",J.Chem.Phys. 43, 1827 (1965).

3) Kirillov, G.A., Murugov, V.M., Punin, V.T., Shemyakin, V.I., "High power laser system ISKRA V", Las.Part.Beams 8(4), 827 (1990).

4) Brederiow, G., Fill, E, Witte, KJ., The Hirin-Power Jodine Lacer, (Spri Verlag, Berlin, 1983)

5) Hohla, K. Kompa, K.L., Handbook of Chemical Lasers, ch. 12, Gross, R.W.St and Bott, J.F. ed., (Wiley \& Sons, 1976).

6) Wilson, J.W., Shapiro, A., "Nuclear-induced excimer fluorescence", J.Appl.Phys. 51(5), 2387 (1980).

7) Wilson, J.W., "Nuclear-induced XeBr" photoytic laser model", Appl.Phys.Lett. 37(8), 695 (1980).

8) Prelas, M.A., Boody, F.P., Miley, G.H., Kunze, J., "Nuclear Driven Flashlamps", Las.Part.Beams 6(1), 25 (1988).

9) Swingle, J.C., Turner, C.E., Jr., Murray, J.R., George, E.V., Krupke, W.F., "Photolytic pumping of the iodine laser by $\mathrm{XeBr}$ ", Appl.Phys. Lett. 28(7), 387 (1976).

10) Miley, G.H., McArthur, D., DeYoung, R., Prelas, M., "Fission Reactor Pumped Lasers: History and Propects", Proc. Fifty Years with Nuclear Fission, ANS Conference (Gaithersburg, MD, 26-28 Apr. 1989).

11) Schneider, R.T., Hohl, F., "Nuclear Pumped Lasers" in Advances in Nuclear Science and Technology, Vol, 16 (Plenum, New York, 1984), 123.

12) Alford, W.J., Hays, G.N., "Measured laser parameters for reactor-pumped $\mathrm{He} / \mathrm{Ar} / \mathrm{Xe}$ and Ar/Xe lasers", J.Appl.Phys. 65, 3760 (1989).

13) Alford, W.J., Hays, G.N., Ohwa, M., Kushner, M.J., "The effects of He addition on the performance of the fission-fragment excited $\mathrm{Ar} / \mathrm{Xe}$ atomic xenon laser", J.Appl.Phys. 69(4), 1843 (1991).

14) Prelas, M.A., "Nuclear-Driven Solid-State Lasers", Proc. Intl. Conf. on Lasers '89 (Soc. of Opt. and Quantum Elec, New Orleans, STS Press, 1990), pg. 263. 
15) Prelas, M.A., Kunze, J.F., "Direct Nuclear Energy Conversion Cycles Uringy Excimer Fluorescence", Proc 6th Intl. Conf. on Emerging Nuclear Eneng Systems (ICENES 91) (Monteray, CA, 16-21 June 1991) (to be publisho.)

16) Hutchinson, M.H.R., "Excimers and Excimer Lasers", Appl.Phys. 21, 95 (19.0.t.".

17) Rhodes, Ch.K., ed., Excimer Lasers. (Springer-Verlag, Berlin, 1979).

18) Basov, N.G., Danilychev, V.A., Popov, Yu.M., Khodkevich, D.D. "Lasear Operating in the Vacuum Region of the Spectrum by Excitation of Liquid Xenon with an Electron Beam", JETP Lett. 12, 329 (1970).

19) Cartwright, D.C, Figueira, J.F, McDonald, T.E., Harris, D.B., Hauer, Aw "Status of Intertial Confinement Fusion Research at Los Alamos Natio.

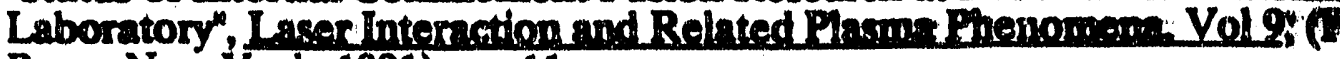
Press, New York, 1991), Pg. 11.

20) Verdeyen, J.T., Lacer Electronics, 2nd Ed (Prentice-Hall, New Jersey, 1989)

21) Wilson, W.L., Williams, R.A., Sauergrey, R., Tittel, F.K., Marowsky,G., "Formation and quenching kinetics of electron beam excited $\mathrm{Xe}_{2} \mathrm{Br}$ ", J.Chem.Phys 77(4), 1830 (1982).

22) Bychkov, Yu.I., Mesyats, G.A., Tarasenko, V.F., "The-short-electron-beamexcited excimer lasers", Proc.Intl. Conf. on Lasers '80, (Society of Optical and. Quantum Elec., McLean, VA, 1981), pg. 682.

23) Moratz, T.J., Kushner, M.J., "A Comparison of Electron Beam and Heavy Ion Excitation of Rare Gas-Halogen Gas Mixtures", Proc. IEEE Conf. on Plasma Sci. (Seattle, WA, May 1988), pg. 93.

24) Gerber, T., Luthy, W., Burkhard, P., "High Efficiency KrF Excimer Flashlamp", Opt.Comm. 35(2), 242 (1980).

25) Kumagai, H., Obara, M., "New high-efficiency quasi-continuous operation of a $\mathrm{KrF}(\mathrm{B}-\mathrm{X})$ excimer lamp excited by micrnwave discharge", Appl.Phys.Lett. 54(26), 2619 (1989).

26) Kumagai, H., Obara, M., "A High-Efficiency, High-Repetition-Rate KrF(B-X) Excimer Lamp Excited by a Microwave Discharge", Jpn.J.Appl. Phys. 28(12), L2228 (1989).

27) Kumagi, H., Obara, M., "New high-efficiency quasi-continuous operation of an ArF(B-X) excimer lamp excited by microwave discharge", A.ppl.Phys.Lett. 55(15), 1583 (1989).

28) Searles, S.K., Hart, G.A., "Stimulated emission at $281.8 \mathrm{~nm}$ from XeBr", Appl.Phys.Lett. 27(4), 243 (1975). 
29) Konovalov, I.N., Tarasenko, V.F., "E-Beam Pumped and E-Beam Controlled XeBr-Laser", Proc. Intl. Conf. on Lasers '80, (Soc. for Optical Quantum Blec., Mclean, VA, 1981), pg. 686.

30) Shevera, V.S., Shuaibov, A.K., "Formation of monohalides of inert gases in a transwerse ac electic discharge", Sov.Phys.Tech.Phys 25(4), 434 (1980).

31) Sze, R.C., Scott, P.B., "High-energy lasing of XeBr in an electric discharge", Appl.Phys.Lett. 32(8), 479 (1978).

32) 7., S.F., Chen, J.W., Liu, M.H., "Discharge-pumped multiwavelength laser", Chin.Phys. 1(3), 580 (1981).

33) Tittel, F.K., Wilson, W.L., Jr., Williams, R.A., "Spontaneous and Stimulered Emision Characteristics ofthe Excimer Xe2 $\mathrm{Br}^{\infty}$, Proc. 12th Intl. Quantam Elec. Conf, Muenchen (Germany, F.R., 22-25 June 1982), pg. 126.

34) Waiters, R.A., "Spectral Emission of Nuclear Excited XeBr" ", Proc. Workshop on Nuclear Pumped Lasers, NASA Conf. Publ. 2107 (Hampton, VA, 25-26 July 1979), pg. 33.

35) Peach, R.O., M.S. Thesis, University of Illinois, 1988.

36) Brau, C.H., Ewing, J.J., "Spectroscopy, Kinetics and Performance of Rare Gas Halide Lasers", in Electronic Transition Lasers, ed. by J.I. Steinfeld (MTT Press, Cambridge, MA, 1976), pg. 195.

37) Torczynski, J.R., Gross, R.J., Hays, G.N., Harms, G.A., Neal, D.R., McArthur, D.A., Alford, WJ., "Fission-Fragment Energy Deposition in Argon", Nuc.Sci.Eng. 101(3), 280 (1989).

38) Zedicker, M.S., An Investigation of the Singlet Delta Oxygen and Ozone Yields from the Pulsed Radiolysis of Oxygen and Oxygen-Noble Gas Mixtures, $\mathrm{Ph} . \mathrm{D}$. Thesis (University of Illinois, 1984).

39) Elsayed-Ali, H.E., Miley, G.H., "Ozone dosimetry for calibration of power deposition in nuclear pumped lasers", Rev.Sci.Instrum. 55(8), 1353 (1984).

40) Wilson, J.W., DeYoung, R.J., "Power density in direct nuclear-pumped ${ }^{3} \mathrm{He}$ lasers", J.Appl.Phys. 49(3), 980 (1978).

41) Miley, G.id., Chapman, R.,Nadler, J., Williams, W., "Radiation Effects on Nuclear Pumped Laser Optics", Proc. 10th Intl. Conf. on Lasers '87 (Lake Tahoe, NV, 11-17 Dec. 1987).

42) Boivineau, M., LeCalve, J., "Formation of the $\mathrm{XeBr}$ " excimer by double optical excitation of the Xe-Br2 van der Waals complex", J.Chem.Phys. 84(8), 4712 (1986).

43) Witte, K.J., Burkhard, P., Luthi, H.R., "Low-Pressure Mercury Lamp Pumped

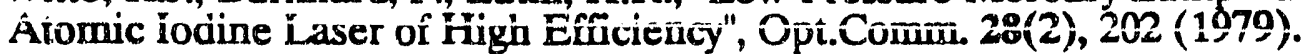


44) DeYoung, R.J., "Low Threshold Solar-Pumped Iodine Laser", IEEE J.Quant.Elec. QE-22(7), 1019 (1986).

45) Luches, A., Perrone, A., "Evidence of $\mathrm{KrF}$ " Broad Band Continuum Emisaion at 400 nm", Opt.Comm. 42(4), 251 (1982).

46) Rice, J.K., Tisone, G.C., Patterson, E.L., "Oscillator Performance and Energy Extraction from a KrF Laser Pumped by a High-Intensity Relativistic Electron Beam", IEEE J.Quant.Elec. QE-16(12), 1315 (1980).

47) Rogulich, V.S., Starodub, V.P., Shevera, V.S., "Emission by KrF" and XeF" excimers in a plasma jet", Sov.Tech.Phys.Lett. 12(5), 249 (1986).

48) Cooper, R., Denison, L.S., Zeglinski, P., Roy, C.R., Gillis, H., "Kinetics of formation of krypton-halogen atom exciplexes in electron beam irradiated gases", J.Appl.Phys. 54(6), 3053 (1983).

49) Shuaibov, A.K., Shevera, V.S," "Formation of inert gas fluorides in an ac discharge", Sov.Phys.Tech.Phys. 24(8), 976 (1980).

50) Luches, A., Nassisi, V., Perrone, A., Perrone, M.R., "Kinetic Studies of $\mathbf{K}_{2} F^{*}$ in Electron-Beam Excited Mixtures", Opt.Comm. 44(2), 109 (1982).

51) Albritton, D.L., "Ion-Neutral Reaction-Rate Constants Measured in Flow Reactors Through 1977", At. Data and Nuc. Data Tables, 22, 1-101 (1978).

52) Wiegand, W.J., "High Pressure Ion Kinetics" in Applied Atomic Collision Physics. Vol. 3, ch. 3, McDaniel, E.W., Nigham, W.L., eds. (Academic Press, New York, 1982).

53) Shaw, M.J., Jones, J.D.C., "Measurements of Some Reaction Rates of Importance in KrF Lasers", Appl.Phys. 14, 393 (1977).

54) Ohwa, M., Obara, M., "Theoretical analysis of efficiency scaling laws for a selfsustained discharge pumped XeCl laser", J.Appl.Phys. 59(1), 32 (1986).

55) Sides, G.D., 'Tiernan, T.O., "Measurement of thermal electron dissociative attachment rate constants for halogen gases using a flowing afterglow technique", J.Chem.Phys. 65(5), 1966 (1976).

56) Maeda, M., Nishitarumizu, T., Miyazoe, Y., "Formation and Quenching of Excimers in Low-Pressure Rare-Gas/Halogen Mixtures by E-Beam Excitation", Jap.J.Appl.Phys. 18(3), 439 (1979).

57) Cooper, R., Mulac, W.A., "A Pulse Radiolysis Study of the Formation of the XeBr Exciplex in Electron Beam Irradiated Xenon-Bromine Mixtures", Chem.Phys.Lett. 99(3), 217 (1983).

58) Lorents, D.C., "The Physics of Electron Beam Excited Rare Gases at High Densities", Physica 82C, 19 (1976). 
59) Duzy, C., Boness, J., "A Study of VUV Fluorescence and Lasing in Electron Beam Excited Xenon", IEEE J.Quant. Elec. QE-16(6), 640 (1980).

60) Borisov, V.M., Vysikailo, F.I., Ivanpva, E.G., Khristoforov, O.B., "Laws governing the fluorescence of $\mathrm{KrF}$ and $\mathrm{XeF}$ excimer molecules in a volume discharge", Sov.J.Quant.Elec. 15(6), 791 (1985).

61) Wilson, J.W., DeYoung, R.J., Harries, W.L., "Nuclear-pumped ${ }^{3} \mathrm{He}$-Ar laser modeling", J.Appl.Phys. 50(3), 1226 (1979).

62) Kushner, M.J., "Response times and energy partitioning in electron-beamexcited plasmas", J.Appl.Phys. 66(6), 2297 (1989).

63) Maeda, M., Takahashi, A., Mizunami, T., Miyazqe, Y., "Kinetic Model for SelfSustained Discharge XeCl Laser", Jap.J.Appl.Phys. 21(8), 1161 (1982).

64) Konovalov, I.N., Losev, V.F., Ryzhov, V.V., Tarasenko, V.F., Tastremsinii A.G., "Radiation of complex molecules of noble gas halides", Opt.Spect.(USSR) 47(2), 137 (1979).

65) Prelas, M.A., Jones, G.L., "Design studies of volume-pumped photolytic systems using a photon transport code", J.Appl.Phys. 53(1), 165 (1982).

66) Javedoni, J.B., Prelas, M.A., "Concentrating Properties of Simple TwoDimensional Geometries for Isotropic Light", Laser Interaction and Related Plasma Phenomena, vol. 7, (Plenum Press, New York), pg. 155.

67) Glassner, A., An Introduction to Ray Tracing (Academic, London, 1989).

68) Palma, G.E., Gagosz, R.M., "Optical Absorption in Fused Silica During Irradiation: Radiation Annealing of the C-Band", J.Phys.Chem. Solids, vol. 33, pg. 177 (1972).

69) McAlpine, A., Sutcliffe, H., "The Radiolysis of Trifuoroiodomethane in the Gas Phase", J.Phys.Chem 73, 3215 (1968).

70) Lee, J., NASA Langley Research Center, personal communication.

71) Yariv, A., Quantum Electronics, 3rd ed., (Wiley \& Sons, New York, 1989), pg. 560.

72) De Young, R.J., Conway, E.J., "Progress in Solar-Pumped Laser Research", Proc. Intl. Conf. on Lasers '85 (Soc. of Opt. and Quant. Elec., Las Vegas, NV, STS Press, 1986), pg. 467.

73) Aldridge, F.T., "Stimulatec -Emission Cross Section and Inversion Lifetime in a Three-Atmosphere lodine Photodissociation Laser", IEEE J.Quant.Elec. QE11(5), 215 (1975). 
74) Ramirez, J.E., Bera, R.K., Hanrahan, R.J., "Measurement of kinetic parameters relevant to the operation of an electron-beam initiated atomic iodine laser", J.Appl. Phys. 57(7), 2431 (1985).

75) Calvert, J.G., Pitts, J.N., Jr., Photochemistry (Wiley \& Sons, New York, 1966), pg. 184.

76) Basov, N.G., Gavrilina, D.K., Leonov, Yu.S., Sautkin, V.A., "Influence of Stimulated Emission on the Formation of Molecular lodine",JETP Lett. 8, 106 (1968).

77) Belousova, I.M., Gorshkov, N.G., Danilov, O.B., Zalesskii, V.Yu., Yachr "Accumulation of iodine molecules in flash photolysis of $\mathrm{CF}_{3} \mathrm{I}$ and $\mathrm{n}-\mathrm{C}$. vapor", Sov.Phys.JETP 38(2), 254 (1974).

78) Beverly, R.E., III, "Pressure-Broadened Iodine-Laser-Amplifier innetics and a Comparison of Diluent Effectiveness", Opt.Comm. 15(2), 204 (1975).

79) Arkhipova, E.V., Borovich, B.L., Zapol'skii, A.K., "Accumulation of excited iodine atoms in iodine photodissociation laser. Analysis of kinetic equations.", Sov.J.Quant.Elec. 6(6), 686 (1976). 

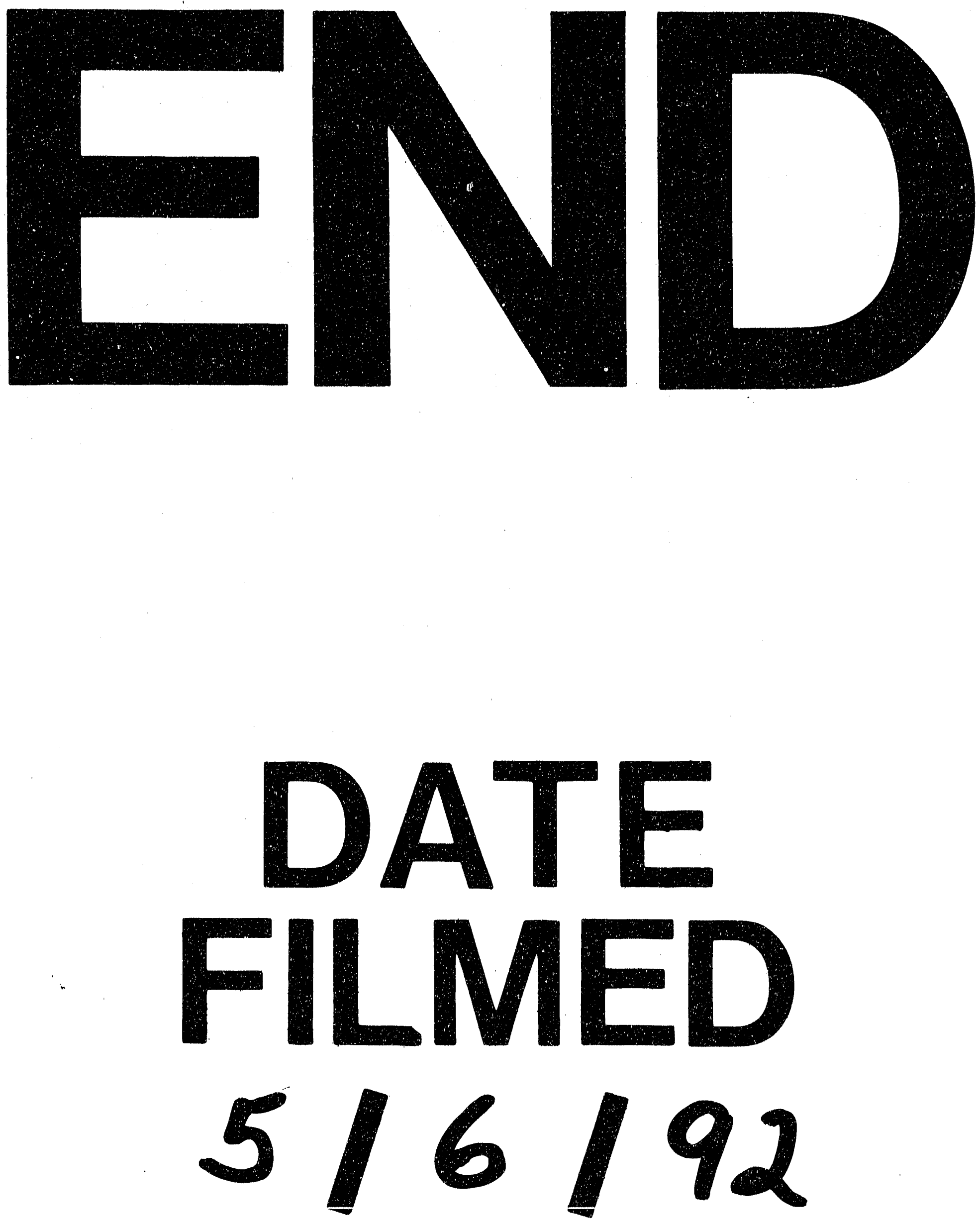

$\exists$ 
